\title{
Studies in the neurobiology of experimental panic
}

Citation for published version (APA):

Schruers, K. R. J. (2001). Studies in the neurobiology of experimental panic. [Doctoral Thesis, Maastricht University]. Universiteit Maastricht. https://doi.org/10.26481/dis.20010919ks

Document status and date:

Published: 01/01/2001

DOI:

$10.26481 /$ dis.20010919ks

Document Version:

Publisher's PDF, also known as Version of record

\section{Please check the document version of this publication:}

- A submitted manuscript is the version of the article upon submission and before peer-review. There can be important differences between the submitted version and the official published version of record.

People interested in the research are advised to contact the author for the final version of the publication, or visit the DOI to the publisher's website.

- The final author version and the galley proof are versions of the publication after peer review.

- The final published version features the final layout of the paper including the volume, issue and page numbers.

Link to publication

\footnotetext{
General rights rights.

- You may freely distribute the URL identifying the publication in the public portal. please follow below link for the End User Agreement:

www.umlib.nl/taverne-license

Take down policy

If you believe that this document breaches copyright please contact us at:

repository@maastrichtuniversity.nl

providing details and we will investigate your claim.
}

Copyright and moral rights for the publications made accessible in the public portal are retained by the authors and/or other copyright owners and it is a condition of accessing publications that users recognise and abide by the legal requirements associated with these

- Users may download and print one copy of any publication from the public portal for the purpose of private study or research.

- You may not further distribute the material or use it for any profit-making activity or commercial gain

If the publication is distributed under the terms of Article $25 \mathrm{fa}$ of the Dutch Copyright Act, indicated by the "Taverne" license above, 
Studies in the Neurobiology of experimental panic 
ISBN 90-806599-1-6 


\title{
Studies in the Neurobiology of experimental panic
}

\author{
Proefschrift:
}

ter verkrijging van de graad van doctor aan de

Universiteit Maastricht

op gezag van de Rector Magnificus, Prof. dr. A.C. Nieuwenhuijzen Kruseman

volgens hel besluit van hel College van Decanen,

in het openbar te verdedigen op

woensdag 19 september 2001 om 14.00 uur

door

Koen Rik Juliaan Schruers 


\section{Promotor:}

Prof. dr. E.J.L. Grie?

\section{Co-Promotor:}

Dr. R. van Diest

\section{Beoordelingscommissie:}

Prof. dr. M. Maes (voorzitter)

Prol. dr. J.F.W. Deakin (University of Manchester)

Prof. or. M.A. van den Hout

Dr. G. Perna (San Rafaele Hospital, Milan)

Prof. dr. H.M. van Praag 
de zee lijkt wel een eindeloze emmer docht de zwemmer zwemmend in hel ruime sop hij was U rood het al pianostemmer en hii zwom mel forse slogen noor zijn job (De Nreurve Snoor) 


\section{Contents}

General overview 5

Chapter 1: Introduction Part 1: The concept of panic disorder 9

Part 2: Experimental pathophysiology of panic $\quad 15$

Chapter 2: Symptom profiles of natural and laboratory panic attacks 35

Chapter 3: $10 \mu \mathrm{CCK}$ premedication and $35 \% \mathrm{CO}_{2}$ challenge in healthy volunteers 49

Chapter 4: Effects of low-dose cholecystokinin on respiratory function 59 in healthy volunteers

Chapter 5: Effects of tryptophan depletion on carbon dioxide provoked panic 65 in panic disorder patients

Chapter 6: L-5 Hydroxytryptophan induced increase in salivary cortisol in healthy volunteers and panic disorder patients

Chapter 7: L-5 Hydroxytryptophan inhibits 35\% carbon dioxide induced panic

Chapter 8: Effects of Tianeptine on $35 \% \mathrm{CO}_{2}$ provoked panic in panic disorder patients 



\section{General overview}

The subject of this thesis is the neurobiology of panic, as it occurs in the condition panic disorder. An experimental model, the so-called $35 \% \mathrm{CO}_{2}$ model, is used to study panic in the laboratory.

Chapter one provides a general introduction on panic disorder and an overview of the existing models of panic that are used to gain insight in its pathophysiology. Emphasis lies on the $35 \% \mathrm{CO}_{2}$ model and, to a lesser extent, on the cholecystokinin ( $\mathrm{CCK}$ ) model. $\mathrm{CO}_{2}$ and $C C K$ are the two panic provoking agents that are used in the studies of this thesis.

A considerable amount of previous work, conducted both at our laboratory (see thesis of $k$. Verburg, 1998) and by the group of Giampaolo Perna in Milan, has validated the $35 \% \mathrm{CO}_{2}$ challenge as an experimental model for panic. Such an experimental model should fulfil four criteria: specificity, clinical validity, replicability and symptom convergence. It was shown that a spectrum of disorders exists, with different degrees of sensitivity to $\mathrm{CO}_{2}$. By far the highest sensitivity is found in panic disorder, however. Clinically effective panic reducing agents have been shown to reduce the vulnerability to a $35 \% \mathrm{CO}_{2}$ challenge. Conversely, ineffective agents have failed to do so. The reaction to the challenge is also readily replicable in panic disorder patients, regarding the provoked anxiety as well as the different panic symptoms. However, when the work underlying the present thesis was started, the symptom convergence of experimentally induced and naturally occurring panic attacks had been insufficiently studied. Accordingly, chapter two is a study in which the symptoms of $35 \% \mathrm{CO}_{2}$ induced panic attacks are compared with the symptoms of panic attacks in real life situations. It was shown that the $35 \% \mathrm{CO}_{2}$ challenge reproduces well the majority of natural panic symptoms. This study therefore rounds off that aspect of the validation of the $35 \% \mathrm{CO}_{2}$ model.

In recent years, the so-called $C \mathrm{CK}$ model has also been proposed as an experimental model for panic. CCX was first identified in 1928 as a hormone in the gastrointestinal tract which caused the gallbladder to contract. It was not until 1975 that the presence of CCK was also discovered in the brain. It even appeared that $\mathrm{CCK}$ is one of the most abundant peptides in the brain. The molecule functions as a neurotransmitter and has, among other functions, a role in human anxiety. The largest body of work on the panicogenic effects of $\mathrm{CcK}$ has been performed by the group of Jacques Bradwejn in Canada. It has been stated that both $\mathrm{CO}_{2}$ and 
cck have their panic provoking effects via similar neural mechanisms. If this is true, their effects can be expected to be additive, when administered in combination. Under this assumption, a previous study was carried out by our group, in collaboration with the department of pharmacology of the Nantes University (M. Bourin).

Contrary to what was expected, no additive effect was found, but rather an inhibitory effect of $\mathrm{CCK}_{\mathrm{K}}$ on $\mathrm{CO}_{2}$. Because of the unexpected nature of the results, a second study was performed in a much larger group of subjects. This study is presented in chapter three. Again, no additive but an inhibitory effect was found, thus confirming the previous study. The results suggest that $\mathrm{CO}_{2}$ and $\mathrm{CCK}$ may act upon different, possibly mutually exclusive, neural pathways.

$\mathrm{CO}_{2}$ is supposed to have its panicogenic effects via triggering of chemoreceptive areas in the brainstem which cause, among other things, respiratory stimulation. This should be an essential quality of a panicogen, according to the false suffocation alarm hypothesis of Donald Klein, a theory on panic that emphasizes the link between panic and the respiratory system. Accordingly, chapter four contains a study on the direct respiratory effects of CCK.

No respiratory stimulation was found, however. The results of these studies on CCK may cast some doubt on the status of CCK as a model for panic. It is possible that CCK is a substance that has general anxiogenic effects, rather than being a specific panicogen.

The method of inducing biochemical changes in neural systems that are proposed to be of importance in panic is also applied in chapter five. In this study, it is the level of serotonin (5HT) which is manipulated in subjects, prior to undergoing a $35 \% \mathrm{CO}_{2}$ panic challenge. Serotonin is known since the mid-nineteenth century as a substance, present in serum after the clotting of blood, which causes vascular smooth muscle to contract. As it is a hydrophylic substance, serotonin does not pass the blood-brain barrier readily. Thus its discovery in the brain in 1953 indicated that $5 \mathrm{HT}$ was being synthesized in the brain. Subsequently, it was discovered that 5 HT plays an important role in several mental disorders, like mood disorders and also anxiety disorders. Serotonin is synthesized out of the amino acid tryptophan (TRP). Tryptophan is a so-called essential amino acid, which means that it is not synthesized in the human body. Therefore the primary source of tryptophan is dietary protein. It enters into the 
brain by means of an active transport through the blood-brain barrier. The same transport mechanism also transports other large neutral amino acids. When one administers a large quantity of such amino acids to an individual, with the exclusion of TRP, they will compete with TRP for the occupancy of the carrier. Due to the limited quantity of TRP available in the body, these amino acids will dominate the transport and entry of IRP into the brain will decrease. Thus, the availability of TRP in the brain, and consequently the synthesis of $5 \mathrm{HT}$, is lowered. From such TRP depletion studies and from pharmacological studies using medication that acts upon the level of $5 \mathrm{HT}$, it has become clear that $5 \mathrm{HT}$ has an important role in panic disorder. Matters, however, are still unclear. There is an ongoing debate whether $5 \mathrm{HT}$ induces anxiogenic or anxiolytic effects in humans and whether the role of $5 \mathrm{HT}$ is a causal one. In chapter five, the TRP depletion method is used in combination with a $35 \% \mathrm{CO}_{2}$ panic challenge. II was shown that TRP depletion greally enhanced the reaction to the challenge. The results suggest that $5 \mathrm{HT}$ has an inhibitory effect on panic and are compatible with a role for $5 \mathrm{HT}$ in the modulation of panic. Based on other challenge studies and on pharmacological studies with serotonergic medications in panic disorder, another theory was formulated, proposing a causal role for $5 \mathrm{HT}$ in panic. According to this theory, panic disorder patients have hypersensitive $5 \mathrm{HT}$ receptors. The study in chapter six is a direct test of this hypothesis. This study makes use of a neuroendocrine challenge paradigm. This inunlves stimulating central $5 \mathrm{HT}$ neurons with $5 \mathrm{HT}$ transmission enhancing drugs and measuring the neuroendocrine consequences. It is known that 5HT stimulates the production of the stress hormone cortisol, via its effect on corticotropin releasing hormone and adrenocorticotrope hormone. Therefore, if panic disorder patients have hypersensitive $5 \mathrm{HT}$ receptors, one would expect a stronger increase in cortisol in panic patients, following the administration of a $5 \mathrm{HT}$ transmission enhancing drug, than in healthy individuals. The results of our study show a similar effect of L-5 hydroxytryptophan (L-5 HTP), the immediate precursor of 5HT, on the level of salivary cortisol in panic disorder patients and healthy volunteers. This indicates that there is probably no $5 \mathrm{HT}$ receptor hypersensitivity in panic disorder. Therefore, such a causal role for $5 \mathrm{HT}$ in the pathophysiology of panic disorder seems unlikely. At the same time, the method of measuring cortisol in saliva was proven to be a useful, non-invasive tool for the assess- 
ment of central serotonergic function.

If a decrease in serotonergic function leads to an enhanced reaction to a panic challenge, as was shown in chapter five, one would expect an increased availability of $5 \mathrm{HT}$ to decrease the reaction. This was examined in the study in chapter seven. The same participants of the study in the previous chapter underwent a $35 \% \mathrm{CO}_{2}$ panic challenge after the administration of $1-5$ hydroxytryplophan (L-5HTP) or placebo. The results show that L-5HIP strongly inhibited the reaction to the challenge. The study in chapter six shows no arguments for a $5 \mathrm{HT}$ receptor hypersensitivity in panic disorder. The results from chapter five show that lowering $5 \mathrm{HT}$ increases the reaction to an experimental panic challenge. The ones from chapter seven indicale that increasing $5 \mathrm{HT}$ inhibits the reaction to such a challenge. Together, therefore, the results from these studies suggest that serotonin is not causally involved, but rather has a modulatory role in panic.

The final chapter of this thesis, chapter eight, contains a pharmacological study, comparing the effect of a six-week treatment with two antidepressants on the reaction to a $35 \% \mathrm{CO}_{2}$ challenge in panic disorder patients. One compound, paroxeline, is a selective serotonin reuplake inhibitor, as routinely used in the treatment of panic disorder. The other, tianepti$n e$, is known as a serotonin reuptake enhancer and has therefore the exact opposite effect on 5 HT metabolism. Tianeptine has, however, been shown to effectively reduce anxiety in depressive patients. The results show an anti-panic effect of both tianeptine and paroxetine. It is concluded that tianeptine probably exerts its effect through non-serotonergic or indirect actions, possibly via modulation of the hypothalamus-pituitary-adrenal axis. 


\section{Chapter 1}

\section{Part 1 The concept of panic disorder}

\section{Clinical picture}

Panic disorder (PD) is characterized by the spontaneous, unexpected occurrence of panic attacks. Panic allacks are relatively short-lived periods of intense fear or discomfort, accompanied by a number of somatic or psychological symptoms. According to DSM IV, at least four symptoms are required, that have to develop abruptly and reach a peak within 10 minutes. These symptoms are:

1. Palpitations, pounding heart or accelerated heart rate

2. Sweating

3. Trembling or shaking

4. Sensations of shortness of breath or smothering

5. Feeling of choking

6. Chest pain or discomfort

7. Nausea or abdominal distress

8. Feeling dizzy, unsteady, lightheaded or faint

9. Derealization (feelings of unreality) or depersonalization (feeling detached from oneself)

10. Fear of losing control or going crazy

11. Fear of dying

12. Paresthesias (numbness or tingling sensations)

13. Chills or hot flushes

The symptoms of panic may be present in various other situations: use of withdrawal of a drug or a medical condition, such as hyperthyroidism or pheochromocytoma. For this reason, DSM IV requires the exclusion of substance use or a general medical condition. Three types of panic attacks are distinguished, based on the presence or absence of situational triggers. 
Firsily, unexpected or "spontaneous" panic attacks are not associated with a situational trigger. Secondly, situationally bound panic attacks occur almost invariably on exposure to, or in anticipation of, a situational cue. Thirdly, the situationally predisposed panic attacks are more likely to occur on exposure to the situational cue or trigger, but are not invariably associated with the cue and do not necessarily occur immediately upon exposure (Faravelli and Paionni 2000). The unexpected panic attacks are considered to be the hallmark of panic disorder. DSM IV requires at least two unexpected attacks for the diagnosis of PD. After the first altack, most patients develop the lear that another attack may occur. Therefore, in the periodes between the panic atlacks, the level of diffuse, anticipatory anxiety increases. DSM IV takes this anticipatory anxiely into account by requiring for the diagnosis of PD at least one of the following:

a. persistent concern about having additional altacks

b. worry about the implications of the attack or its consequences

c. a significant change in behavior related to the attacks.

Panic disorder is often accompanied by agoraphobia, the fear of being in places or situations from which escape might be difficult or embarrassing or in which help may not be available in the event of a panic attack. Although some controversy exists in the literature, most evidence suggests that agoraphobia develops after panic attacks begin, and are due to the above mentioned anticipatory anxiely (MCNally 1994).

\section{Syndromal validity}

The use of explicit diagnostic criteria and of structured interviews have greatly improved diagnostic reliability of $\mathrm{PD}$, basis for its syndromal validity. Interrater reliability can be expressed as kappa, a coefficient that expresses the level of agreement corrected for chance. The kappa coefficient ranges from negative values through 0 to 1 . With negative values, the observer agreement is less than might be expected from chance agreement. 
With a value of 0 , the agreement is entirely explained by chance. With positive values, the agreement is higher than chance. By conventional standards, values below 50 indicate poor reliability, those between .50 and .70 indicate fair reliability and those above .70 indicate good reliability (MCNally 1994).

It has been shown that PO can be reliably diagnosed in anxiety disorder clinics: kappa's range from .7510 .90 for panic disorder or panic disorder with agoraphobia, at least in settings where the rate of diagnosis is high and expert clinicians conduct structured interviews (McNally 1994). Therefore in the setting where the research for the present thesis was conducted, a tertiary referral clinic, diagnostic reliability and hence syndromal validity can be considered as good.

\section{Epidemiology}

Twelve month prevalence of PD is around 1\%. Lifetime prevalence rates range from 1,4\% to $3,8 \%$. Across epidemiological surveys, prevalence is about twice as high in women, compared to men (Faravelli and Paionni 2000; Overbeek el al 2000).

PD most commonly develops around the age of 25 , but the age of onset varies considerably. Hazard rates for women range from 25 to 35 years, for men between 30 and 45 (Wittchen and Essau 1993).

Panic disorder has a high degree of comorbidity with other anxiety disorders like social phobia (20-75\%), generalized anxiety disorder (20\%), obsessive compulsive disorder (14\%) and post-traumatic stress disorder (6\%) (Goisman et al. 1994; Overbeek et al. 2000; Pelissolo and Lepine 1998). There is also a considerable comorbidity with major depression, with reported rates ranging between 30 and 60\% (Weissman et al 1997). Substance abuse is common in PD, with a prevalence of $36 \%$ according to the Epidemiological Catchment Area Study (Regier et al. 1990). 


\section{Quality of life and economic burden}

Studies in community samples show that 35\% of the people with panic disorder felt they were in fair of poor physical health and $38 \%$ felt they were in poor emotional health, whereas people with no panic disorder had significantly lower levels of negative perceptions of their physical and mental health (24\% and 16\%). Around $27 \%$ of the persons with panic disorder were receiving welfare or some form of disability compensation, a much higher rate than among people without panic disorder (Markowitz et al. 1989; Mendlowicz and Stein 2000; Weissman 1991). Studies in clinical samples also show a considerably decreased quality of life in patients with panic disorder, compared to normal subjects (Mendlowicz and Stein 2000).

There is little direct information on the economic costs of panic disorder to society. However, because of the association with increased utilization of medical care, the costs are considerable. One study examining both the direct costs, including all the medical care, and the indirect costs due to lost productivity showed a total cost of $\$ 94801$ per year, before treatment. After treatment those costs were reduced to $\$ 60139$ (Salvador Carulla et al. 1995; Zambler and Katon 1998).

\section{Conclusion}

In summary, it may be concluded that PD, being a relatively recent concept, is a clinically valid syndrome. It refers to a quite common condition that significanily affects people's quality of life and may represent an important economical burden at societal level. 


\section{REFERENCES}

Faravelli C, Paionni N (2000): Panic disorder: clinical course, morbidity and comorbidity. In

Griez E, Faravelli C, Nutl D, Zohar J (eds), The European Certificate Textbook of Anxiety Disorders: In press, John Wiley \& Sons.

Goisman RM, Warshaw MG, Pelerson LG, el al (1994): Panic, agoraphobia, and panic disorder with agoraphobia. Data from a multicenter anxiety disorders study.

The Journal of nervous and mental disease 182:72-9.

Markowitz JS, Weissman MM, Ouellette R, Lish JD, Klerman GL (1989): Quality of life in

panic disorder. Archives of general psychiatry 46:984-92.

McNally R (1994): Panic disorder. A critical analysis. New York, USA: The Guilford Press. Mendlowicz MV, Stein MB (2000): Quality of life in individuals with anxiely disorders. The American journal of psychiatry 157:669-82

Overbeek T, Vermetten E, Griez E (2000): Epidemiology of anxiety disorders. In Griez E,

Faravelli C, Nutt D, Zohar J (eds), The European Certificate Textbook of Anxiety

Disorders: In press, John Wiley \& Sons.

Pelissolo A, Lepine JP (1998): Epidemiology of depression and anxiety disorders. In

Montgomery SA, den Boer JA (eds), SSRI's in depression and anxiety: John Wiley and Sons Itd, $p P$ 1-21.

Regier DA, Farmer ME, Rae DS, et al (1990): Comorbidity of mental disorders with alcohol and other drug abuse. Results from the Epidemiologic Catchment Area (ECA) Study. Jama 264:2511-8.

Salvador Carulla L, Segui J, Fernandez Cano P, Canet ) (1995): costs and offset effect in panic disorders. The British journal of psychiatry. Supplement:23-8.

Weissman MM (1991): Panic disorder: impact on quality of life. The Journal of clinical psychiatry 52 Suppl:6-8; discussion 9.

Weissman MM, Bland RC, Canino GJ, et al (1997): The cross-national epidemiology of panic disorder. Archives of general psychiatry 54:305-9.

Wittchen HU, Essau CA (1993): Epidemiology of panic disorder: progress and unresolved 
Chinglot

issues. Journal of psychiatric research 27 Supplement 1:47-68.

Zambler T, Kalon W (1998): Panic disorder in the general medical setting. Journal of Psychosomatic Research 44:25-42. 


\section{Part 2 Experimental pathophysiology of panic}

\section{The importance of challenge tests}

Spontaneous panic attacks are unpredictable and, therefore, hard to study. The information we obtain from panic disorder patients about their panic attacks is subjective and entirely retrospective.

To be able to study the phenomena of this illness more directly, models of panic were developed, using different types of challenges to provoke panic under laboratory conditions.

Such a model should respond to certain criteria (Uhde and Tancer 1990 based on Guttmacher et al. 1983 and Gorman et al. 1987):

1. The symptoms of an induced panic allack must closely mimic the symptoms of a spontaneous altack.

2. Reaction to the test should be specific for panic disorder patients.

3. Clinically effective medication for panic disorder should also lessen the reaction to the challenge and clinically ineffective agents should fail to do so.

4. The results of the challenge should be replicable.

Up to now, there is no such thing as a definite diagnostic test for panic disorder. The currently available laboratory models respond in a different degree to these criteria of an ideal model, as will be discussed further.

Further, challenge tests are important in unraveling the role of different neuronal systems in the mechanism of panic attacks. 


\section{History}

In 1871 the American military surgeon Da Costa described the syndrome of "irritable heart". Da Costa's syndrome was characterized by spells of dizziness, breathlessness and palpitations, chest discomfort and anxiety (Da Costa 1871). One year later, Westphal published his famous account of a series of patients whose chief complaints existed of anxiety attacks, inability to walk in certain streets and to cross open squares and a tendency to the generalization of behavioral incapacitation (Westphal 1872). Because of the inability to walk across certain public places, Westphal called the condition "agoraphobia". In fact, both Da Costa and Westphal were providing early detailed clinical descriptions of cases of panic disorder and agoraphobia.

At about the same time, a German physician,.E. Cordes, reported on 27 cases of "Platzangst" (the German term for agoraphobia). Suffering himself from the disorder, cordes noticed that his condition worsened with bright light and in air polluted with carbon dioxide. "Alcohol", he noted, "always helps" (Cordes 1872). Half a century later, Drury showed that patients with "irritable heart" indeed developed intolerable hyperpnea at a lower level of inspired carbon dioxide than did healthy controls (Orury 1920). However, this very first experimental approach of panic remained largely unnoticed.

In a comprehensive overview, cohen and white reported that a number of abnormal physiologic responses could be found in subjects with the disorder (Cohen and white 1951). In particular they noticed melabolic anomalies, with abnormal oxygen consumption and excessive lactate production during muscular exercise. Like Drury, they found that these patients were overreactive to carbon dioxide, with "intolerable hyperpnea, increased sighing, and symptoms identical with anxiety attacks" when breathing a mixture containing an excess of carbon dioxide (Cohen and White 1951). The alleged excessive lactate production suggested that lactate administration may bring about the symptoms of anxiety neurosis. This inspired Pitts and Mcclure's early experiments with lactate infusion (Pitts and Mcclure 1967). Curiously, although carbon dioxide hypersensitivity was mentioned in the same report, it took another thirty years to confirm that carbon dioxide administration experimentally indu- 
ces atlacks in panic disorder patients. Both lactate infusion and carbon dioxide inhalation have since emerged as experimental models of high heuristic value in anxiety research. Both models will be reviewed at some length in the present paper.

\section{The lactate model}

Assuming that the lactate ion itself may produce anxiety attacks in vulnerable persons, Pitts and Mcclure conducted a double blind, placebo controlled study in 14 patients with anxiety neurosis and 10 healthy controls. The experiment was carefully designed, the effects of the infusion being assessed by a "blinded" observer, who was unaware of the purpose of the study. Based on a standard checklist and subjects self report, symptoms of an anxiety attack were found in 13 of the 14 patients after lactate infusion, but only in 2 of the 10 controls. Glucose in saline produced no attacks at all. Adding calcium to the lactate significantly reduced the response to the procedure. All patients rated the lactate-induced state as very similar, if not identical, to their real-life attacks.

Pitts and Mcclure interpreted their findings as being the first instance of experimentally induced anxiety symptoms in susceptible individuals. They speculated that anxiety attacks may be brought about by a lactate specific mechanism, probably chelation of ionized calcium by lactate at the surface of excilable membranes.

Pitts and Mcclure's findings fostered interest in the underlying pathophysiology of anxiety neurosis. In the early seventies, there were at least three controlled studies that replicated the original finding of lactate-precipitated anxiety attacks (Fink et al. 1969; Ketly el al. 1971; Bonn el al. 1971). All studies yielded a response rate of $80 \%$ to $100 \%$ in patients, compared with $0 \%$ to $25 \%$ in controls. Despite these repeated confirmations of lactate's anxiogenic effect in anxiety neurosis, no progress was made in advancing our general understanding of the underlying mechanisms of this phenomenon. The early speculations on ionized calcium were challenged by the finding that ethylenediamine tetra-acetic (EDTA), a potent chelator of free calcium, failed to reproduce the effect of lactate in patients (Pitts and Allen 
1979). Shifts in acid-base equilibrium were found, but it was immediately pointed out that lactate infusion does not mimic the physiological state of naturally occurring hyperlactacidemia. A rise in endogenous lactate induces a metabolic acidosis; exogenous administration of lactate results in a systemic alkalosis.

In the 1980s, Liebowitz and coworkers (1984) initiated a large-scale investigation on the effects of lactate provocation in patients with panic disorder (PD). Relying on the predefined diagnostic criteria of the DSM III they established that lactate induces panic attacks (PA) in about $60 \%$ to $80 \%$ of PD patients compared with $0 \%$ to $20 \%$ of healthy controls. Subsequent studies strongly suggested that lactate had diagnostic specificity amongst DSM III anxiety disorders. Lactate does neither affect patients with obsessive compulsive disorder (OCD, Gorman et al. 1987), or those with social phobia (Liebowitz et al. 1985a). Results are less clear-cut in generalized anxiely (GAD): in one study (Lapierre el al. 1984) only 2 of 16 GAD patients panicked but the response rate in PD patients in that sample was also very low, as only 6 out of 23 had a PA. In another report, 12 out of 22 PD subjects and 5 out of 9 GAD patients proved to be lactate-sensitive (Cowley et al. 1988).

Lactate vulnerability is sensitive to clinically successful treatment: when panic free under effective antidepressant medication, 13 patients became insensitive to lactate-induced PA. After drug discontinuation, 3 of them had a PA under lactate (Fyer et al. 1985). These results show that effective pharmacological treatment protects against the effect of lactate infusion. However, lactate vulnerability may exist in clinically well, but panic-prone individuals. To this extent, lactate vulnerability may be a trait marker.

Contrasting with the growing body of data on the validity of the lactate infusion as a laboratory model for panic, no convincing progress has been made in answering the question why patients panic from lactate. Numerous biochemical and physiological measures during lactate challenges yielded only meager results (Liebowitz et al. 1985b). Neither hypocalcemia, nor metabolic alkalosis appears to play a crucial role in lactate precipitated PA's. In sharp contrast to anticipatory and generalized anxiety, lactate-elicited PA's are nol attended by a large increase in plasma cortisol, suggesting a lack of activitation of the hypothalamus-pitvitary-adrenal (HPA) axis in panic (Hollander et al. 1989). Circulating catecholamines show 
an inconsistent and modest increase (Liebowitz et al. 1986). Cardiovascular modifications seen during lactate infusion in panickers may be compatible with sympathetic activation of central origin (Liebowitz et al. 1985b; Liebowitz et al 1986). However, propranolol fails to block lactate induced PA's, and isoproterenol shows inconsistent effects (Gorman et al 1984; Nesse el al 1984; Rainey el al. 1984). Clonidine, an alpha-2 agonist, partially prevented laclate-induced PA's (Coplan et al. 1992a). The most striking effect of a lactate infusion is that it causes subjects to hyperventilate (patients more than controls), particularly those who panic more frequently. Because lactate infusion induces a systemic metabolic alkolosis, with increased $\mathrm{pH}$ and bicarbonate in all subjects, hyperventilation and hypocapnia are unexpected and appear to be paradoxical (Liebowitz et al. 1986).

\section{The role of hyperventilation}

The finding that hyperventilation is associated with lactate-triggered panic and that hypocapnia is more prominent in patients than in controls prompted lactate investigators to explore the role of hyperventilation in the genesis of panic. During the post-World War II period, a body of clinical literature linking hyperventilation and anxiety developed, mainly in Europe. Hyperventilation, due to "bad breathing habits" was regarded as a key mechanism in some anxiely syndromes. Individuals with the so-called "hyperventilation syndrome" were believed to have spells of self-induced hypocapnia, generating physical symptoms which they could not explain and, in turn, causing further arousal and anxiety (Lum 1975). To explore the role of hyperventilation in panic, Gorman and associates submitted a group of PD patients to voluntary hyperventilation. Breathing a slightly hypercapnic mixture $(5 \%$ $\left.\mathrm{CO}_{2}\right)$ was used as a control condition. Unexpectedly, it was not the forced hyperventilation, but rather the carbon dioxide condition that proved to be panicogenic (Gorman et al. 1984). At the same time, our group had become interested in an old fashioned procedure, consisting of one single-breath administration of a $35 \% \mathrm{CO}_{2}-65 \%$ oxygen mixture, which was claimed to be anxiolytic (Wolpe 1973). Under controlled conditions, the procedure proved devoid of 
any anxiolytic elfecls (Griez and van den Hout 1982; van den Hout and Griez 1982). On the contrary, it appeared to mimic symptoms of panic attacks (Van den Hout and Griez 1984). The role of hyperventilation was further explored in normals and in patients with PD, carefully controlling for cognitive factors and suggestion. All experiments showed that acute hypocapnia induced by voluntary hyperventilation failed to induce PA's (Griez et al. 1988; van den Hout el al. 1988; Zandbergen el al. 1990).

Even though patients do hyperventilate in real life as well as in laboratory-induced panic, hypocapnia neither is sufficient nor necessary to cause panic attacks (Griez et al. 1987a).

\section{Carbon dioxide as a model for panic}

Essentially, two main procedures have been developed that use carbon dioxide to explore the mechanisms of PD. Continuous breathing of a $5 \% \mathrm{CO}_{2}$ mixture for $10-20$ minutes is known as the $5 \% \mathrm{CO}_{2}$ challenge. Subjects usually breathe through a mask for several minutes to the point of panic. Some studies have used a canopy. As with lactate infusion, $\mathrm{CO}_{2}$ administration ceases either on request of the subjects or upon a PA. The so-called $35 \% \mathrm{CO}_{2}$ challenge relies on a single vital-capacity inhalation of a mixture containing $35 \% \mathrm{CO}_{2}$ and $65 \% \mathrm{O}_{2}$. Subjects use a self-administration mask. The effects are immediate symptoms of a PA appearing within a malter of seconds upon inhalation and waning after 301060 seconds. The $5 \% \mathrm{CO}_{2}$ challenge has been used after Gorman and coworkers' unexpected finding while trying to control for hypocapnia. Researchers began using the $35 \% \mathrm{CO}_{2}$ method when, contrary to previous clinical claims (Ley 1985), it appeared to be anxiogenic rather than anxiolytic. Each challenge has its own advantages and disadvantages, using the same pharmacological agent, and both may involve the same underlying mechanisms of panic.

Following the results of Gorman et al (1984), the method with continuous breathing of low concentrations of $\mathrm{CO}_{2}$ became widely used. Overall, the effects are similar to those of lactate studies. There have been a number of experiments to assess the specificity and sensitivity of the procedure, but results are difficult to interpret due to methodological differences 
across the studies (Sanderson and Wetzler 1990). In their review of the literature, Sanderson and Wetzler (1990) pointed out a number of problems. There are different methods of administration (e.g. mask vs. canopy), the $\mathrm{CO}_{2}$ concentration may vary (some authors use $7 \%$ $\mathrm{CO}_{2}$ ) and the way the subjects are instructed is not standardized. An important methodological difficulty is the operational definition of a PA. Even though most studies do refer to DSM $\mathrm{III}(\mathrm{R})$ criteria, the way investigators assess the presence of a PA differs widely from one study 10 another.

An overall evaluation of the single-breath $35 \% \mathrm{CO}_{2}$ procedure is easier because most of the studies using this approach has been done by two groups working together quite closely. Consequently, there are lew methodological differences between studies. In parlicular, concentration of $\mathrm{CO}_{2}$, dosage, subjects instruction and assessment of induced symptoms are similar in most of these studies. Also, the results are not merely expressed as PA vs. no PA; the effect is also assessed as subjective anxiety, expressed on a visual analogue scale immediately upon inhalation. This circumvents the problem of setting arbitrary criteria for the recognition of a PA.

After it had become clear that a $35 \% \mathrm{CO}_{2}$ inhalation may be panicomimetic (Van den Hout and Griez 1984), this challenge was administered to a group of patients meeting DSM III criteria for PD. Compared with healthy controls, PD patients reported significantly more anxiety. In fact, they rated the inhalation experience as being strikingly similar to a real-life PA. Normals reported some neurovegetative symptomatology resembling that of a PA, but failed to experience anxiety (Griez et al. 1987b). The vulnerability of PO patients to $35 \% \mathrm{CO}_{2}$ has subsequently been documented in other studies (Fyer et al. 1987; Gorman et al. 1990; Perna el al. 1994a).

Several studies have addressed the question whether $35 \% \mathrm{CO}_{2}$ susceptibility is specific for individuals suffering from PA's. Perna and coworkers have shown that subjects with sporadic PA's tend to respond in the same way as those meeting the DSM III R defined threshold for PD, in contrast to normals who never had PA's (Perna et al. 1995C).

Griez et al. demonstrated that $35 \% \mathrm{CO}_{2}$ elicited anxiety acts as a marker of PD among a mixed group of subjects with various anxiety disorders, all of whom displayed high ratings 
on anticipatory anxiety (Griez et al. 1990b). Therefore, $\mathrm{CO}_{2}$ susceptibility is not a matter of baseline anxiety in highly aroused patients.

In the first of a series of subsequent experiments, a group of PD patients was compared with OCD patients and healthy controls (Griez et al 1990a). $\mathrm{CO}_{2}$-triggered anxiety was significantly higher in PO patients than in OCO patients and in normals, with no difference between the latter groups. These results have been replicated by Perna el al. (1995b). In another experiment, 28 subjects with simple phobia and 30 healthy controls were challenged with $35 \% \mathrm{CO}_{2}$. Phobics were separated into situational phobics and animal phobics. Those with animal phobias had the same response as controls. Patients with situational phobias, however, reacted differently, and had $\mathrm{CO}_{2}$-induced anxiety which tended to resemble that of $\mathrm{PD}$ patients (Verburg et al 1994). These results are in keeping with epidemiological data linking situational phobias and agoraphobia. Something worth noting is that the aformentioned distinction between animal and situational phobias has been acknowledged in the DSM IV. PD patients have been compared with GAD patients (Verburg et al. 1995). While PD patients reacted with a marked increase in anxiety, there was no significant reaction in GAD subjects. Very stringent selection criteria were applied to select pure GAD patients, excluding any lifelime history of PA's. Thus, the sample size was small with only 9 GAD patients, and replication in a larger group of patients would be welcome. However, these preliminary results lend experimental validity to the nosological distinction between PD and GAD.

The case of social phobia is less clear-cut. Caldirola et al. (1997) published results suggesting that patients with a social phobia are sensitive to a $35 \% \mathrm{CO}_{2}$ challenge. Data from Gorman and coworkers (1990) seem to support the idea of some $\mathrm{CO}_{2}$ vulnerability in social phobics. However, in the latter study a double, instead of a single inhalation was administerer. Our group has unpublished data showing social phobics, with no history of PA's to be $\mathrm{CO}_{2}$ insensitive (Verburg et al., unpublished). It is noteworthy that social phobics are not sensitive to laclate infusion.

The $35 \% \mathrm{CO}_{2}$ challenge has been administered to patients with mood disorders as well. Perna el al. (1995a) showed patients with major depression not to be sensitive to the test. verburg et al. (1998c) compared PD patients with and without comorbid depression. In this 
study, the presence of a comorbid depression was associated to a higher vulnerability to the challenge.

A number of investigations have been conducted to address the sensitivity of the $35 \% \mathrm{CO}_{2}$ lest to a clinically successful treatment. Upon re-testing after six weeks, an effective treatment with clonazepam attenuated the $\mathrm{CO}_{2}$ triggered reaction (Pols et al. 1991). The same applied to a six week treatment with fluvoxamine (Pols et al 1996). Using toloxatone, a MAO inhibitor, a blunting effect on the $35 \% \mathrm{CO}_{2}$ challenge could be seen after only one week of treatment (Perna et al. 1994C). These findings strongly support the validity of the $35 \% \mathrm{CO}_{2}$ model (Bertani el al. 1997; Perna et al. 1997).

Assuming that the development of PA relies on a constitutional predisposition, at least some relatives of PD patients, although free of manifest PA's, might be expected to have inherited a "panic proneness" trait. In a study by Perna and coworkers (Perna el al. 1995d), 23 first degree relatives of PD patients underwent a $35 \% \mathrm{CO}_{2}$ challenge. Five of them (22\%) had a $\mathrm{CO}_{2}$ triggered PA as compared $1051 \%$ of PD patients and $2 \%$ of healthy controls. The same group performed a $\mathrm{CO}_{2}$ challenge in a population of twins. Their results showed a high concordance ratio, as far as $\mathrm{CO}_{2}$ proneness is concerned, in monozygotic twins compared with dizygotic Iwins (Perna et al. 1993).

Carbon dioxide is a basic factor in the control of breathing. The partial pressure of $\mathrm{CO}_{2}$ is continuously monitored by peripheral and central chemoreceptors, and the depth and frequency of respiratory movements are adapted accordingly. Because disrupted breathing is a central feature of panic it is tempting to link the high $\mathrm{CO}_{2}$ vulnerability of PD subjects to a disturbed chemosensitivity. Our group has data that may be consistent with a high $\mathrm{CO}_{2}$ chemosensitivity in PO (Lousberg et al. 1988; Pols et al. 1993). However, othes studies have shown negative results (Woods et al. 1986). In another study by our group, we were unable to replicate earlier findings on elevated chemosensitivity in patients with PD (Zandbergen et al 1991). Finally, the Columbia group published a study with positive findings in male subjects (Papp et al. 1989).

In summary, the issue of an over-sensitivity of chemoreceptive areas in Po subjects is still open to debate. Within the broader context of breathing control, there is growing evidence 
from clinical epidemiology that some relationship may exist between PD and chronic obstructive pulmonary diseases (COPD). There is an increased prevalence of PD among patients with COPD (Karajgi el al. 1990; Shavit et al. 1992). Moreover, patients with PD have an increased childhood prevalence of respiratory diseases, in particular asthma and bronchilis (Zandbergen et al. 1991; Perna el al. 1994d; Verburg et al. 1995).

\section{Other provocative agents}

Various other agents have been used to trigger PA's experimentally, though few have been as much investigated as lactate and $\mathrm{CO}_{2}$. The beta agonist isoprotenerol has been reported 10 produce laboratory PA's resembling those induced by lactate (Rainey et al. 1984), but there is conflicting evidence (Nesse et al. 1984). Calfeine stimulates anxiety and caffeine intoxication may, at times, cause altacks similar to PA's. PD patients have been shown to be more sensitive to caffeine than controls, but it seems that caffeine is an analogue of generalized anxiety rather than of PD (Charney et al. 1985). Patients with PD are very sensitive 10 yohimbine, an alpha 2 antagonist. This substance induces bursts of anxiety with symptoms resembling true PA's (Charney et al. 1987). Yohimbine apparently triggers an hypersensitivity of adrenergic pathways in patients with a PD. However, it is questionable whether yohimbine-induced PA's are as specific as those provoked by lactate or $\mathrm{CO}_{2}$.

Several serotonergic compounds may be anxiogenic (Bourin et al. 1995). In particular, mchlorophenylpiperazine (M-CPP) has been tested. Results are not clear: among other factors, the effect of $\mathrm{m}$-CPP depends on the route of administration. Moreover, $\mathrm{m}$-C.PP may be anxiogenic in OCD as well. Fenfluramine is believed to stimulate anxiety (Targum and Marshall 1989). Again, however, it is not clear whether this applies specifically to subjects with PD. The neuropeptide cholecystokinin (CCK) has been shown to trigger PA's in PD, which are similar to real-life PA's (Bradwejn el al. 1991). CCK administration reliably reproduces the symptoms of a $P A$, and PD subjects are more sensitive to the challenge than subjects without reallite PA's (Bradwejn el al. 1992). The effect of CCK is sensitive to antidepressants which are 
effective in the treatment of PD. Therefore, CCK meets a number of criteria for a valid laboratory model of PD even though, to date, its diagnostic specificity is not as well established as for $\mathrm{CO}_{2}$ (Bourin el al. 1995). The $\mathrm{CCK}$ and $35 \% \mathrm{CO}_{2}$ challenge have been compared, and found to be similar in their behavioral effects. Both substances elicit, as well in healthy volunteers as in patients, the same type of panic-like symptoms, with prominent respiralory symplomatology (Bradwejn and Koszycki 1991). Together with lactate and $\mathrm{CO}_{2}, \mathrm{CCK}$ offers a most interesting approach to the experimental modeling of $\mathrm{PD}$. It is of interest to note that both $\mathrm{CO}_{2}$ and $\mathrm{CCK}$ have marked stimulating effects on respiration (Bradwejn et al. 1998).

\section{The metabolic hypothesis}

When it became clear that not only lactate, but also $\mathrm{CO}_{2}$ could trigger PA's, it was hypothesized that it was not lactate, but rather $\mathrm{CO}_{2}$ that was the key factor responsible for both panicogenic procedures. Although anionic compounds such as lactate do not pass the blood-brain barrier, it was observed that some limited fenestrated areas do exist, through which some amount of lactale may penetrate into the central nervous system (CNS). Carr and Sheehan (1984) postulated that lactate passing via the aforementioned areas, may be oxidized intracellularly into water and $\mathrm{CO}_{2}$, resulting in a final intraneuronal hypercapnia. This is in contrast 10 the peripheral metabolic alkalosis (Bradwejn et al. 1998).

According to this theory, the final common pathway of both lactate infusion and $\mathrm{CO}_{2}$ inhalation is a hypercapnic acidosis in some sensitive areas of the CNS. This theory is based on the assumption that lactate penetrates into the CNS, and is subsequently metabolized. The findings that $D$-lactate, which is not metabolized, may have some panic-provoking properties (Gorman et al. 1990) and that, in primates, no lactate could be found into the CNS (Coplan et al. 1992b), seriously invalidated Carr and Sheehans explanation. However, recent work, using magnetic resonance spectroscopy evidenced the presence of increased levels of lactate in the brain during lactate infusion (Dager et al. 1994). The same authors have shown that lactate-induced panic in PO patients is associated with a greater increase in brain lactate 
than in comparison subjects. Intriguingly, Dager and coworkers (1995) found that, after hyperventilation, brain lactate increases more in PD patients than in controls. These findings raise renewed interest in a metabolic hypothesis 10 account for the vulnerability of PD subjects to both lactate and $\mathrm{CO}_{2}$. Lactate and $\mathrm{CO}_{2}$ are end products of the anaerobic and aerobic metabolism, respectively. Why should an accumulation of these substances cause panic in susceptible individuals?

An appealing hypothesis has been formulated by Klein (1993). The vital threat represented by an excess of laclate or $\mathrm{CO}_{2}$ may trigger an inborn suffocation alarm. This phylogeneticalIy evolved alarm causes acute distress, and breathlessness, urging "air hunger" and flight to open surroundings. PA's may be false alarms in sensitive individuals who have a disregulated hypersensitive suffocation detector.

In this sense, panic is qualitatively distinct from fear and anticipatory anxiety. Klein correctly points to several differences between panic and anticipatory anxiety. PA's are seldom accompanied by a stimulation of the HPA axis. Cortisol elevation has been commonly reported in fear and phobic anxiety. PA's are characterized by the prominence of respiratory and cardiac symptoms, in particular breathlessness. This is not the case for fear, or phobic or generalized anxiety. The distinction between anticipatory anxiety and panic is supported by the differential effect of some antidepressants and most benzodiazepines. Recently, it was experimentally shown that PD patients remain vulnerable to lactate-induced panic after intravenous administration of diazepam, even though their anticipatory anxiely was considerably decreased (Liebowitz et al. 1995). Hence, PA's may be a distinct type of anxiety, closely related to an inborn survival mechanism being erroneously triggered in susceptible individuals. One may then predict that, beside experimental settings, real life situations with increased lactate or $\mathrm{CO}_{2}$ fluctuations would increase the likelihood of a PA in these individuals. From this perspective, chronic hyperventilation may be a habit that protects one from hypercapnia. PA's that occur during sleep may be explained by increasing levels of $\mathrm{CO}_{2}$ during slow-wave sleep. The false suffocation alarm theory may account for an impressive number of both laboratory findings and clinical observations. Several aspects of the hypothesis, however, are still in need of experimental support. Over the past thirty years the 
experimental pathophysiology of panic has produced an impressive body of literature. However, we are in need of explanatory hypotheses. The above respiratory/melabolic line suggests directions of interest for future research.

In the meantime, biological investigation sets the stage for an experimentally based understanding of anxiety disorders. Although the underlying mechanisms of panic are far from clearly established, laboratory challenges may become useful tools for validating clinical diagnoses (Battaglia and Perna 1995; Verburg et al. 1998b; Hsiao el al. 1989).

This second part of the introduction is largely based on: Griez E. and Schruers K. (1998) : Experimental Pathophysiology of panic; Journal of Psychosomatic research 45 (6):493-503 


\section{REFERENCES}

Battaglia M, Perna G (1995): ROC Analyses of $35 \% \mathrm{CO}_{2}$ test for panic disorder. Psychiatry research 29:111-119.

Bertani A, Perna G, Phd, Arancio C, Caldirola D, Bellodi L (1997): Pharmacologic effect of imipramine, paroxetine, and sertraline on 35\% carbon dioxide hypersensitivity in panic patients: a double-blind, random, placebo-controlled study. journal of clinical psychopharmacology 17:97-101.

Bonn JA, Harrison J, Rees WL (1971): Lactate-induced anxiety: therapeutic application. The British journal of psychiatry; 119:468-70.

Bourin M, Malinge M, Guitton 8 (1995): Provocative agents in panic disorder. Therapie 50:301-6.

Bradwejn J, Koszycki D (1991): Comparison of the panicogenic effect of cholecystokinin 3033 and carbon dioxide in panic disorder. Progress in neuropsychopharmacology and biological psychiatry 15:237-9.

Bradwejn J, Koszycki D, Shriqui C (1991): Enhanced sensitivity to cholecystokinin tetrapeptide in panic disorder. Clinical and behavioral findings. Archives of general psychiatry 48:603-10.

Bradwejn J, Koszycki D, Payeur R, Bourin M, Borthwick H (1992): Replication of action of cholecystokinin tetrapeptide in panic disorder: clinical and behavioral findings. The American journal of psychiatry 149:962-4.

Bradwejn J, LeGrand JM, Koszycki D, Bates JH, Bourin M (1998): Effects of cholecystokinin tetrapeptide on respiratory function in healthy volunteers. The American journal of psychiatry 155:280-2.

Caldirola D, Perna G, Arancio C, Bertani A, Bellodi L (1997): The $35 \% \mathrm{CO}_{2}$ challenge test in patients with social phobia. Psychiatry research 71:41-8.

Carr DB, Sheehan DV (1984): Panic anxiely: a new biological model. The journal of clinical psychiatry 45:323-30.

Charney DS, Honinger GR, Jatlow PI (1985): Increased anxiogenic effect of caffeine in PD. 
The Archives of General Psychiatry 42:233-243.

Charney DS, Woods SW, Goodman WK, Heninger GR (1987): Neurobiological mechanisms of panic anxiety: biochemical and behavioral correlates of yohimbine-induced panic altacks. The American journal of psychiatry 144:1030-6.

Cohen ME, White PO (1951): Life situations, emotions and neurocirculatory asthenia. Proceeding of the Association for Research in Nervous and mental diseases 13:335-357. Coplan JD, Liebowitz MR, Gorman JM, et al (1992a): Noradrenergic function in panic disorder. Effects of intravenous clonidine pretreatment on lactate induced panic. Biological psychiatry 31:135-46.

Coplan JD, Sharma T, Rosenblum LA, et al (1992b): Effects of sodium lactate infusion on cisternal laclate and carbon dioxide levels in nonhuman primates. The American journal of psychiatry 149:1369-73.

Cordes E (1872): Agoraphobia, a symptom of paratic exhaustion. Arch Psychiatrie 3:521-574. Cowley DS, Stephen R, Dager R, McClennan), Roy-Byrne PP, Dunner DL (1988): Response to lactate infusion in generalized anxiety disorders. Biological psychiatry 24:409-414.

Da costa JM (1871): An irritable heart, a clinical form of functional cardiac disorder and its consequences. Am. J. M. Sc. 61:17.

Dager SR, Marro KI, Richards TL, Metzger GD (1994): Preliminary application of magnetic resonance spectroscopy to investigate lactate-induced panic. The American journal of psychiatry 151:57-63.

Dager SR, Strauss WL, Marro KI, Richards TL, Metzger GD, Artru AA (1995): Proton magnetic resonance spectroscopy investigation of hyperventilation in subjects with panic disorder and comparison subjects. The American journal of psychiatry 152:666-672.

Drury AN (1920): The percentage of carbon dioxide in the alveolar air, and the tolerance to accumulating carbon dioxide in cases of so-called "irritable heart". Heart 7 105: 1918-1920.

Fink M, Taylor MA, Volavka f (1969): Anxiety precipitated by lactate. The New England journal of medicine 281:1429.

Fyer AJ, Liebowitz MR, Gorman JM, Davies SO, Klein DF (1985): Lactate vulnerability of 
remitted panic patients. Psychiatry research 14:143-148.

Fyer MR, Uy J, Martinez J, el al (1987): $\mathrm{CO}_{2}$ challenge of patients with panic disorder. The American journal of psychiatry 144:1080-2.

Gorman JM, Askanazi J, Liebowitz MR, et al (1984): Response to hyperventilation in a group of patients with panic disorder. The American journal of psychiatry 141:857-61. Gorman JM, Fyer MR, Liebowitz MR, Klein DF (1987): Pharmacologic provocation of panic atlacks. In Meltzer HY (ed), Psychopharmacology: the third generation of progress. New York: Raven Press, pp 985-993.

Gorman JM, Papp LA, Martinez J, et al (1990): High-dose carbon dioxide challenge test in anxiety disorder patients. Biological psychiatry 28:743-57.

Griez E, van den Hout MA (1982): Effects of carbon dioxide-oxygen inhalations on subjective anxiety and some neurovegetative parameters. Journal of behavior therapy and experimental psychiatry 13:27-32.

Griez E, Pols HJ, van den Hout MA (1987a): Acid-base balance in real life panic. Journal of affective disorders 12:263-6.

Griez E], Lousberg $H$, van den Hout MA, van der Molen $G M(1987 b)$ : $\mathrm{CO}_{2}$ vulnerability in panic disorder. Psychiatry research 20:87-95.

Griez E, Zandbergen J, Lousberg $\mathrm{H}$, van den Hout $\mathrm{M}$ (1988): Effects of low pulmonary $\mathrm{CO}_{2}$ on panic anxiety. Comprehensive psychiatry 29:490-7.

Griez E, de Loof C, Pols H, Zandbergen J, Lousberg H (1990a): Specific sensitivity of patients with panic attacks to carbon dioxide inhalation. Psychiatry research 31:193-9.

Griez E, Zandbergen J, Pols $\mathrm{H}$, de Loof C (1990b): Response to $35 \% \mathrm{CO}_{2}$ as a marker of panic in severe anxiety. The American journal of psychiatry 147:796-7.

Guttmacher LB, Murphy DL, Insel TR (1983): Pharmacologic models of anxiety. Comprehensive psychiatry 24:312-26.

Hollander E, Liebowitz MR, Gorman JM, Cohen B, Fyer A, Klein DF (1989): Cortisol and sodium lactate-induced panic. Archives of general psychiatry 46:135-40.

Hsiao JK, Bartko JJ, Potter WZ (1989): Diagnosing diagnoses. Receiver operating characteristic methods and psychiatry. Archives of general psychiatry 46:664-7. 
Karajgi B, Rifkin A, Doddi S, Kolli R (1990): The prevalence of anxiety disorders in patients with chronic obstructive pulmonary disease. The American journal of psychiatry 147:200-1.

Kelly D, Mitchell Heggs N, Sherman D (1971): Anxiety and the effects of sodium lactate assessed clinically and physiologically. The British journal of psychiatry; the journal of mental science 119:129-41.

Klein DF (1993): False suffocation alarms, spontaneous panics, and related conditions. An integrative hypothesis. Archives of general psychiatry 50:306-17.

Lapierre YD, Knott VJ, Gray R (1984): Psychophysiological correlates of sodium lactate. Psychopharmacology bulletin 20:50-7.

Ley $R$ (1985): Agoraphobia, the panic attack and the hyperventilation syndrome. Behaviour research and therapy 23:79-81.

Liebowitz MR, Fyer AJ, Gorman JM, et al (1984): Lactate provocation of panic altacks. I.

Clinical and behavioral findings. Archives of general psychiatry 41:764-70.

Liebowitz MR, Fyer AJ, Gorman JM, et al (1985a): Specificity of lactate infusions in social phobia versus panic disorders. The American journal of psychiatry 142:947-50.

Liebowitz MR, Gorman JM, Fyer A), et al (1985b): Lactate provocation of panic attacks. II.

Biochemical and physiological findings. Archives of general psychiatry 42:709-19.

Liebowitz MR, Gorman JM, Fyer A, Dillon D, Levitt M, Klein DF (1986): Possible mechanisms

for lactate's induction of panic. The American journal of psychiatry 143:495-502.

Liebowitz MR, Coplan JD, Martinez ), et al (1995): Elfects of intravenous diazepam pretreatment on lactate-induced panic. Psychiatry research 58:127-38.

Lousberg H, Griez E, van den Hout MA (1988): Carbon dioxide chemosensitivity in panic disorder. Acta psychiatrica Scandinavica 77:214-8.

Lum LC (1975): Hyperventilation: the tip and the iceberg. Journal of psychosomatic research 19:375-83.

Nesse RM, Cameron OG, Curtis GC, McCann DS, Huber Smith MJ (1984): Adrenergic function in patients with panic anxiety. Archives of general psychiatry 41:771-6.

Papp LA, Goetz R, Cole R, et al (1989): Hypersensitivity to carbon dioxide in panic disorder. 
The American journal of psychiatry 146:779-81.

Perna G, Cocchi S, Nobile M, Griez E (1993): A new biological marker for genetic studies in panic disorder: preliminary data on the $35 \% \mathrm{CO}_{2}$ challenge test. Psych. Genetics 3 (suppl. 3) 184.

Perna G, Battaglia M, Garberi A, Arancio C, Bertani A, Bellodi L (1994a): Carbon dioxide/oxygen challenge test in panic disorder. Psychiatry research 52:159-71.

Perna G, Bertani A, Diaferia G, Arancio C, Bellodi L (1994b): Prevalence of respiratory diseases in patients with panic and obsessive compulsive disorders. Anxiety 1:100-1.

Perna G, Cocchi S, Bertani A, Arancio C, Bellodi L (1994C): Pharmacologic effect of toloxatone on reactivity to the $35 \%$ carbon dioxide challenge: a single-blind, random, placebocontrolled study. Journal of clinical psychopharmacology 14:414-8.

Perna G, Barbini B, Cocchi S, Bertani A, Gasperini M (1995a): 35\% CO2 challenge in panic and mood disorders. Journal of affective disorders 33:189-94.

Perna G, Bertani A, Arancio C, Ronchi P, Bellodi L (1995b): Laboratory response of patients with panic and obsessive-compulsive disorders to $35 \% \mathrm{CO}_{2}$ challenges. The American journal of psychiatry 152:85-9.

Perna G, Gabriele A, Caldirola D, Bellodi L (1995C): Hypersensitivity to inhalation of carbon dioxide and panic attacks. Psychiatry research 57:267-73.

Perna G, Cocchi S, Bertani A, Arancio C, Bellodi L (1995d): $35 \% \mathrm{CO}_{2}$ sensitivity in healthy first degree relatives of patients with panic disorder. The American journal of psychiatry 152:623-5.

Perna G, Bertani A, Gabriele A, Politi E, Bellodi L (1997): Modification of 35\% carbon dioxide hypersensitivity across one week of treatment with clomipramine and fluvoxamine: a double-blind, randomized, placebo-controlled study. Journal of clinical psychopharmacology 17:173-8.

Pitts FN, Allen RE (1979): Biochemical induction of anxiety. In Fann WE (ed), Phenomenology and Treatment of Anxiety. New York: Spectrum Publications.

Pitts FN, Jr., MCClure JN, Jr. (1967): Lactate metabolism in anxiety neurosis. The New England journal of medicine 277:1329-36. 
Pols H, Zandbergen J, de Loof C, Griez E (1991): Attenuation of carbon dioxide-induced panic after clonazepam treatment. Acta psychiatrica Scandinavica 84:585-6.

Pols $H$, Lousberg H, Zandbergen J, Griez E (1993): Panic disorder patients show decrease in ventilatory response $10 \mathrm{CO}_{2}$ after clomipramine treatment. Psychiatry research 47:295-6.

Pols HJ, Hauzer RC, Meijer JA, Verburg K, Griez EJ (1996): Fluvoxamine attenuates panic induced by $35 \% \mathrm{CO}_{2}$ challenge. The Journal of clinical psychiatry 57:539-42.

Rainey JM, Jr., Pohl RB, Williams M, Knitler E, Freedman RR, Elledgui E (1984): A comparison of lactate and isoproterenol anxiety states. Psychopathology 17 Suppl 1:74-82.

Sanderson WC, Wetzler S (1990): Five percent carbon dioxide challenge: valid analogue and marker of panic disorder? Biological psychiatry 27:689-701.

Shavit RG, Gentil V, Mandetta R (1992): The association of panic-agoraphobia and asthma: contributing factors and clinical implication. General Hospital Psychiatry 14:420-423.

Targum SD, Marshall LE (1989): Fenfluramine provocation of anxiety in patients with panic disorder. Psychiatry research 28:295-306.

Uhde TW, Tancer ME (1990): Chemical models of panic: a review and critique. In Tyrer $P$ (ed), Psychopharmacology of anxiety. London, Oxford: Oxford University Press.

Van den Hout MA, Griez E (1982): Cardiovascular and subjective responses to inhalation of carbon dioxide. A controlled test with anxious patients. Psychotherapy and psychosomatics 37:75-82.

Van den Hout MA, Griez E (1984): Panic symptoms after inhalation of carbon dioxide. The British journal of psychiatry; the journal of mental science 144:503-7.

Van den Hout MA, Boek C, van der Molen GM, Jansen A, Griez E (1988): Rebreathing to cope with hyperventilation: experimental tests of the paper bag method. Journal of behavioral medicine 11:303-10.

Verburg C, Griez E, Meijer ) (1994): A 35\% carbon dioxide challenge in simple phobias. Acta psychiatrica Scandinavica 90:420-3.

Verburg K, Griez E, Meijer J, Pols H (1995): Respiratory disorders as a possible predisposing factor for panic disorder. Journal of affective disorders 33:129-34.

Verburg K, Pols H, de Leeuw M, Griez E (1998a): Reliability of the 35\% carbon dioxide 
panic provocation challenge. Psychiatry research 78:207-14.

Verburg K, Perna G, Bellodi L, Griez E (1998b): The 35\% panic provocation challenge as a diagnostic test for panic disorder. In Bellodi L, Perna G (ed), The panic respiration connection. Milan: Medical Media Srl.

Verburg K, Klaasen T, Pols H, Griez E (1998C): Comorbid depressive disorder increases vulnerability to the $35 \%$ carbon dioxide $\left(\mathrm{CO}_{2}\right)$ challenge in panic disorder patients. Journal of affective disorders 49: 195-201

Westphal C (1872): Agoraphobia: a neuropathic phenomenon. Arch. Psychiatrie Nervenkrankheiten 3:138-161.

Wolpe (1973): The practice of behavior therapy (2nd edition): Oxford Pergamon.

Woods SW, Charney DS, Loke J, Goodman WK, Redmond DE, Jr., Heninger GR (1986): Carbon dioxide sensitivily in panic anxiety. Ventilatory and anxiogenic response to carbon dioxide in healthy subjects and patients with panic anxiety before and after alprazolam treatment. Archives of general psychiatry 43:900-9.

Zandbergen ), Lousberg HH, Pols H, de Loof C, Griez EJ (1990): Hypercarbia versus hypocarbia in panic disorder. Journal of affective disorders 18:75-81.

Zandbergen J, Pols $\mathrm{H}$, de Loof C, Griez EJ (1991): Ventilatory response to $\mathrm{CO}_{2}$ in panic disorder. Psychiatry research 39:13-9. 


\title{
Chapter 2
}

\section{Symptom profiles of natural and laboratory panic attacks}

\begin{abstract}
Background: Little accurate information is available about the symptomatology of real-life panic attacks and about how well they are reproduced by an experimental model such as the $35 \% \mathrm{CO}_{2}$ challenge. Method: Real-life panic symptoms were assessed in a group of 67 panic disorder patients, using daily life monitoring. Panic symptoms elicited by a $35 \% \mathrm{CO}_{2}$ challenge were assessed in 61 panic disorder patients, and their frequency was compared with the real-life symptoms. Results: The most frequent real-life symptoms were palpitations, dizziness and trembling. The $35 \% \mathrm{CO}_{2}$ challenge reproduced well the majority of reallife symptoms.

Conclusion: The findings suggest that the $35 \% \mathrm{CO}_{2}$ challenge is a marker for spontaneous panic attacks, which are considered the core of panic disorder.
\end{abstract}

\section{Introduction}

A number of studies have addressed the symptom profiles of real life panic attacks (PA's). In an epidemiological study in Canada 47 out of 3258 people from the general population were diagnosed with panic disorder (PD) and they reported on their usual PA symptomatology. The most common symptoms were heart pounding, sweating, trembling or shaking and the fear of dying or acting crazy (Dick et al. 1994). In a cohort study in 457 young men in Switzerland, 9 PD patients were identified and interviewed about their usual panic symptomatology. The most frequently reported panic symptoms in this small sample were palpitations, faintness, fear of losing control and trembling (Vollrath et al. 1990).

In a large-scale international treatment study, a total of 1168 PD outpatients were interviewed about the symptoms of their last severe panic attack. Here, the most common symp- 
toms were palpitations, dizziness, flushes or chills and trembling or shaking (Briggs et al. 1993). Similarly, the symptoms of the last PA were assessed in a Japanese sludy in 207 PD outpatients. Palpitations, dyspnea and dizziness or faintness were the most common symptoms (Shioiri et al. 1996). The relatively small differences between the symptom frequencies can possibly be attributed to differences in population (general population versus psychiatric outpatients) or in assessment (evaluation of the last PA versus the usual PA symptomatology). These studies share however one common shortcoming: they all rely on the patient's retrospective report of their symptoms. To our knowledge, only one study used daily life monitoring of PA's, with a symptom by symptom assessment: in a study in 94 PD patients, de Beurs et al. (1994) noted a total of 529 real life PA's. The most frequently reported symptoms were palpitations, dizziness, sweating and shortness of breath.

One aim of the present study is to report on the frequency of real-life PA-symptoms, in light of the frequencies reported in the above literature. A second aim is to compare the symptomatology of the "natural" PA's with 35\% $\mathrm{CO}_{2}$ provoked "laboratory" PA's. According to criteria formulated repeatedly by others (Guttmacher et al. 1983, Gorman et al. 1987, Uhde and Tancer, 1990, verburg et al. 1998a), the $35 \% \mathrm{CO}_{2}$ challenge has shown to be a valid laboratory model for panic attacks. Firstly, it has a high, although not complete specificity for PD. PD patients respond to the challenge, as do patients with situational phobics, which latest category has been suggested to have links with PD (Verburg et al. 1994.

In contrast, patients with obsessive compulsive disorder, generalized anxiety disorder or mood disorder are not responsive (Griez et al. 1990, verburg el al, 1995, verburg et al, 1998b). Patients with social phobia appear to show a somewhat less clear response to a $35 \%$ $\mathrm{CO}_{2}$ challenge.

A study from our group found that social phobia patients do not react with higher subjective anxiety than to a $35 \%$ challenge than healthy controls (Verburg et al., Unpublished). Caldirola et al (1997) suggest that social phobics respond like PD patients to $35 \% \mathrm{CO}_{2}$. Other studies with $\mathrm{CO}_{2}$ in social phobia suggest an intermediate response, between PO patients and healthy controls (Gorman 1990, Papp et al. 1993). Overall, there seems to be a " $\mathrm{CO}_{2}$ sensitivity spectrum", which closely matches the so-called panic spectrum (Perna, 1995). 
Secondly, several studies suggest that the reliability of the $35 \% \mathrm{CO}_{2}$ challenge is good, although differences in measuring $\mathrm{CO}_{2}$ reactivity make the results difficult to compare (Perna et al. 1994, Perna el al. 1997, Bertani et al. 1997, Schmidt et al. 1997, verburg et al. 1998c). It must be noted however that one early study has suggested that very frequently repeated challenges may cause some desensitization (Van den Hout et al. 1987). On the other hand, schmidt el al. (1997) found no habituation over 5 consecutive inhalations of $35 \% \mathrm{CO}_{2}$ in patients with $\mathrm{PD}$.

Thirdly the method has been shown to be clinically valid. Clinically effective anti-panic agents like TCA'S, SSRI's, reversible MAO-inhibitors and high potency benzodiazepines reduce the behavioral and physiological reactivity to 35\% $\mathrm{CO}_{2}$ (Pols et al, 1991, 1993, 1996, Perna et al, 1994, Bertani el al, 1997, Gorman et al, 1997, Nardi et al, 1997, Bocola et al, 1998). The symptoms produced by a $35 \% \mathrm{CO}_{2}$ challenge are reported to resemble closely those experienced by PD patients during a PA (Griez et al, 1987, Perna et al, 1994). However, up to now there has been only one study, to our knowledge, that specifically addressed this lopic, comparing symptoms of real-life PA's and $\mathrm{CO}_{2}$ provoked PA's. No significant differences were found (De Loof et al. 1990). The sample size in this particular study was very small and assessment of the real-life PA symptoms heavily relied on patients' memories as it was based on a retrospective report of symptoms usually experienced during a PA. The present study was undertaken in order to further document the phenomenology of both natural and laboratory induced PA's.

\section{Methods}

\section{Subjects}

Subjects were 101 outpatients of the Academic Anxiety Center of the University of Maastricht. All patients met DSM III-R criteria for panic disorder. Eleven patients also met criteria for major depression, diagnosed as secondary to the PO and not clinically predominant. Three patients had comorbid social phobia. From 18 patients no data for comorbidity were 
available. Subjects were 63 women and 33 men, aged between 22 and 67 , with a mean of 41.2 years.

At the time of data collection, all patients were free of medication.

\section{Procedures}

Data were routinely collected at the clinic and subsequently analyzed. One part of the subjects ( $n=67)$ were handed auto evaluation cards, with the 13 DSM III-R panic symptoms on one side and a Visual Analogue Anxiety Scale (VAAS) on the other (range: 0 - $100 \mathrm{~mm}$ ).

They were asked 10 fill in a card immediately following a panic attack (PA), during a period of one week. Only the attacks with four or more neurovegetative symptoms plus a score of at least $25-\mathrm{mm}$ on the VAAS were analyzed.

Another part of the subjects $(n=61)$ underwent a $35 \% \mathrm{CO}_{2}$ challenge, consisting of inhating of one vital capacity of a mixture of $35 \% \mathrm{CO}_{2}$ and $65 \% \mathrm{O}_{2}$. Before and immediately after the challenge subjects filled in a panic symptom list (PSL) containing the 13 DSM IV panic symploms rated on a scale of 0 to 4 , as well as a VAAS.

Criteria for a PA in these experimental conditions were an increase in at least four neurovegetative symptoms plus an increase of at least $25 \mathrm{~mm}$ on the VAAS (Klaassen et al. 1998). Both groups partly overlapped: 27 subjects both filled in the auto-evaluation cards and underwent the $\mathrm{CO}_{2}$ challenge.

\section{Statistical anolysis}

The frequency of each symptom was calculated in both the "natural" PA group and the "laboratory" PA group. In the "natural" PA group, symptom frequency was calculated using all PA's as well as only the first one reported by each patient. The percentage of subjects that reported a particular symptom in each group was compared, using a chi-square test for each symptom. For the patients who reported more than one "natural" PA, the first one was used for analysis. Significance level was set at $P<0.05$ for all analyses. 


\section{Results}

Sixty-seven patients reported a total of 347 real life PA's. The average number of PA's per patient was 5.2 in one week. When looking at the first PA registered, the most frequent symptom was palpitations, reported by $75 \%$ of the patients. About two third of the patients reported dizziness and trembling/shaking. About $60 \%$ reported sweating. In around one third numbness/tingling, choking, flushes/chills, depersonalization/derealization, fear of dying, fear of going crazy/losing control or chest pain/discomfort was present. The least frequent symptoms were nausea abdominal distress and dyspnea. When all 347 PA's reported by the 67 patients were used for calculation, the percentages of PA's in which a particular symptom was present, as well as the order of frequencies, remained virtually the same. The percentage of patients reporting a particular symptom during their first recorded PA is presented in table 1, as well as the percentage of PA's in which a particular symptom was present, using all PA's of every patient for analysis. In addition, the findings of five other studies, reporting frequencies of symptoms in PD patients, are presented. For the laboratory PA's, the frequencies of the symptoms were, in order of frequency:

dizziness $95.1 \%$, dyspnea $85.2 \%$, choking $82.2 \%$, palpitations $73.8 \%$, trembling/shaking and depersonalization/derealization $68.9 \%$, sweating $67.2 \%$, numbness $52.2 \%$, flushes/chills, fear of dying and fear of going crazy/losing control each $49.2 \%$, nausea $47.5 \%$ and chest pain $39.3 \%$. When the frequencies were compared with the ones of the natural PA's, significant differences were found for dyspnea $(P<0.001)$, choking $(P<0.001)$, dizziness ( $P<$ $0.001)$, derealization/depersonalization $(P<0.001)$ and nausea $(P<0.002)$. (Fig. 1)

\section{Discussion}

The frequency of most of the "natural" PA symptoms in the present stujdy resembles the reported frequencies in the literature (table 1 ). However, in our sample dyspnea and chest pain are less frequent than in any other reported study (Vollrath et a!. 1990, Briggs et al. 
1993, Dick et al. 1994, Shoiri et al. 1996). Additionally, the frequency of choking in the present study was lower than in all but one of these studies. It is not likely that these differences are due 10 a difference in methodology, especially in the way of assessing the PA symptoms, since the same differences exist with a study that also used real life sampling (de Beurs et al. 1994). A possible explanation of the lower prevalence of these symptoms in our study may be related to the heterogeneity of PD itself. Several investigators have suggested, based on the symptomatology of PA's, that PD, as defined by the current criteria, may be a heterogeneous entity.

Following three different ways of cluster analysis of panic symptoms, Briggs et al. (1993), divided PD patients into two groups, characterized by the presence or absence of prominent respiratory symptoms.

The first, "respiratory", cluster exists of PA's characterized by dyspnea, chest pain, choking, fear of dying and tingling/ numbness. The second, "residual" cluster exists of PA's with the other symptoms. The authors further substantiate their dichotomy in two ways. Firstly the patients who have prominent respiratory symptoms appear to experience relatively more spontaneous versus situational PA's than other PD subjects. Secondly the former (i.e. "respiratory") group responds relatively better to imipramine than to alprazolam, while the opposite is true for the latter group (Briggs el al. 1993). Other studies find similar clusters, based on slightly different methods. De Beurs et al. (1994) used factor analysis to analyze 1276 PA's in 94 PD patients and also find a cluster containing dyspnea, choking, chest pain and fear of dying. Argyle and Roth (1989) used "principal component analysis" to group symptoms. Their "factor 1 " contains dyspnea, choking, chest pain, palpitations and lingling.

These cluster analyses show that cardiac and respiratory symptoms are often linked together. It is likely that patients with prominent cardiac and respiratory symptoms are referred 10 a general hospital, instead of an anxiety clinic that is part of a large psychiatric hospital, like ours. Several studies have shown that part of the patients with complaints of chest pain who visit an emergency care unit and are diagnosed as not having a cardiac problem, do suffer from PD, the reported frequencies ranging from 2210 59\% (Beitman et al. 1987, Serlie et al.1995, Fleet, 1996, 1997). Our own group conducted a survey at the Maastricht Academic 
Hospital among 194 patients presenting at the emergency department with chest pain or palpitations. The results confirm that PD is a common diagnosis: at least $20 \%$ of these 194 patients had PD and no cardiac disorder (Kuijpers et al. 2000). Furthermore a recent pilot study comparing the symptom profiles of these PD patients in the general hospital with the ones in the anxiety clinic of the psychiatric hospital showed that cardio-respiratory symptoms are more frequent in the general hospital group (Schruers et al. 2000). It seems therefore that the patients with mainly these cardiorespiratory symptoms are underrepresented in the present study, possibly due 10 a referral bias. If this is indeed the case, then one would expect a higher $\mathrm{CO}_{2}$-sensitivity in a sample with more cardiorespiratory symptoms, since a specific association has been shown to exist between a prominent respiratory subtype and $\mathrm{CO}_{2}$ hypersensitivity (Biber and Alkin, 1999). A similar sludy, comparing $\mathrm{CO}_{2}$ sensitivity between PD patients in a psychiatric hospital and an emergency department of a general hospital is currently underway in our center.

The second part of this study concerns the symptom frequencies of laboratory provoked versus natural PA's. It is confirmed that the $35 \% \mathrm{CO}_{2}$ challenge reproduces the majority of the PA symptoms that PO patients experience in real life (De Loof et al. 1990). A minority of the symploms, namely dyspnea, choking, dizziness, derealization/depersonalization and nausea appear to be even more frequent in the challenge group. These differences may be explained by the already mentioned specific characteristics of the sample of patients. As explained above, the frequency of respiratory symptoms in the real life PA's is relatively low, compared to other samples. Also, the symptom derealization/depersonalization has been reported to be less frequent in an older sample of PD patients (mean age of 40), as compared to a younger one (mean age of 35) (Cassano et al. 1989). This could explain the lower frequency of this symptom in the present sample with a mean age of 41 years. Dizziness has been reported to belong to the group of symptoms that specifically react to treatment with imipramine, as do the respiratory symptoms, and could therefore be linked with these (Mavissakalian 1996). However, dizziness is also a very frequent $\mathrm{CO}_{2}$-induced symptom in healthy volunteers (Koszycki et al. 1991, Perna et al. 1994). In PD patients, this frequency is even higher (Perna 1994). The very high frequency $(95 \%)$ of $\mathrm{CO}_{2}$-induced dizziness in the 
present study could therefore partly be due to an aspecific effect of $\mathrm{CO}_{2}$.

Panic spectrum disorders are characterized by different degrees of $\mathrm{CO}_{2}$ sensitivity. The highest sensitivity is found in PD patients (Perna 1995). However, within this category, there are also differences in sensitivity, based on panic symptom profiles. Biber and Alkin (1999) recently described a specific association between a respiratory symptom subtype and 35\% $\mathrm{CO}_{2}$ sensitivity. These patients with prominent respiratory symptoms are also the ones that have more spontaneous PA's (Briggs et al. 1993, Perna et al. 1994). Further, these patients respond better to pharmacological treatment with imipramine than with alprazolam (Briggs et al. 1993). Spontaneously occurring attacks, characterized by prominent respiratory symptoms and preferentially responding to treatment with imipramine are exacily what Klein (1993) considers to be the core of panic disorder. The present study shows that inhalation of one vital capacity of $35 \% \mathrm{CO}_{2} / 65 \% \mathrm{O}_{2}$ reproduces mainly the (cardio)respiratory panic symptoms. These results, together with the ones from Briggs et al. (1993), Perna et al. (1994) and Biber and Alkin (1999) suggest that the $35 \% \mathrm{CO}_{2}$ challenge is a marker for Klein's model of central core spontaneous PA's. 


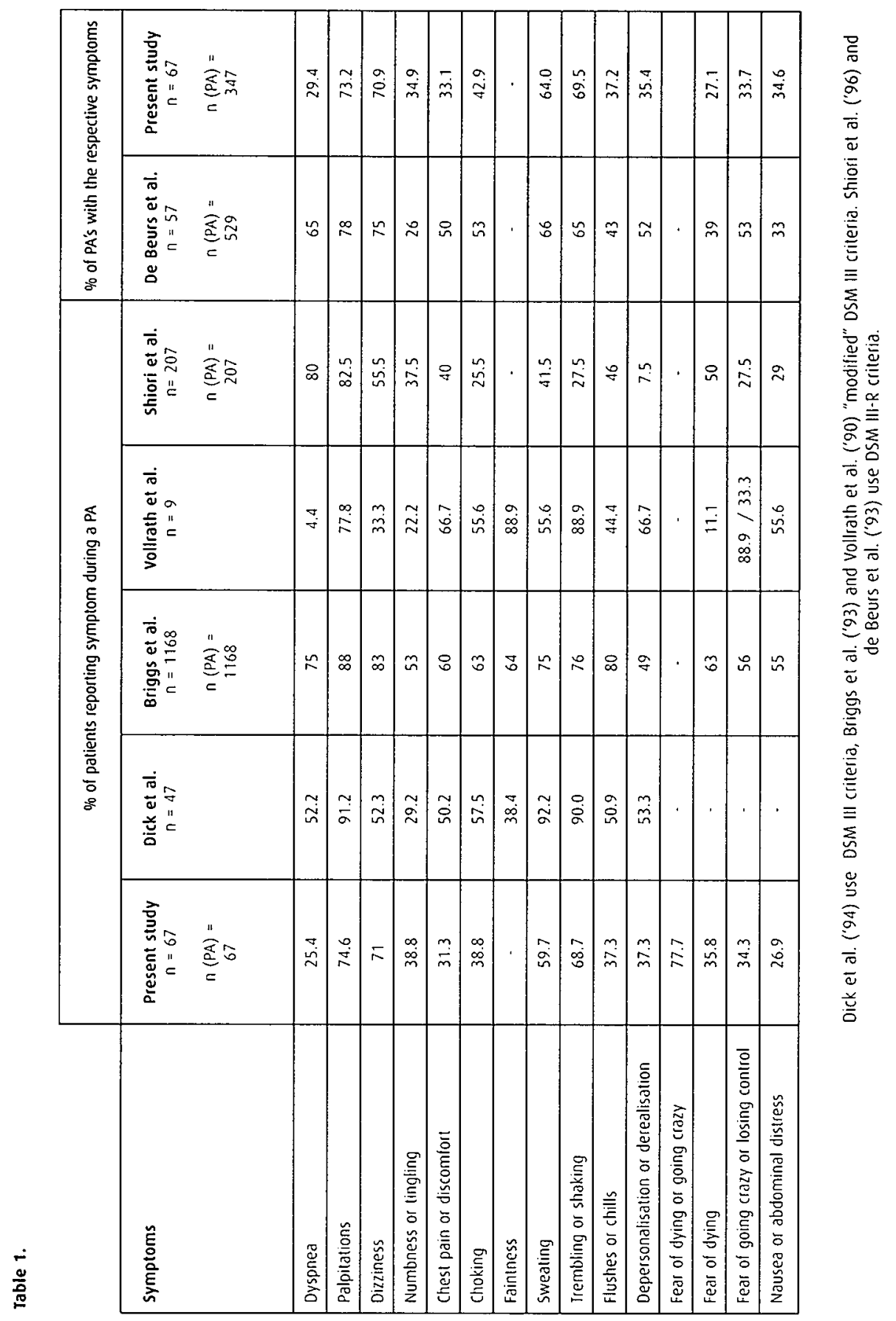




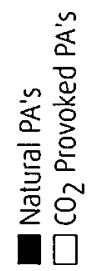

है

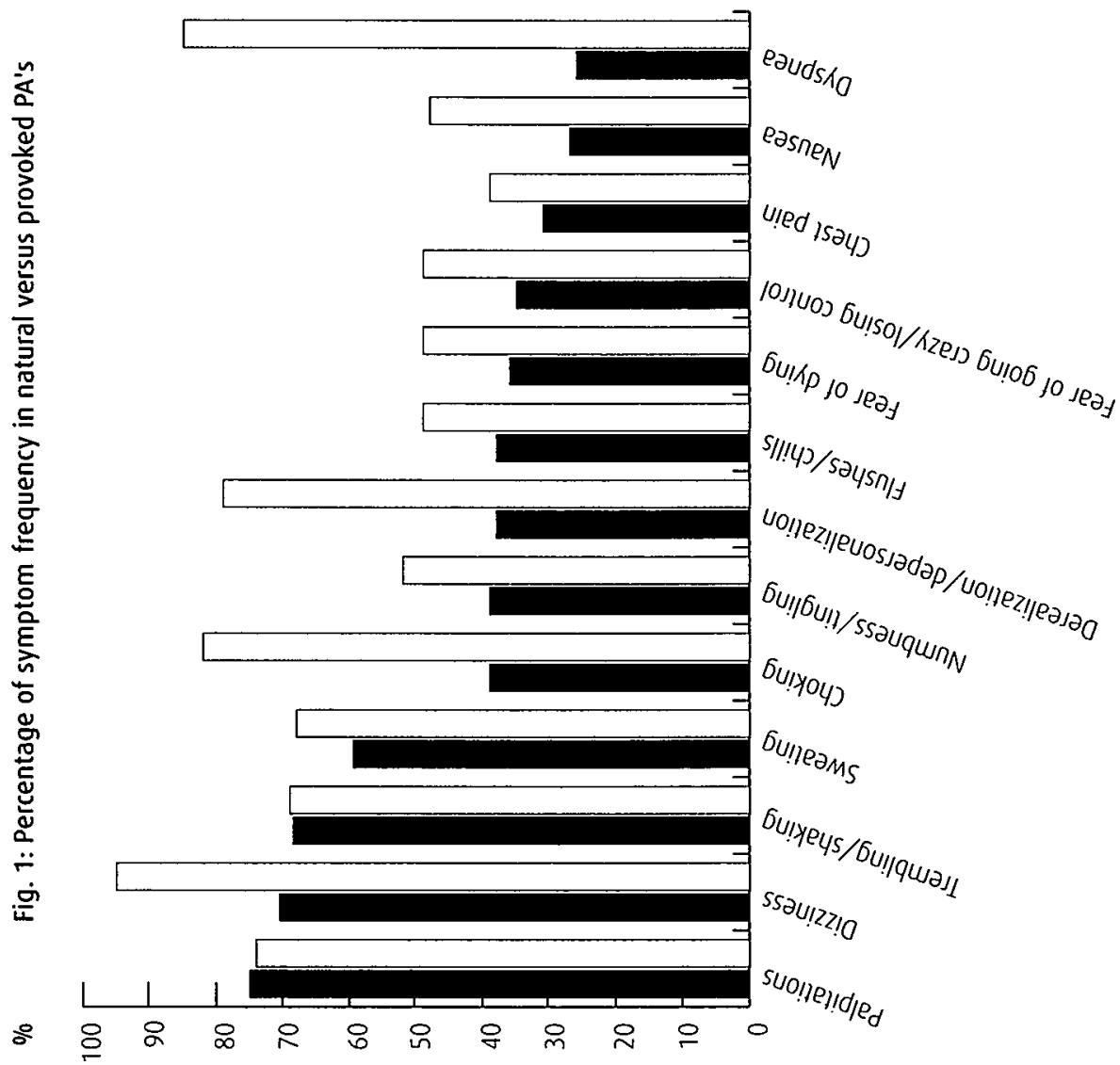




\section{REFERENCES}

Argyle N, Roth M (1989): The definition of panic attacks, Part 1. 7:175-86.

Beitman BD, Basha I, Flaker G, et al. (1987): Atypical or nonanginal chest pain. Panic disorder or coronary aftery disease? Archives of internal medicine 147:1548-52.

Bertani A, Perna G, Phd, Arancio C, Caldirola D, Bellodi L (1997): Pharmacologic effect of imipramine, paroxetine, and sertraline on 35\% carbon dioxide hypersensitivity in panic patients: a double-blind, random, placebo-controlled study. Journal of clinical psychopharmacology 17:97-101.

Biber B, Alkin T (1999): Panic disorder subtypes: differential responses to $\mathrm{CO}_{2}$ challenge. The American journal of psychiatry 156:739-44.

Bocola V, Trecco MD, Fabbrini G, Paladini C, Sollecito A, Martucci N (1998): Antipanic effect of fluoxetine measured by $\mathrm{CO}_{2}$ challenge test. Biological psychiatry 43:612-5.

Briggs AC, Stretch DD, Brandon S (1993): Subtyping of panic disorder by symptom profile.

The British journal of psychiatry; the journal of mental science 163:201-9.

Caldirola D, Perna G, Arancio C, Bertani A, Bellodi L (1997): The $35 \% \mathrm{CO}_{2}$ challenge test in patients with social phobia. Psychiatry research 71:41-8.

Cassano GB, Petracca A, Perugi G, Toni C, Tundo A, Roth M (1989): Derealization and panic attacks: a clinical evaluation on 150 patients with panic disorder/agoraphobia.

Comprehensive psychiatry 30:5-12.

de Beurs E, Garssen B, Buikhuisen M, Lange A, van Balkom A, Van Dyck R (1994):

Continuous monitoring of panic. Acta psychiatrica Scandinavica 90:38-45.

de Loof C, Zandbergen J, Griez E (1990): Are there differences between narurally occuring and provoked panic altacks? The case of carbon dioxide induced panic altacks. In Soldates C, Rabavilles A (eds), Psychiatry today. Amsterdam, The Netherlands: Elsevier science publishers.

Dick CL, Bland RC, Newman SC (1994): Epidemiology of psychiatric disorders in Edmonton. Panic disorder. Acta psychiatrica Scandinavica. Supplementum 376:45-53. 
Fleet RP, Dupuis G, Marchand A, Burelle D, Arsenault A, Beitman BD (1996): Panic disorder in emergency department chest pain patients: prevalence, comorbidity, suicidal ideation, and physician recognition. The American journal of medicine 101:371-80.

Fleet RP, Beitman BD (1997): Unexplained chest pain: when is it panic disorder? Clinical cardiology 20:187-94.

Gorman JM, Papp LA, Martinez l, et al (1990): High dose carbon dioxide challenge test in anxiety disorder patients. Biological psychiatry 28:743-57

Gorman JM, Browne ST, Papp LA, et al (1997): Effect of antipanic treatment on response to carbon dioxide. Biological psychiatry 42:982-91.

Griez EJ, Lousberg $\mathrm{H}$, van den Hout MA, van der Molen GM (1987): $\mathrm{CO}_{2}$ vulnerability in panic disorder. Psychiatry research 20:87-95.

Griez E, de Loof C, Pols H, Zandbergen J, Lousberg H (1990): Specific sensitivity of patients with panic attacks to carbon dioxide inhalation. Psychiatry research 31:193-9.

Guttmacher LB, Murphy DL, Insel TR (1983): Pharmacologic models of anxiety. Comprehensive psychiatry 24:312-26.

Klaassen T, Klumperbeek J, Deutz NE, van Praag HM, Griez E (1998): Effects of tryptophan depletion on anxiety and on panic provoked by carbon dioxide challenge. Psychiatry research 77:167-74.

Klein DF (1993): False suffocation alarms, spontaneous panics, and related conditions. An integrative hypothesis. Archives of general psychiatry 50:306-17.

Koszycki D, Bradwejn J, Bourin M (1991): Comparison of the effects of cholecystokinintetrapeptide and carbon dioxide in health volunteers. European neuropsychopharmacology 1:137-41.

Kuijpers PM, Honig A, Griez EJ, Braat SH, Wellens HJ (2000): Paniekstoornissen, pijn op de borst en palpitaties: een pilotonderzoek op een Nederlandse Eerste Harthulp. Nederlands tijdschrift voor geneeskunde 144:745-9.

Mavissakalian MR, Perel JM (1996): The relationship of plasma imipramine and N-desmethylimipramine to response in panic disorder. Psychopharmacology bulletin 32:143-7. 
Nardi AE, Valenca AM, Zin WA, Figuiera I, Marques C, Versiassi M (1997): Short term clonezepam treatment in carbon dioxide induced panic attacks. ). Bras. Psig. 46:611-614.

Papp LA, Klein DF, Martinez J, el al. (1993): Diagnostic and substance specificity of carbondioxide-induced panic. The American journal of psychiatry 150:250-7.

Perna G, Battaglia M, Garberi A, Arancio C, Bertani A, Bellodi L (1994): 35\% CO $2 / 65 \% \mathrm{O}_{2}$ inhalation test in panic patients. Psychiatry research 52:159-172.

Perna G, Gabriele A, Caldirola D, Bellodi L (1995): Hypersensitivity to inhalation of carbon dioxide and panic attacks. Psychiatry research 57:267-73.

Perna G, Bertani A, Gabriele A, Politi E, Bellodi L (1997): Modification of 35\% carbon dioxide hypersensitivity across one week of treatment with clomipramine and fluvoxamine: a double-blind, randomized, placebo-controlled study. Journal of clinical psychopharmacology 17:173-8.

Pols $H$, Zandbergen ), de Loof C, Griez E (1991): Attenuation of carbon dioxide-induced panic after clonazepam treatment. Acta psychiatrica Scandinavica 84:585-6.

Pols $H$, Lousberg $H$, Zandbergen J, Griez E (1993): Panic disorder patients show decrease in ventilatory response to $\mathrm{CO}_{2}$ after clomipramine treatment. Psychiatry research 47:295-6. Pols HJ, Hauzer RC, Meijer JA, Verburg K, Griez EJ (1996): Fluvoxamine attenuates panic induced by $35 \% \mathrm{CO}_{2}$ challenge. The journal of clinical psychiatry 57:539-42.

Schmidt NB, Trakowski JH, Staab JP (1997): Extinction of panicogenic effects of a $35 \% \mathrm{CO}_{2}$ challenge in patients with panic disorder. Journal of abnormal psychology 106:630-8.

Schruers K, Kuijpers PM, Honig A, Griez E (2000): Panic symptoms determine type of health care (poster at the 14th conference of the European Health Psychology Society, Leiden, The Netherlands, 16-19 August 2000).

Serlie AW, Erdman RA, Passchier J, Trijsburg RW, ten Cate FJ (1995): Psychological aspects of non-cardiac chest pain. Psychotherapy and psychosomatics 64:62-73.

Shioiri T, Someya T, Murashita J, Takahashi S (1996): The symptom structure of panic disorder: a trial using factor and cluster analysis. Acta psychiatrica Scandinavica 93:80-6. Uhde TW, Tancer ME (1990): Chemical models of panic: a review and critique. In Tyrer $P$ (ed), Psychopharmacology of anxiety. London, Oxford: Oxford University Press. 
van den Hout MA, van der Molen GM, Griez E, Lousberg $H$, Jansen A (1987): Reduction of $\mathrm{CO}_{2}$-induced anxiely in patients with panic attacks after repeated $\mathrm{CO}_{2}$ exposure. The American journal of psychiatry 144:788-91.

Verburg C, Griez E, Meijer J (1994): A 35\% carbon dioxide challenge in simple phobias. Acta psychiatrica Scandinavica 90:420-3.

Verburg K, Griez E, Meijer J, Pols H (1995): Discrimination between panic disorder and generalized anxiety disorder by $35 \%$ carbon dioxide challenge. The American journal of psychiatry 152:1081-3.

Verburg K, Perna G, Bellodi L, Griez E (1998a): The 35\% panic provocation challenge as a diagnostic test for panic disorder. In Bellodi L, Perna G (eds), The panic respiration connection. Milan, Italy: Medical Media Srl.

Verburg K, Klaassen T, Pols H, Griez E (1998b): Comorbid depressive disorder increases vulnerability to the $35 \%$ carbon dioxide $\left(\mathrm{CO}_{2}\right)$ challenge in panic disorder patients. Journal of affective disorders 49:195-201

Verburg K, Pols H, de Leeuw M, Griez E (1998C): Reliability of the 35\% carbon dioxide panic provocation challenge. Psychiatry research 78:207-14

Vollrath M, Koch R, Angst J (1990): The Zurich Study. IX. Panic disorder and sporadic panic: symptoms, diagnosis, prevalence, and overlap with depression. 239:221-30. 


\section{Chapter 3}

\section{$10 \mu \mathrm{G} \mathrm{CCK}$ premedication and $35 \% \mathrm{CO}_{2}$ challenge in healthy volunteers}

Koen Schruers, Henk Pols, Theo Overbeek and Eric Griez: $10 \mu \mathrm{g}$ cck Premedicolion and 35\% $\mathrm{CO}_{2}$ Chollenge in Healthy volunteers. Prog. Neuro-Psychophormacol. \& Biol. Psychiol. 2000. Vol. 24, pp. $409-418$

\section{Abstract}

1. The purpose of the study was to confirm whether a subtreshold dose of CCK-4 would enhance the vulnerability of healthy subjects to a $35 \%$ carbon dioxide challenge.

2. 40 subjects, with no prior or present psychiatric disorder and in good physical health were challenged with a vital capacity breath of a $35 \%$ carbon dioxide $65 \%$ oxygen mixture, immediately after an intravenous injection of $10 \mu \mathrm{g}$ CCK-4 or placebo, according 10 a random order, double blind, separate group design

3. Subjects reported significantly less anxiety and panic symptoms upon carbon dioxide after premedication with $c(K-4$ than after placebo.

4. CCK-4 and carbon dioxide seem to inhibit rather than enhance each other's effects, possibly through an effect on different neurobiological systems.

Abbreviations: carbon dioxide $\left(\mathrm{CO}_{2}\right)$, cholecystokinin ( $\mathrm{CCK}$ ), hypothalamus pituitary adrenal (HPA) axis, obsessive compulsive disorder (OCD), panic attack (PA), panic symptom list (PSL), state trait anxiety inventory (STAI-1), visual analogue anxiety scale (VAAS), zung self rating scale for anxiety (SAS). 


\section{Introduction}

The carbon dioxide $\left(\mathrm{CO}_{2}\right)$ challenge is well established as experimental model for panic. The same is proposed for the cholecystokinin (CCK) challenge (van Megen et al. 1996a, Griez and Schruers 1998).

In a study that compared $\mathrm{CCK}_{-4}$ and $\mathrm{CO}_{2}$ in panic disorder, 22 patients received either $25 \mathrm{\mu g}$ of $\mathrm{CCK}-4$ or a single inhalation of $35 \% \mathrm{CO}_{2}$. The panic attacks with either agent were qualitatively and quantitatively very similar (Bradwejn and Koszycki 1991).

In another study with 26 healthy volunteers the panic attack rate for $\mathrm{CCK}_{4} 4$ and $\mathrm{CO}_{2}$ was similar, 17 vs. 21\% respectively (Koszycki et al. 1991). Therefore, it was suggested that both agents might act on the same neurobiological pathways (Bradwejn and Koszycki 1991, Koszycki et al 1991). Under this assumption the authors conducted an earlier experiment in which 27 healthy volunteers were premedicated with a subliminal dose of $5 \mu \mathrm{gCCK}-4$ or placebo before undergoing a $35 \% \mathrm{CO}_{2}$ challenge. We hypothesised that pre-treatment with CCK would enhance the reaction to the $\mathrm{CO}_{2}$ challenge. Unexpectedly, the group that was pre-treated with $\mathrm{CCK}-4$ showed significantly less panic symptoms upon $\mathrm{CO}_{2}$ challenge than the group that was pre-treated with placebo. Because of the unexpected nature of these results, and to examine whether there may be a paradoxical effect of CCK at very low dosage in combination with $\mathrm{CO}_{2}$, the authors pre-treated 40 healthy volunteers in the present study with $10 \mu$ cCK-4 or placebo, before undergoing a $35 \% \mathrm{CO}_{2}$ challenge. The design was identical to the previous study. We still expected $\mathrm{CCK}_{-4}$ to facilitate the reaction to the $\mathrm{CO}_{2}$ challenge.

\section{Methods}

\section{Subjects}

Forty healthy volunteers participated in the study (14 men and 26 women, mean age 32.13 $( \pm 11.20)$ years). They were recruited through local advertisements and paid for their participation. Screening consisted of the Symptom check List (SCL-90) and a physical health 
questionnaire. Written informed consent was obtained after explanation of the procedures. Subjects underwent a physical examination and a psychiatric interview, including the MINI (Sheehan el al. 1997), to exclude any DSM IV psychiatric diagnosis, sporadic panic attacks or a family history of panic disorder.

\section{Study design}

All subjects were medication free in the three weeks before the study. Subjects underwent a $35 \% \mathrm{CO}_{2}$ challenge, preceded by a slow (<1 min.) intravenous injection containing either a $0.5 \mathrm{ml}$ solution of $10 \mu \mathrm{cCK}-4$ or $0.5 \mathrm{ml}$ of a $9 \%$ saline solution, in a double blind, randomised, separate group design. Each group consisted of 20 subjects.

Before the intravenous injection, baseline anxiety was assessed using the state Anxiety Inventory (STAI-1) and the Zung Self Rating Scale for Anxiety (SAS). Also, subjects filled in a visual analogue scale of anxiety (VAAS) ranging from 0 to 100 , and a panic symptom list (PSL) consisting of the 13 panic symptoms of a panic attack, as described by DSM IIIR, on a scale from 0 to 4 (total range $0-52$ ). The $35 \% \mathrm{CO}_{2}$ challenge was performed exactly 2 minutes after the injection. Before and directly after the inhalation of the gas mixture subjects again filled in the VAAS and PSL.

\section{Assessment}

Outcome measures were the increases on the VAAS and PSL scales as calculated by the difference post minus pre-inhalation. For each subject the difference in these outcome measures was calculated $\left(\mathrm{CCK}_{-} \times \mathrm{CO}_{2}\right.$ minus PLACEBO $\left.\times \mathrm{CO}_{2}\right)$. Also, the number of panic attacks was calculated for each group. The criteria for a panic attack were an increase of at least $25 \mathrm{~mm}$ on the VAAS after the $\mathrm{CO}_{2}$ test, plus an increase in at least four neurovegetative symptoms on the PSL.

\section{Dato analysis}

Data were analysed using a non parametric test for two independent samples (MannWhitney). The results are presented as means \pm standard deviations and are considered significant at a level of $P \leq 0.05$. All analyses were carried out using SPSS for Windows. 


\section{Results}

All forty subjects completed the study, there were no dropouts. Scores on the STAI-1 before placebo injection and before CCK-4 injection were $24.85( \pm 6.12)$ and 24.45 ( \pm 4.57 ) (NS). On the SAS these scores were $25.55( \pm 4.33)$ and $24.65( \pm 3.12)$ respectively (NS). The subjective level of anxiety on the VAAS before placebo or CCK-4 was $5.15( \pm 7.73)$ and 1.65 ( \pm 2.74) respectively (NS). These scores indicate that there were no baseline differences in anxiety between the Iwo groups. Compared to placebo, a $10 \mu \mathrm{g}$ injection of CCK-4 caused more physical symptoms as measured with the PSL. Delta PSL over placebo versus CCK was $0.40( \pm 0.88)$ versus $5.15( \pm 5.54)(P<0.005)$. There was also a difference in subjective anxiety on the VAAS, delta VAAS over placebo versus CCK being $1.10( \pm 3.32)$ and 6.05 $( \pm 12.29$ ) respeclively $(P<0.05)$.

To examine the pharmacological interaction between CCK or placebo with the $\mathrm{CO}_{2}$ challenge, the delta VAAS and PSL-scores over the $\mathrm{CO}_{2}$ challenge were calculated for each subject. The difference in VAAS for the pharmacological placebo $x \mathrm{CO}_{2}$ interaction was $9.00( \pm 12.77)$ and for $\mathrm{CCK} \times \mathrm{CO}_{2}$ it was $-0.75( \pm 13.15),(P=0.087)$ The differences in PSL score for the pharmacological placebo $\times \mathrm{CO}_{2}$ and $\mathrm{CCK} \times \mathrm{CO}_{2}$ interactions were $4.20( \pm 3.89)$ and 1.40 (2.95) respectively $(P<0.05)$. The number of panic attacks was $1(5 \%)$ in the $C C K$-group, after $C C K$ alone and none in the placebo group. After the combination of $\mathrm{CCK}_{\mathrm{K}}$ or placebo and $\mathrm{CO}_{2}$ the PA-rate was 1 in either group.

Table 1

\begin{tabular}{|l|l|l|l|l|l|l|l|l|}
\hline & \multicolumn{1}{|c|}{ STAI } & \multicolumn{1}{c|}{ SAS } & \multicolumn{1}{c|}{ VAAS1 } & PSL1 & $\Delta$ VAAS 2-1 & $\Delta$ PSL2-1 & $\Delta$ VAAS3-2 & $\Delta$ PSL3-2 \\
\hline CCK & 24.65 & 24.65 & 1.65 & 0.55 & 6.05 & 5.15 & 0.75 & 1.40 \\
& $( \pm 3.12)$ & $( \pm 3.12)$ & $( \pm 2.74)$ & $( \pm 0.69)$ & $( \pm 12.29)$ & $( \pm 5.54)$ & $( \pm 13.15)$ & $( \pm 2.95)$ \\
\hline PLAC & 24,85 & 25.55 & 5.15 & 0.40 & 1.10 & 0.40 & 9.00 & 4.20 \\
& $( \pm 6.12)$ & $( \pm 4.33)$ & $( \pm 7.73)$ & $( \pm 0.68)$ & $( \pm 3.32)$ & $( \pm 0.88)$ & $( \pm 18.77)$ & $( \pm 3.89)$ \\
\hline Mann- & NS & NS & NS & NS & $P<0.05$ & $P<0.001$ & $P<0.05$ & $P=0.87$ \\
\hline
\end{tabular}




\section{Discussion}

The results of the present study indicate that premedication with $10 \mu \mathrm{g}$ CCK-4 does not augment the carbon dioxide vulnerability in healthy volunteers. On the contrary, $\mathrm{CO}_{2}$ susceptibility seemed to be antagonised.

The present results confirm those of the study conducted earlier (Pols et al 1999). In that study, a significant reduction in panic symptoms was found after $\mathrm{CO}_{2}$ challenge in the $\mathrm{CCK}$ group, but no difference in anxiely. In the present study, we find a reduction in panic symptoms in the group pre-treated with $10 \mu \mathrm{g} C \mathrm{CK}$ as well as a trend for a reduction in anxiety. This means that the argument that a dose of $5 \mathrm{\mu g}$ may simply have been too low to find a synergistic effect, since the panicogenic effect is known to be dose dependent (Bradwejn et al. 1991), seems unlikely. For the second time our results suggest that both agents, cck-4 and $\mathrm{CO}_{2}$, may have an antagonistic effect at symptom level in healthy volunteers.

\section{Psychological factors}

Psychological factors are known to influence the response to challenge procedures (Rapee 1995). Since it has not yet been determined whether CCK-4 crosses the blood-brain barrier, a primary peripheral action cannot be completely ruled out. It would be conceivable that volunteers who experience symptoms due to cCK-4 injection, would associate them with impending threat and pay less attention to the symptoms provoked by the $\mathrm{CO}_{2}$ challenge, thus underreporting the experienced sensations. The fact that the two challenges were performed with only two minutes in between, however, would make it very difficult for a participant to distinguish between the effects of the respective agents. it seems more likely that report of symptoms is based on perception of the accumulated sensations, which have been reported 10 appear similar (Bradwejn and Koszycki 1991, Koszycki et al.1991).

\section{Neurobiological factors}

Panic symptomatology after injection of CCK or pentagastrin has been reported to last between 1 and 4 minutes (Bradwejn et al. 1991, Abelson and Nesse 1994). Therefore, the pos- 
sibility exists that the maximum effect of CCK had already subsided when the subjects inhaled the $\mathrm{CO}_{2}$. In this case, the finding that the combination of $\mathrm{CCK}$ and $\mathrm{CO}_{2}$ caused less symptoms than expected could point to a mechanism like prepulse inhibition. Prepulse inhibition is mainly described in an acoustic startle paradigm where it means that the response to an intense auditory stimulus is reduced when this stimulus is immediately preceded by a weaker stimulus (zhang et al. 1999). It is mainly used as an animal model of deficient sensorimotor gating to study the pathophysiology and new treatments of schizophrenia (Swerdlow and Geyer 1998). In humans, prepulse inhibition deficits are documented in patients with schizophrenia, where they correlate with certain cognitive symptoms (Braff et al. 1999). To our knowledge there are no comparable data on prepulse inhibition in panic disorder. The results of the present study could be interpreted as a pharmacological prepulse inhibition. This would confirm the assumption of the present study that $\mathrm{CCK}_{4} 4$ and $\mathrm{CO}_{2}$, at least partly, act on the same neurobiological systems. This assumption is based on the fact that both agents are claimed to fulfil the criteria for an ideal panicogenic agent (Bradwejn 1995, verburg et al. 1998) and that their effects appear symptomatologically similar (Bradwejn and Koszycki 1991). These are indirect arguments, however. At present there is no direct evidence for a (partly) shared mechanism of action. Some differences remain to be cleared. A first question that remains concerns the dose-response relationship of CCK: Higher doses of cCK do not just cause more volunteers to 'panic' but also elicit a higher number as well as a higher sum intensity of symptoms in each volunteer (Bradwejn et al. 1991). This seems not compatible with the description of panic as an "all or nothing phenomenon" by Klein, triggered by an over-sensitive false suffocation alarm (Klein 1993).

Secondly, CCK causes activation of the HPA axis (Spath et al. 1988, Depot et al. 1999, Shlik et al. 1997) and the same is true for its analogue, pentagastrin (McCann et al. 1995, Abelson et al. 1994). (linical panic attacks, as well as panic attacks provoked by $\mathrm{CO}_{2}$ or lactate are not accompanied by activation of the HPA axis. Klein claims the absence of HPA activation to be a hallmark of panic (Klein 1993).

A third question concerns the diagnostic specificity of CCK: pentagastrin, a synthetic analogue, has shown to be capable of producing panic attacks in patients with obsessive-com- 


\section{।}

pulsive disorder, a condition which is not associated with the spontaneous panic attacks that are typical for panic disorder (de Leeuw et al. 1996). With $\mathrm{CO}_{2}$, no PA's could be provoked in OCD patients (Verburg et al 1998). Although some failed to find this effect (van Megen et al 1996b). Furthermore, pentagastrin has also panic inducing properties in patients with social phobia (Mc Cann et al 1997a, Mc Cann et al 1997b, van Vliet et al. 1997).

A possible answer to these questions could lie in the possibility that $\mathrm{CCK}$ and $\mathrm{CO}_{2}$ may not act via the same mechanism but rather exert their apparently similar effect via stimulation of different systems. Possible candidates for these systems are the behavioural inhibition system and the fight/flight system, described by Gray and McNaughton (1996). The fight/flight system includes the periaqueductal gray, the medial hypothalamus and the amygdala. It is responsible for responses to unconditioned aversive stimuli, like suffocation, and possibly mediates the panic attacks in panic disorder. The behavioural inhibition system consists of the septal area, the hippocampal formation and their interconnections. It is responsible for responses to conditioned aversive stimuli and possibly plays a role in generalised anxiety disorder and the anticipatory anxiety in panic disorder (Gray and McNaughton 1996, Graeff et al. 1993). Extreme stimulation of this system, possibly a more general stress system, may result in extreme fear, phenomenologically resembling panic (Gray and McNaugton 1996). It appears that the behavioural inhibition system is capable of acting to inhibit the fight/flight system, possibly by serotonergic afferents to the periaqueductal gray (Deakin and Graeff 1991). This way anxiety could actively inhibit panic (Deakin and Graeff 1991).

It would be conceivable that $\mathrm{CCK}$ exerts its inhibitory action on the effects of $\mathrm{CO}_{2}$ via this mechanism. At this moment, however, this remains purely speculative. The hypothesis could, however, be tested by using higher doses of $\mathrm{CCK}^{-4}$ as premedication, for a $\mathrm{CO}_{2}$ (or lactate) challenge, with the prediction that an at least equal antagonism would occur. Or the possible interaction between the two agents could be studied by challenging with $\mathrm{CO}_{2}$ and subsequently injecting (CK-4 or placebo. Also 'combination challenge' studies could be performed in a patient population. 


\section{Conclusion}

The present study indicates that low dose CCK-4 premedication does not enhance but rather antagonises, $\mathrm{CO}_{2}$ vulnerability in healthy volunteers, thus confirming the unexpected results of a previous study.

\section{Acknowledgement}

The authors gratefully acknowledge Mrs. Lensing and Mrs. Bongaerts for their research assistance and Mrs. Esten, Van Kempen, and Noteborn for preparing the manuscript. We also wish to thank Prof. M. Bourin especially, for preparing the CCK and for providing methodological assistance.

\section{REFERENCES}

Bradwejn, J (1995) Cholecystokinin and Panic Disorder. In: Cholecystokinin and anxiety: from Neuron to Behaviour, J. Bradwejn and E. Vasar (Eds.), pp. 73-86, Springer-Verlag, Heidelberg, Germany.

Bradwejn, J. and Koszycki, D. (1991) Comparison of the Panicogenic Effect of Cholecystokinin 30-33 and Carbon Dioxide in Panic Disorder. Prog. Neuropsychopharmacol. \& Biol. Psychiat 15 (2): 237-239.

Bradwejn, J., Koszycki, D. and Bourin, M. (1991) Dose Ranging Study of the Effects of Cholecystokinin in Healthy Volunteers. J. Psychiatry Neurosci. 16 (2): 91-95.

Braff, D.L., Swerdlow, N.R., Geyer, M.A. (1999) Symptom correlates of prepulse deficits in male schizophrenic patients. Am J Psychiatry 156: 596-602.

Deakin, J.W. and Graeff, F.G. (1991) 5-HT and Mechanisms of Defence.

f Psychopharmacol 5 (4): 305-315. 
De Leeuw, A.S., den Boer, J.A., Slaap, B.R. and Westenberg, H.G. (1996) Pentagastrin has Panic-inducing Properties in Obsessive Compulsive Disorder.Psychopharmacol-Berl. 126 (4): $339-344$.

Depot, M., Caille, G., Mukherjee, J., Katzman, M.A., Cadieux, A., Bradwejn, J. (1999) Acute and chronic role of 5-HT 3 neuronal system on behavioural and neuroendocrine changes induced by intravenous cholecystokin tetrapeptide administration in humans. Neuropsychopharmacol 20: 177-187.

Graeff, F.G., Silveira, M.C., Nogueira, R.L., Audi, E.A. and Oliveira, R.M. (1993) Role of the Amygdala and Periaqueductal Gray in Anxiety and Panic. Behav Brain Res 58: 123-131. Gray, J.A. and McNaughton, N. (1996) The Neuropsychology of Anxiety:

Reprise In: Perspectives on Anxiety, Panic, and Fear. Volume 43 of the Nebraska Symposium on Motivation, pp. 61-134. University of Nebraska Press, Lincoln and London. Griez, E.J..L. and Schruers, K. (1998) Experimental Pathophysiology of Panic. J. Psychosom. Res. 45 (6): 493-503.

Klein, D.F. (1993) False Suffocation Alarms, Spontaneous Panics, and Related Conditions An Integrative Hypothesis. Arch. Gen. Psychiatry 50 : 306-317.

Koszycki, D., Bradwejn, J. and Bourin, M. (1991) Comparison of the Effects of Cholecystokinin-Tetrapeptide and Carbon Dioxide in Healthy Volunteers. Eur. Neuropsychopharmacol. 1 (2): 137-141.

McCann, U.D., Slate, S.0., Geraci, M. and Uhde, T.W. (1995) Peptides and Anxiety:

A Dose-Response Evaluation of Pentagastrin in Healthy Volunteers.Anxiety 1 (6): 258-267. McCann, U.D., Slate, S.O., Geraci, M., Roscow, T.D. and Uhde, T.W. (1997a).

A Comparison of the Effects of Intravenous Pentagastrin on patients with Social Phobia,

Panic Disorder and Healthy Controls. Neuropsychopharm 16 (3): 229-237.

McCann, U.D., Morgan, C.M., Geraci, M., Slate, S.O., Murphy, D.L. and Post, R.M. (1997b)

Effects of the 5-HT3 antagonist, ondansetron, on the behavioural and Physiological

Effects of Pentagastrin in Patients with Panic Disorder and Social Phobia.

Neuropsychopharm 17(6): 360-9.

Pols, H., Griez, E., Bourin, M. and Schruers, K. (1999) Effect of CCK-4 on a 35\% Carbon 
Dioxide Challenge in Healthy Volunteers. Accepted for publication. Prog. Neuropsychopharmacol. \& Biol. Psychiat.

Rapee, R.M. (1995) Psychological Factors Influencing the Affective response to Biological

Challenge Procedures in Panic Disorder. J Anxiety Dis 9: 59-74

Sheehan, D.V., Lecrubier, Y., Harnett Sheehan, K., Janavs, J., Weiller, E., Keskiner, A.,

Schinka, J., Knapp, E., Sheehan, M.F., and Dunbar, G.C. (1997) The Validity of the MINI

International Neuropsychiatric Interview (MINI) according to the SCID-P and its

Reliability. Eur. Psychiat. 12 : 232-241.

Schlik, J., Aluoja, A., Vasar, V. Vasar, E.Podar, T., Bradwejn, J. (1997) Effects of citalopram

treatment on behavioural, cardiovascular and neuroendocrine response to cholecystokinin tetrapeptide challenge in patients with panic disorder. J Psychiatry Neurosc 22: 332340.

Spat Schwalbe, E., Piroth, L., Pietrowsky, R., Born, J., and Fehm, H.L. (1988) Stimulation of the Pituitary Adrenocortical System in man by cerulein, a Cholecystokinin-8-Like Peptide. Clin. Physiol. Biochem. 6 (6): 316-320

Swerdlow, N.R., Geyer, M.A. (1998) Using an animal model of deficient sensorimotor gating to study the pathophysiology and new treatments of schizophrenia. Scizophr Bull 24: $285-231$.

Van Megen, H.J., Westenberg, H.G., den Boer, J.A., and Kahn, R.S. (1996a) Cholecystokinin in Anxiety. Eur. Neuropsychopharmacol. 6 (4): 263-80.

Van Vliet, I.M., Westenberg, H.G., Slaap, B.R., den Boer, J.A. and Ho-Pian, K.L. (1997) Anxiogenic Effects of Pentagastrin in Patients with Social Phobia and Healthy Controls. Biol Psychiat 42(1): 76-78.

Verburg, K., Perna, G., Bellodi, L., and Griez, E. (1998) The 35\% CO2 Panic Provocation Challenge as a Diagnostic Test for Panic Disorder. In: The Panic Respiration Connection, Laura Bellodi and Giampaolo Perna (Eds.), pp. 51-68, MDM Medical Media SrL, Milan. Zhang, J., Engel, J.A.. Ericson, M., Svensson, L. (1999) Involvement of the medial geniculate body in prepulse inhibition of acoustic startle. Psychopharmacol-Berl. 141: 189-196. 


\title{
Chapter 4
}

\section{Effects of low-dose cholecystokinin on respiratory function in healthy volunteers}

Koen Schruers, Nololia Coycedo, Theo Overbeek, Hogen Büchold, Michel Bourin, Eric Griez. Europeon Neuropsychophormocology 10 (2000) 419-421

\begin{abstract}
Injection of high doses of cholecystokinin tetrapeptide (CCK-4), a recent experimental model for panic, causes panic attacks and respiratory stimulation, a key feature of panic, in healthy volunteers. However, it has not yet been established whether respiratory stimulation is specifically linked to panic or merely an effect of arousal in general. Results of the present study show that respiratory stimulation is not merely linked to higher arousal and suggest a link between cck-provoked panic and respiratory stimulation.
\end{abstract}

\section{Introduction}

Special significance is given to respiratory symptoms in panic disorder, and they are often considered key symptoms (Klein 1993). In Klein's view, panic attacks (PA's) are caused by the triggering of an oversensitive false suffocation alarm. By administering a high dose of cholecystokinin tetrapeptide (CCK-4), PA's can be provoked in panic disorder patients as well as in healthy volunteers (Bradwejn et al. 1991, 1992). In a study investigating the effect of a high dose of CCK-4 on respiratory function in healthy volunteers, Bradwejn et al. (1998) found an increase in ventilation, blood pressure, heart rate, and number and intensity of panic symptoms and panic attacks. They concluded that the panicogenic effect of CCK might be partly mediated by stimulation of the brain stem regions that control respiration. In that study, a large dose of $50 \mu \mathrm{g}$ CCK-4 was administered. This dose induced PA's in 60\% of the subjects. It cannot be inferred from the published data whether respiratory stimulation 
occurred in each of the subjects who panicked (Bradwejn et al. 1998). The occurrence of respiratory stimulation could simply be due to arousal, and not necessarily to panic. To hypothesize a link between PA's and respiratory stimulation one needs to administer a high dose of CCK and to demonstrate that ventilatory stimulation occurs in those who panic and fails to occur in those who do not panic. An alternative approach would be to use a low dose of cCK. At a dose of $10 \mu \mathrm{g}$, the incidence of PA's is low in healthy volunteers. This dose is, however, sufficient to cause arousal (Bradwejn el al. 1991). In the present study, we evaluated the respiratory and behavioral effects of such a low dose of CCK-4 in healthy volunteers under the hypothesis that respiratory stimulation after cCK may merely be the result of an increase in arousal and not necessarily be linked to panic.

\section{Experimental procedures}

Sixteen subjects participated in the study. Subjects had no current or prior history of psychiatric disorders and no family history of psychiatric illness. They were physically healthy and drug-free at the time of the experiment. All subjects provided written informed consent. Subjects reported to the Academic Anxiety Center of Maastricht University (The Netherlands) at $9.00 \mathrm{a} . \mathrm{m}$. They were randomly assigned to one of two conditions- placebo or $10 \mathrm{\mu g}$ CCKin a double blind, random order, crossover design. Subjects were seated in a comfortable recliner chair and an intravenous catheter was placed in an antecubital vein. The mouthpiece through which subjects were instructed to breathe was attached to a pneumotachograph, which was linked to a computer for data storage. After a 10-minute accommodation period, baseline data were collected and subjects were given a bolus injection of $10 \mu \mathrm{g} \mathrm{CCK}-4$ or placebo. Behavioral response to the challenge was measured with a visual analog scale of anxiety (VAAS) and a panic symptom list (PSL) consisting of 13 DSM IV panic symptoms, rated on a 0-4 scale. Both scales have been used previously to assess experimental anxiety (Verburg et al. 1995, Pols et al. 1999, Schruers et al. 2000). Twenty minutes later, the same procedure was repeated with the subjects who had received cck now receiving placebo, and 
vice versa. Pulse rate was measured at 20 -second intervals following the challenge for a 2.5 minute period. Respiration was measured during the same period. Respiratory data were analyzed by MANOVA using the average values of lidal volume (VI), breathing frequency ( $f$ ), minute ventilation $(\mathrm{Ve})$, oxygen volume $\left(\mathrm{VO}_{2}\right)$, and carbon dioxide volume $\left(\mathrm{VCO}_{2}\right)$ obtained during the 2.5 minutes following the challenge. t-Tests were used to evaluate heart rate and behavioral responses to the challenge using the difference with baseline. A two-tailed significance level of $\rho \leq 0.05$ was used for all analyses. Data are expressed as mean + SD.

\section{Results}

Significantly higher scores were found in both anxiety and panic symptoms after cck than after placebo. Also, a significantly higher heart rate was found after CcK (table 1).

No significant effect was found for any of the respiratory parameters (table 2). No PA's were noted in either group. The experimental criteria for a PA were an increase of 25 on the VAAS plus an increase in neurovegetative symptoms on the PSL (Pols et al. 1999).

Table 1 : Behavioral measures and heart rate

\begin{tabular}{|l|l|l|l|l|}
\hline & CCK & PLACEBO & $\mathbf{t}$ & $\mathbf{P}$ \\
\hline VAAS & $4.5 \pm 7.3$ & $0.6 \pm 1.7$ & 2.155 & $<0.05$ \\
PSL & $2.4 \pm 1.6$ & $0.2 \pm 0.4$ & 5.775 & $<0.001$ \\
\hline Heart rate & $80.4 \pm 12.5$ & $72.6 \pm 10.2$ & 5.308 & $<0.001$ \\
\hline
\end{tabular}


Table 2 : Respirotory measures

\begin{tabular}{|l|l|l|l|l|}
\hline & CCK & PLACEBO & $F$ & $P$ \\
\hline $\mathbf{f}$ & $16.4 \pm 2.7$ & $16.3 \pm 2.9$ & 0.005 & NS \\
\hline $\mathrm{TV}$ & $0.69 \pm 0.17$ & $0.68 \pm 0.17$ & 0.52 & NS \\
\hline $\mathrm{VCO}_{2}$ & $0.27 \pm 0.05$ & $0.25 \pm 0.03$ & 0.977 & NS \\
\hline $\mathrm{VO}_{2}$ & $0.29 \pm 0.04$ & $0.29 \pm 0.05$ & 0.001 & NS \\
\hline $\mathrm{V}_{\mathrm{E}}$ & $10.7 \pm 2$ & $10.1 \pm 1.4$ & 0.763 & NS \\
\hline
\end{tabular}

\section{Discussion}

The present study indicates that administration of a low dose $(10 \mu \mathrm{g})$ of $\mathrm{CCK}-4$, insufficient to cause panic altacks, provokes anxiety and an increase in neurovegetative symptoms and heart rate. There was, however, no increase in any of the respiratory parameters. This means that the occurrence of arousal is not sufficient to cause respiratory stimulation. It is possible that respiralory stimulation is only present when a panic atlack occurs.

Animal studies suggest that there is, indeed, a role for $C C K$ in the control of breathing. Microiontophoretic application of CCK-8, mainly a CCK-A receptor agonist, into the nucleus tractus solitarius causes decreases in neuronal firing as well as in respiratory rate in cats. These changes can be partially reversed by CCK-4, a CCK-B receptor agonist (Denavit-Soubié el al. 1985). Different doses of CCK-4 have also been systemically administered to anesthetized dogs. The highest doses, ranging from $8.51011 .8 \mathrm{\mu g} \mathrm{kg}^{-1}$ with a mean of $2.6 \mathrm{\mu g} \mathrm{kg}^{-1}$, are reported to cause an increase in VE, mainly by an effect on breathing frequency, with varying results on blood pressure and heart rate. The weight of the dogs ranged from 13.6 $1023.6 \mathrm{~kg}$, resulting in mean highest doses ranging from 116.96 to $202.96 \mu$ g CCK-4 (Bates and Bradwejn 1995). The results from the latter study and from the one in healthy volunteers by Bradwejn et al. (1998), logether with those of the present study, suggest that a sti- 
mulating effect of $\mathrm{CCX}-4$ on respiration only occurs at high dosages.

The number, intensity, and time to onset of panic symptoms and the number of PA's in response to CCK are also known to be dose-related in healthy volunteers (Bradwejn el al. 1991). Moreover, CCK dose-dependently induces anxiely and panic responses, as well as changes in heart rate and diastolic blood pressure, in panic disorder patients (Bradwejn et al. 1992). A similar relationship may exist between $\mathrm{CCK}$ dose and respiratory stimulation since a high dose $(50 \mu g)$ of $C C K$ causes respiratory stimulation and a low dose $(10 \mu \mathrm{g})$ does not (present sludy).

Klein's lalse suffocation alarm theory (Klein 1993) would then predict that a dosis between 10 and 50 h would only provoke a PA in subjecls with respiratory stimulation. CCK, at a dosis of $50 \mathrm{jg}$, seems to provoke an increase in tidal volume in some normals, without triggering a PA (Bradwejn 1998). Unforlunately, in that study data are not presented for each individual subject. It is, therefore, unclear whether the nine subjects who did panic all had respiratory stimulation following injection of $\mathrm{CCK}$.

To clearly establish whether the occurrence of $c(K$-provoked panic depends on respiratory stimulation, the above study could be replicated, additionally investigating whether respiratory stimulation exclusively occurs in subjects who panic. Alternatively, doses between 10 and $50 \mathrm{H} \mathrm{CCK} \mathrm{could} \mathrm{be} \mathrm{administered} \mathrm{to} \mathrm{healthy} \mathrm{volunteers} \mathrm{or} \mathrm{PO} \mathrm{patients} \mathrm{while} \mathrm{recording} \mathrm{beha-}$ vioral, cardiovascular, and respiratory parameters. In this way, one can establish at what dose respiratory stimulation occurs and, in addition, whether this is invariably linked to panic.

Acknowledgement: The authors would like to thank Prof. Harm Kuipers for kindly lending his laboratory and for providing technical assistance. 


\section{REFERENCES}

Bates, J.H.T. and Bradwejn, J. (1995) Ventilatory response to cholecystokinin tetrapeptide in anaesthetized dogs. NeuroReport 6, 2513-2517.

Bradwejn, J., Koszycki, D., Bourin, M. (1991) Dose ranging study of the effects of cholecystokinin in healthy volunteers. ) Psychiatry Neurosc 16, 91-95.

Bradwejn, J., Koszycki, D., Covetoux-du Tertre, A., Reines, S., Karkanias, C. (1992) A doseranging study of the behavioral and cardiovascular effects of CCK-tetrapeptide in panic disorder. Biol Psychiatry 32, 903-912.

Bradwejn, J., LeGrand, J.M., Koszycki, D., Bates, J.H.T., Bourin, M. (1998) Effects of cholecystokinin tetrapeptide on respiratory function in healthy volunteers. Am J Psychiatry 155, $280-282$.

Denavit-Soubié, M., Hurlé M.A., Morin-Surun, M.P., Foutz, A.S., Champagnat, J. (1985) The effects of cholecystokinin-8 in the nucleus tractus solitarius. Ann N Y Acad Sci 448 , 375-384.

Klein, D.F. (1993) False suffocation alarms, spontaneous panics, and related conditions. Arch Gen Psychiatry 50, 306-317.

Pols, H., Griez, E., Bourin, M., Schruers, K. (1999) Effect of CCK-4 on a 35\% carbon dioxide challenge in healthy volunteers. Prog. Neuropharmacol Biol Psychiatry 23, 1345-1350. Schruers, K., Pols, H., Overbeek, T., Griez, E. (2000) $10 \mu \mathrm{g}$ CCK-4 premedication and 35\% $\mathrm{CO}_{2}$ challenge in healthy volunteers. In press, Prog. Neuropsychopharmacol. Biol. Psychiatry.

Verburg, K., Griez, E., Meijer, J., Pols, H. (1995) Discrimination between panic disorder and generalized anxiety disorder by 35\% carbon dioxide. Am. J. Psychiatry 152, 1081-1083. 


\title{
Chapter 5
}

\section{EFFECTS OF TRYPTOPHAN DEPLETION ON CARBON DIOXIDE PROVOKED PANIC IN PANIC DISORDER PATIENTS}

Koen Schruers, Tineke Kloossen, Henk Pols, Theo Overbeek, Nicoloos E.P. Deutz

and Eric Griez. Psychiolry Research 93 (2000) 179-187

\begin{abstract}
Results of an earlier study in healthy volunteers suggest that the serotonergic system is involved in anxiety related mechanisms. We studied the influence of tryptophan depletion on the response to a $35 \%$ carbon dioxide challenge. Twenty four panic disorder patients received a mixture of amino acids, either with or without tryptophan, under double blind conditions. There was a significant increase in anxiety as well as in neurovegetative symptoms in the depletion group, compared to the placebo condition. Furthermore, when we compare the results of the placebo group with earlier panic provocation studies, it seems also that a balanced amino acid mixture might have a protective effect against a panic provocation. We conclude that the panic enhancing effect of tryptophan depletion as well as the polential protective effect of tryplophan administration in panic disorder patients can be explained by the Deakin-Graeff theory of anxiety.
\end{abstract}

\section{Introduction}

Arguments for a role of the serotonergic (5HT) system in panic disorder (PD) come from treatment studies on the one hand (Den Boer and Westenberg, 1991) and challenge studies on the other (Targum 1991, van Vliet et al., 1996). A method to challenge the 5HT system is 10 deplete individuals of tryptophan (Young et al., 1985). In a previous experiment, we examined the effects of tryptophan depletion on carbon dioxide $\left(\mathrm{CO}_{2}\right)$ provoked panic in healthy volunteers (Klaassen et al., 1998) and found a significant increase in neurovegetative symp- 
toms in response to the $35 \% \mathrm{CO}_{2}$ challenge in the $5 \mathrm{HT}$-depleted subjects. There was, however, no difference in anxiety over the $\mathrm{CO}_{2}$ challenge, as measured with a visual analog scale, between the subjects who were or were not depleted of tryptophan. It appeared that the combination of $5 \mathrm{HT}$ depletion and a $\mathrm{CO}_{2}$ challenge could not induce panic, defined according lo OSM IV crileria, in normal subjects.

Two other studies used a combination of TRP depletion and a panic provoking agent to study anxiety in normal volunteers. Goddard el al. (1995) used yohimbine and koszycki el al. (1996) CCK. Both failed to find increased anxiety after TRP depletion plus the challenge.

However Goddard et al. did find that subjects reported an increase in nervousness. They explained that ratings of nervousness and anxiety tend to change in parallel in panic patients but that healthy volunteers preferentially report nervousness rather than anxiety, perhaps because the term anxiety is more suggestive of mental disorder.

In panic disorder patients, TRP depletion has been shown to increase panic anxiety following a $5 \% \mathrm{CO}_{2}$ challenge (Miller et al., 1996). IRP depletion alone, however, was not anxiogenic or panicogenic in a sample of unmedicated panic disorder patients (Goddard et al., 1994). It is, therefore, possible that vulnerability 10 TRP depletion in PD patients may only become apparent after panic provocation. In the present study, we test the hypothesis that panic disorder patients are vulnerable to the combination of IRP depletion and a $35 \% \mathrm{CO}_{2}$ challenge. We predicted that such patients will show more neurovegetative symptoms and anxiety after the challenge when depleted of tryptophan than when they are not.

\section{Methods}

\section{Subjects}

Twenty-four patients with panic disorder with or without agoraphobia (DSM IV criteria) parlicipated in the study. Participants were recruited among the patients of the Academic Anxiety Center of Maastricht as well as through advertisement in a local newspaper. The diagnosis was made by means of a semi-structured interview (Mini International 
Neuropsychiatric Interview, Sheehan et al.,1997) and confirmed by two experienced psychiatrists (KS and $E G$ ). There was no concurrent axis I or axis II disorder. Also, none of the patients had a prior history of affective disorder. All subjects had sought professional help for their problem al least once in the past. Inclusion criteria were: age between 18 and 65, good physical health, and written informed consent. No concurrent psychotropic medication (benzodiazepines, antidepressants or beta-blockers) was allowed in the 14 days before the experimental procedures. None of the patients had been on diazepam or fluoxetine that require a longer wash-out period. The study was approved by the medical ethics commitlee of the University of Maastricht.

\section{Design and procedures}

The experiment was conducted according to a randomized, double blind, placebo controlled, separate group design. Twelve subjects were allocated to the tryptophan depletion condition and twelve to the placebo condition. The subjects arrived at the clinic at $8.30 \mathrm{AM}(\mathrm{t}=\mathrm{Oh})$ after an overnight fast and filled in a visual analog anxiety scale (VAAS). Blood samples were drawn to measure plasma tryptophan levels. After ingestion of the mixture, the subjects remained on the ward. They were allowed to read or watch a nature documentary on video. Subjects had ad libitum access to mineral water or linden-blossom tea, a tea without particular stimulating or sedative properties. The amount of water or tea consumed was not monitored. Side effects (headache, feeling cold, feeling hot, dizziness, sleepiness, perspiration, blurred vision, drowsiness, nausea, palpitations, dry mouth, abdominal complaints, fatigue) were monitored at 9.00 and $13.00 \mathrm{~h}(\mathrm{t}=5 \mathrm{~h})$ by using a 5 -point scale, previously used in a comparable design by Klaassen et al. (1998). Another blood sample was taken to measure total plasma tryptophan levels. This was followed by the $\mathrm{CO}_{2}$ challenge in which subjects had to inhale through a mask one vital breath capacity of a gas mixture containing $35 \%$ $\mathrm{CO}_{2}$ and $65 \% \mathrm{O}_{2}$. Directly before and after inhalation, the subjects filled in the VAAS and a panic symptom list (PSL, consisting of 13 symptoms of a panic attack, as described by DSM IV), on a scale from 0 to 4 (total range 0-52).

After the experiment, the participants were offered a meal, consisting of bread, fruit and a salad, to restore their tryptophan levels. 


\section{Amino Acid Mixtures}

The Iryptophan-deficient amino acid mixture (100 g) was made according to the method used by Young el al. (1985). It contained $5.5 \mathrm{~g} \mathrm{L-alanine,} 4.9 \mathrm{~g} \mathrm{~L}$-arginine, $2.7 \mathrm{~g} \mathrm{~L}$-cysteine, $3.2 \mathrm{~g}$ glycine, 3.2 L-histidine, $8.0 \mathrm{~g}$ isoleucine, $13.5 \mathrm{~g} \mathrm{~L}$-leucine, $3.0 \mathrm{~g}$ methionine, $5.7 \mathrm{~g} \mathrm{~L}$ phenylalanine, $12.2 \mathrm{~g}$ L-proline, $6.5 \mathrm{~g} \mathrm{L-threonine,} 6.9 \mathrm{~g} \mathrm{L-tyrosine,} 8.9 \mathrm{~g} \mathrm{L-valine,} 8.9 \mathrm{~g} \mathrm{L-lysi-}$ ne and $6.9 \mathrm{~g} \mathrm{~L}$-serine. The placebo mixture contained also $3 \mathrm{~g}$ of L-tryptophan (Klaassen et al. 1998).

A mixture of $33 \mathrm{~g}$ fatty acids (vegetable fat) and $63 \mathrm{~g}$ of carbohydrates (maltodextrine, glucose and polysaccharides), flavored with artificial apricol, was added to make the amino acid mixture soluble in water, as well as more palatable (Klaassen et al.,1998). The subjects drank the mixture whitin 20 minutes. The mixture was purchased from Nutricia Nederland, zoetermeer, The Netherlands.

\section{Plasma tryptophan levels}

Collected blood was immediately centrifuged for $5 \mathrm{~min}$. at $11,000 \mathrm{~g}$ at $4^{\circ} \mathrm{C}$. Then $100 \mu \mathrm{l}$ of plasma was mixed with $4 \mathrm{mg}$ sulfosalicylic acid and frozen at $-80^{\circ} \mathrm{C}$ until analysis (Van Eijk et al., 1994). Total plasma tryptophan concentration was analysed by high-performance liquid chromatography (Van Eijk et al., 1993).

\section{Doto onalysis}

Due to the non-normal distribution of the data, non-parametric tests were used for all analyses. Significance levels were sel at $P<0,05$ (Iwo tailed). The main outcome measures were the VAAS and PSL scores. A Mann-Whitney U-test was used to calculate baseline differences at $\mathrm{t}=\mathrm{Oh}$ and $\mathrm{t}=5 \mathrm{~h}$ between placebo and TRP depletion. The same method was used for analysis of the effects of the $\mathrm{CO}_{2}$ challenge, using the post scores (scores after the $\mathrm{CO}_{2}$ challenge) and the net scores (scores after $\mathrm{CO}_{2}$ minus score before $\mathrm{CO}_{2}$ challenge). To solve possible ceiling effects of the VAAS and PSL-scores, the delta \% scores were also calculated as described in detail by Verburg et al. (1998). The intensity of the individual symptoms of the PSL was compared before and after the $\mathrm{CO}_{2}$ test between the TRP $(+)$ and TRP $(\cdot)$ condition, 
using a Mann-Whitney U-test, and within each condition, using a Wilcoxon Signed Rank test. For the side effects, the total scores of the questionnaires per individual side effect were calculated, using a Mann-Witney test.

The number of panic attacks following the $\mathrm{CO}_{2}$ challenge was calculated for each group and compared with a chi-square test. Criteria for a panic attack were a rise of at least $25 \mathrm{~mm}$ on the VAAS, plus an increase in panic symptomatology (Pols et al., 1996).

The change in plasma TRP levels within each group was analyzed using Wilcoxon's test and the difference between the conditions with a Mann-Whitney test.

\section{Results}

\section{Subjects}

Twenty-four subjects entered the study. There were no dropouts. All subjects were included in the analysis. There were five men and seven women in the TRP depletion group and four men and eight women in the TRP balanced group. Mean age in the TRP (-) group was 43 (s.d. 12) years and in the TRP (+) group 37 (s.d. 11) years.

\section{Plasmo tryptophon levels}

The mean total plasma tryptophan level at $t=0$ has 49 (s.d.6) $\mu \mathrm{M}$ in the TRP (-) group and 51 (s.d. 9) $U M$ in the TRP (+) group (NS). At $t=5$ h the levels were 12 (s.d. 27) $\mu M$ and 74 (s.d. 39) $\mu M$ respectively $(P<0.001)$. In the TRP $(-)$ group, the mean drop in TRP level was 28 (s.d. 26) $\mu M(P<0.02)$. In the TRP (+) group, levels rose with a mean of 23 (s.d. 38) $\mu M$ $(P=0.06)$.

\section{Side effects}

No significant difference between the two groups was found for any of the side effects (Table 1). 


\section{Behavioral ratings}

Baseline VAAS scores at $\mathrm{t}=0 \mathrm{~h}$ did not differ significantly between the two groups. At $\mathrm{t}=5 \mathrm{~h}$ (just before the $\mathrm{CO}_{2}$ challenge), tryptophan depletion did not have a significant effect on the PSL or VAAS scores. However, tryptophan depletion had a significant effect on the net increase in the VAAS and PSL scores after the $\mathrm{CO}_{2}$ challenge. The net increase in VAAS score in the TRP (-) group was 47 (s.d. 25) and 13 (s.d. 31) in the TRP $(+)$ group $(P<0.02)$. The mean delta PSL score was 16 (s.d. 10) in the TRP (-) group and 7 (s.d .7) in the TRP (+) group $(P<0.05)$. (Table 2 ).

The rise in VAAS-scores in the IRP (+) group was observable in 9 out of 12 patients. In two patients the VAAS remained constant and in one patient there was a small decrease (of $7 \mathrm{~mm}$ ). In the TRP (-) group, the VAAS scores rose in 11 patients and remained constant in one. The rise in PSL-score was observable in every patient in each condition.

The mean scores of the individual panic symptoms are presented in table 3.

The number of panic attacks following the $\mathrm{CO}_{2}$ challenge was 1 in the TRP (+) group and 10 in the TRP $(-)$ group $(P<0.01)$.

There was no significant linear correlation between the response to $\mathrm{CO}_{2}$, as measured by the VAAS and PSL, and baseline TRP levels. Also, within each group there was no significant linear correlation between the change from baseline in TRP levels and response to $\mathrm{CO}_{2}$, indicating that the individual responses were fairly heterogeneous. This is also illustrated by the relatively broad standard deviations of both the behavioral measures and the TRP levels.

\section{Discussion}

The subjects in the tryptophan depletion group were significantly more anxious and had more panic symptoms than did the subjects in the placebo group after the challenge. Two studies have addressed the issue of panic provocation (with $5 \% \mathrm{CO}_{2}$ ) after tryptophan depletion in patients with panic disorder (Kent et al., 1996, Miller et al., 1996). Kent et al. reported two findings specific to panic disorder patients: an increased baseline room air res- 
piratory response to TRP depletion and a decreased ability to clear $\mathrm{CO}_{2}$ during room air breathing and $5 \% \mathrm{CO}_{2}$ challenge. There was, however, no difference in anxiety measures between depleted and control subjects. They conclude that TRP depletion may exacerbate an existing vulnerability towards an abnormal ventilatory response in PD patients. Miller et al. found that more patients experienced a crescendo anxiety on the IRP (-) than the TRP (+) occasion.

Carbon dioxide is known to stimulate the medullary chemoreceptors that conduct viscerosensory information to the solitary nucleus (Benarroch et al., 1986, Ruggiero et al., 1991, Grove et al., 1997). Additionally, $\mathrm{CO}_{2}$ stimulates peripheral arterial chemoreceptors, located in the aortic and carotid bodies. Increase in activity of these receptors increases discharge frequency in their afferent nerves, which also terminate centrally in the solitary nucleus (MC Queen and Pallot, 1983).

Evidence suggests that at least part of the response of the peripheral chemoreceptors involves conversion of $\mathrm{CO}_{2}$ to $\mathrm{H}+/ \mathrm{HCO}_{3}$ ( $\mathrm{MC}$ Queen and Pallot, 1983). The central chemoreceptors are probably mainly stimulated via this conversion of $\mathrm{CO}_{2}$ to $\mathrm{H}$ ' (Loeschke, 1983).

The solitary nucleus stimulates the paraventricular nucleus of the thalamus which in turn activates the periaqueductal gray (PAG). The PAG has been implicated as a structure that appears to be involved in the mediation of panic (Graeff, 1993). During the electrical stimulation of the PAG humans have documented feelings of fear and death as well as autonomic activation such as piloerection, sweating, increase in pulse and respiratory rate and blushing (Nashold et al., 1974). These symptoms are quite reminiscent of the criteria for ideal panic disorder probes postulated by Gorman et al. (1987), suggesting that stimulation of the PAG may be a key event in triggering panic (Grove et al., 1997). Deakin and Graeff (1991) point that the PAG may be a site of activation during acute unconditioned aversive stimuli, such as pain, asphyxia, and innate fear inducing stimuli producing panic, fight, flight or freezing behaviors in animals and humans. Additionally, this state may be homologous to the suffocation alarm model proposed by Klein (1993), in which panic disorder patients with poor PAG regulatory control respond with panic attacks and escape responses during the administration of respiratory panicogens (Grove et al., 1997). 
Serotonin-containing neurons located primarily in the median raphe nucleus exert predominantly inhibitory effects on brainstem nuclei that control cardiovascular and ventilatory function (Blier et al., 1987, Grove et al., 1997). Tryptophan depletion leads to substantially reduced levels of serotonin in the brain (Young et al., 1985, Tagliamonte et al., 1973, Gessa et al., 1974, Moja et al., 1989). It is conceivable that this would reduce the inhibitory serotonergic control over these brainstem nuclei, thus facilitating stimulation of the PAG and, ultimately, panic.

While the decline in the rate of synthesis and level of serotonin in the brain is the most likeIy factor mediating the observed behavioral effects, it should however be noted that other, non 5-HT metabolic, effects may play a role. Acute TRP depletion may have affected brain peptides, second messengers, receptor synthesis or some other non specific metabolic aspect of brain function (Delgado et al., 1990). Similarly, TRP depletion and consequent reduction of 5-HT may have altered some balance between 5-HT and other neurotransmitters such as noradrenaline, dopamine, acetylcholine or gamma-amino-butyric acid, which could also contribute to behavioral effects (Delgado et al., 1990, Goddard et al., 1995).

In a recent experiment, comparing depletion of tryptophan and lysine, another essential amino acid, Klaassen et al. (1999) found the effects of TRP depletion on mood and memory to be specific for the depletion of TRP and therefore not caused by the depletion of an amino acid per se. Also, Delgado et al. (1990), investigating reversal of antidepressant-induced remission by rapid depletion of plasma tryptophan, noted that the rapidity of the return of depressive symptoms during the TRP-depleted state argues against some non specific reduction in protein synthesis secondarily affecting receptors or peptides.

The results from the present study are in line with those from Kent et al. (1996) and Miller et al. (1996), indicating that TRP-depletion aggravates panic. A closer examination of our data suggests, however, that the matter may be more complicated.

In a paper, summarizing the results of several experiments in which a total of 318 PD patients underwent a $35 \% \mathrm{CO}_{2}$ challenge (without TRP depletion), verburg et al. (1998) report an increase in VAAS and PSL scores of 38 and 11 respectively.

In the present study we find higher values in the TRP (-) condition: scores of 47 and 16 resp. 
In the TRP (+) condition one would expect to find values similar to the scores reported by verburg et al., since this is the placebo condition and with the same population, namely PD patients. We find however a mean increase of only 13 on the VAAS and 7 on the PSL. Furthermore, in our earlier similar study in healthy volunteers we find increases of 10 for the VAAS and 8 for the PSL in the TRP (-) group, and of 3 and 6 in the TRP (+) group. These values are in the same range as the ones of the TRP $\left(^{+}\right)$group in the present study.

This means that PD patients who were administered an amino acid mixture containing tryptophan react to a $35 \% \mathrm{CO}_{2}$ challenge more or less the way healthy volunteers would.

The IRP $\left(^{+}\right)$condition therefore seems not to be a true placebo condition. Our results suggest that tryptophan depletion does not only augment the reaction to a 35\% CO2 challenge but also that tryptophan (or a balanced mixture of amino acids) may have a protective effect against the $\mathrm{CO}_{2}$ challenge. Indeed we found a trend for the TRP level to rise in the TRP (+) condition. Furthermore, a rise of TRP in the balanced mixture condition is a consistent finding throughout the TRP depletion literature (Smith et al., 1987, Young et al., 1989, Delgado et al., 1990, Benkelfat et al., 1994, Barr et al., 1994, Weltzin et al., 1994). This is also true for the sludy of Miller et al. (1996) in PD patients. In the other study in PD, no TRP mixture was used as placebo (Kent et al., 1996). The rise of plasma TRP in the TRP $(+)$ condition of the present study seems therefore to be expected, especially since the balanced mixture contains $3 \mathrm{~g}$ of L-TRP, which is more than the $2.3 \mathrm{~g}$ used by Young et al. (1985).

Moreover, two studies do also report an opposite behavioral effect in the TRP $(+)$ group, compared to the placebo condition. Smith et al. (1987), investigating the effects of 5HT depletion in normal males, reported a rise on the Multiple Adjective Assessment checklist in the depletion condition and a lowering in the balanced mixture condition, for depression as well as anxiety scores. Similarly, Benkelfat et al. (1994), investigating subjects at risk for affective disorder, find a rise in the TRP (-) condition and a drop in the TRP (+) condition for the Spielberger State Anxiety inventory as well as the anxious subitem of the Profile of Mood States. Our results are in line with these findings.

A conceptual framework for a panic-enhancing effect of tryptophan depletion as well as for a potential protective effect of tryptophan administration in PD patients is offered by the 
Deakin-Graeff theory (Deakin and Graefl, 1991). According to this theory, serotonergic input to the periaqueductal gray may be involved in the mediation of panic (unconditioned fear), while the amygdala is involved in the pathogenesis of anticipatory anxiety and avoidance (conditioned fear). The PAG receives serotonergic innervation from the dorsal raphe nucleus and the theory proposes that an increased availability of serotonin in this part of the brain increases inhibition in the PAG and thereby restrains panic-like responses (Graeff et al., 1996, Nutt, 1998). A decrease of serotonergic input, in this view, would act to aggravate panic.

This remains speculative, however. It is conceivable that methodological factors other than being administered an amino acid mixture with TRP could account for differences in findings in the present study and previously published reports. Also, the present study was not designed to examine this topic.

In conclusion, the results of the present study support the view that lowering brain serotonin (by tryptophan depletion) aggravates experimental panic in panic disorder patients. There are also some indications that a rise in serotonin may act to restrain panic. To test this latter possibility in a more direct way, an experiment should be conducted in which the plasma tryptophan level is deliberately raised, for example by administering TRP or 5-OH TRP. An experiment of this kind is currently underway in our laboratory.

\section{Acknowledgements}

The authors wish to thank Mrs. Leclair and Bongaerts for their research assistance and Mrs. Noteborn, Esten and van Kempen for preparing the manuscript. 
Table 1: Mean side effects $( \pm s d)$ in TRP( + ) and TRP(-) condition (maximum score per ilem is 8 )

\begin{tabular}{|l|l|l|}
\hline & TRP $~$ & TRP- \\
\hline Headache & $0.91( \pm 1.02)$ & $0.87( \pm 0.85)$ \\
Sleepiness & $1.21( \pm 1.25)$ & $1.33( \pm 1.09)$ \\
Dizziness & $1.29( \pm 1.23)$ & $0.74( \pm 0.75)$ \\
Nausea & $1.20( \pm 1.35)$ & $0.63( \pm 0.92)$ \\
Palpitations & $0.54( \pm 1.06)$ & $0.33( \pm 0.56)$ \\
Abdominal distress & $0.62( \pm 0.87)$ & $0.17( \pm 0.49)$ \\
Feeling cold & $0.50( \pm 0.90)$ & $0.27( \pm 0.60)$ \\
Feeling hot & $0.79( \pm 0.91)$ & $0.71( \pm 0.90)$ \\
Dry mouth & $1.44( \pm 1.31)$ & $0.71( \pm 0.81)$ \\
Tiredness & $1.33( \pm 1.23)$ & $1.12( \pm 1.02)$ \\
Blurred vision & $0.62( \pm 0.97)$ & $0.50( \pm 0.70)$ \\
Perspiration & $0.63( \pm 0.76)$ & $0.71( \pm 0.80)$ \\
Drowsiness & $1.12( \pm 1.26)$ & $0.88( \pm 0.79)$ \\
\hline
\end{tabular}


Table 2: Anxiety and neurovegetotive symptoms (S.D.) before and ofter $\mathrm{CO}_{2}$, increase and delta $\%$ increase

\begin{tabular}{|c|c|c|c|c|c|c|}
\hline \multicolumn{4}{|c|}{ Before } & \multicolumn{3}{|l|}{ Alter } \\
\hline & $\operatorname{IRP}(+)$ & $\operatorname{IRP}(-)$ & $p$ & $\operatorname{TRP}(+)$ & $\operatorname{IRP}(-)$ & $p$ \\
\hline VAAS & $23.75( \pm 30.81)$ & $18.42( \pm 24.76)$ & NS & $36.50( \pm 33.37)$ & $65.85( \pm 28.56)$ & $<0.05$ \\
\hline$P S L^{*: *}$ & $5.66( \pm 4.14)$ & $9.08( \pm 9.42)$ & NS & $12.46( \pm 7.09)$ & $25.16( \pm 11.82)$ & $<0.02$ \\
\hline
\end{tabular}

\begin{tabular}{|c|c|c|c|c|c|c|}
\hline \multicolumn{4}{|c|}{ Net increase } & \multicolumn{3}{|l|}{ Delta \% increase } \\
\hline & $\operatorname{TRP}(+)$ & $\operatorname{TRP}(-)$ & p & $\operatorname{TRP}(+)$ & $\operatorname{IRP}(-)$ & p \\
\hline VAAS" & $12.75( \pm 30.81)$ & $47.42( \pm 24.76)$ & $<0.025$ & $27.22( \pm 33.17)$ & $7.16( \pm 4.73))$ & $<0.02$ \\
\hline $\mathrm{PSL}^{* / x}$ & $6.80( \pm 6.83)$ & $16.08( \pm 10.47)$ & $<0.05$ & $58.40( \pm 28.02)$ & $17.43( \pm 11.72)$ & $<0.05$ \\
\hline
\end{tabular}

"Visual anologue anxiety scale score; " panic symptom list score.

\section{Toble 3: Intensity of symptoms induced by $\mathrm{CO} 2$}

\begin{tabular}{|c|c|c|c|c|}
\hline TRP - & IRP + & $\begin{array}{l}\text { IRP - } \\
\text { within } \\
\text { group }\end{array}$ & $\begin{array}{l}\text { IRP + } \\
\text { within } \\
\text { group }\end{array}$ & $\begin{array}{l}\text { IRP - / IRP + } \\
\text { belween group }\end{array}$ \\
\hline
\end{tabular}

\begin{tabular}{|c|c|c|c|c|c|c|c|}
\hline Pre $\mathrm{CO}_{2}$ & Posl $\mathrm{CO}_{2}$ & $\mathrm{PrCCO}_{2}$ & Post $\mathrm{CO}_{2}$ & $\begin{array}{l}\text { Post } \mathrm{CO}_{2}- \\
\text { Pre } \mathrm{CO}_{2} \\
\mathrm{P}\end{array}$ & $\begin{array}{l}\text { Post } \mathrm{CO}_{2}- \\
\text { Pre } \mathrm{CO}_{2} \\
\text { P }\end{array}$ & $\begin{array}{l}\text { Pre } \mathrm{CO}_{2} \\
\text { p }\end{array}$ & $\begin{array}{l}\text { Post CO2 } \\
\text { p }\end{array}$ \\
\hline
\end{tabular}

\begin{tabular}{l|llllllll}
\hline Palpitations & $0.42 \pm 0.67$ & $1.75 \pm 1.36$ & $0.17 \pm 0.39$ & $0.67 \pm 0.65$ & 0.007 & 0.014 & 0.320 & 0.041 \\
Swealing & $0.23 \pm 0.58$ & $2.00 \pm 1.41$ & $0.83 \pm 0.94$ & $1.08 \pm 0.94$ & 0.026 & 0.480 & 0.699 & 0.128 \\
Irembling/shaking & $0.75 \pm 1.22$ & $2.08 \pm 1.16$ & $0.33 \pm 0.65$ & $0.50 \pm 0.80$ & 0.004 & 0.414 & 0.368 & 0.002 \\
Dyspnea & $0.42 \pm 0.51$ & $2.33 \pm 1.15$ & $0.17 \pm 0.39$ & $1.50 \pm 1.45$ & 0.003 & 0.011 & 0.187 & 0.130 \\
Choking & $0.17 \pm 0.39$ & $2.50 \pm 1.17$ & $0.17 \pm 0.39$ & $1.17 \pm 1.27$ & 0.002 & 0.026 & 1.000 & 0.130 \\
Chestpain/disconifort & $0.08 \pm 0.29$ & $0.67 \pm 0.29$ & $0.50 \pm 1.17$ & $0.50 \pm 1.17$ & 0.020 & 1.000 & 0.265 & 0.280 \\
Nausea & $0.67 \pm 1.15$ & $1.17 \pm 1.40$ & $1.00 \pm 1.04$ & $1.00 \pm 1.13$ & 0.109 & 1.000 & 0.301 & 0.878 \\
Diziness & $1.17 \pm 1.03$ & $3.08 \pm 1.08$ & $0.75 \pm 0.62$ & $1.92 \pm 1.38$ & 0.004 & 0.010 & 0.298 & 0.037 \\
Dereal./depers. & $0.67 \pm 1.15$ & $2.50 \pm 1.51$ & $0.50 \pm 0.67$ & $1.33 \pm 1.37$ & 0.009 & 0.026 & 0.974 & 0.067 \\
Fear of losing control & $0.25 \pm 0.62$ & $1.33 \pm 1.72$ & $0.00 \pm 0.00$ & $0.17 \pm 0.39$ & 0.041 & 0.149 & 0.053 & 0.157 \\
Fear of dying & $0.33 \pm 0.65$ & $1.75 \pm 1.60$ & $0.17 \pm 0.58$ & $0.67 \pm 1.15$ & 0.011 & 0.034 & 0.328 & 0.057 \\
Paresthesias & $0.58 \pm 1.16$ & $2.08 \pm 1.24$ & $0.67 \pm 1.23$ & $1.08 \pm 1.62$ & 0.039 & 0.157 & 0.917 & 0.094 \\
Flushes/chills & $0.33 \pm 0.49$ & $1.83 \pm 1.27$ & $0.25 \pm 0.62$ & $0.75 \pm 1.14$ & 0.004 & 0.109 & 0.444 & 0.034 \\
\hline
\end{tabular}




\section{REFERENCES}

Barr, L.C., Goodman, W.K. , McDougle, C.J., Delgado, P.L., Heninger, G.R., Charney, D.S., Price, L.H., 1994. Tryptophan depletion in patients with obsessive compulsive disorder who respond to serotonin reuplake inhibitors. Archives of General Psychiatry 51: $309-317$. Benarroch, E.E., Granata, A.R., Ruggiero, D.A., Park, D.H., Reis, D. J., 1986. Neurons of C1 area mediate cardiovascular responses initiated from ventral medullary surface.

American Physiological Society 250: R932 - R945.

Benkelfat, C. Ellenbogen, M.A., Dean, P., Palmour, R.M., Young, S.N. , 1994.

Mood lowering effect of tryptophan depletion. Enhanced susceptibility in young men at genetic risk for major affective disorders. Archives of General Psychiatry 51: 687 - 697. Blier, P., De Montigny, C. , Chaput, Y. , 1987. Modifications of the serotonin system by antidepressant treatments: implications for the therapeutic response in major depression. Journal of Clinical Psychopharmacology 7 (Suppl. 6): 245 - 35S.

Deakin, J.F.W., Graeff, F.G. , 1991. 5-HT and mechanisms of defence. Journal of Psychopharmacology 5: $305-315$.

Delgado, P.L., Charney, D.S., Price, L.H., Aghajanian, G.K., Landis, H., Heninger, G.R. , 1990.

Serotonin function and the mechanism of antidepressant action. Reversal of antidepressant-induced remission by rapid depletion of plasma tryptophan. Archives of General Psychiatry 47: 411- 418.

Den Boer, J.A. , Westenberg, H.G.M., 1991. Do panic attacks reflect an abnormality in serotonin receptor subtypes? Human Psychopharmacology 6 (Suppl.): 25-30.

Gessa, G.L. , Biggio, G., Fadda, F. , Corsini, G.U., Tagliamonte, A., 1974. Effect of the oral administration of tryptophan free amino acid mixtures on serum tryptophan, brain tryptophan and serotonin metabolism. Journal of Neurochemistry 22: $869-870$.

Goddard, A.W., Sholomskas, D.E., Walton, K.E., Walton, K.E. , Augeri, F.M., Charney, D.S., Heninger, G.R., Goodman, W.K., Price, L.H. , 1994. Effects of tryptophan depletion in panic disorder. Biological Psychiatry 36: 775 - 777.

Goddard, A.W., Charney, D.S., Germine, M., Woods, S.W., Heninger, G.R., Krystal, J.H., 
Goodman, W.K., Price, L.H., 1995. Effects of tryptophan depletion on responses to yohimbine in healthy human subjects. Biological Psychiatry 38: $74-85$.

Gorman, J.M. , Fyer, M.R., Liebowitz, M.R., 1987. Pharmacological provocation of panic attacks. In: Meltzer, H. (Ed.), Psychopharmacology, The Third Generation of Progress.

Raven, New York, pp. 985 - 993

Graeff, F.G.,1993. Role of 5-HT in defensive behavior and anxiety. Reviews in the Neurosciences 4: 181- 211.

Graeff, F.G., Guimaraes, F.S., De Andrade, T.G., Deakin, J.F., 1996. Role of 5-HT in stress, anxiety and depression. Pharmacology, Biochemistry and Behavior 54: 129-141. Grove, G., Coplan, J.D., Hollander, E., 1997. The neuroanatomy of 5-HI dysregulation in panic disorder. The Journal of Neuropsychiatry and Clinical Neurosciences 9: 198 - 207. Kent, J.M., Coplan, J.D., Martinez, J., Karmally, W., Papp, L.A., Gorman, J.M., 1996.

Ventilatory effects of tryptophan depletion in panic disorder: a preliminary report.

Psychiatry Research 64: 83 - 90.

Klaassen, T., Klumperbeek, J., Deutz, N.E.P., van Praag, H.M., Griez, E., 1998. Effects of tryptophan depletion on anxiety and on panic provoked by carbon dioxide challenge. Psychiatry Research 77: 167- 174

Klaassen, I., Riedel, W.J., Deutz, N.E.P., van Someren, A., van Praag, H.M., 1999. Specificity of the tryptophan depletion method. Psychopharmacology 141: $279-286$. Klein, D.F., 1993. False suffocation alarms, spontaneous panics, and related conditions. An integrative hypothesis. Archives of General Psychiatry 50: 306 - 317. Koszycki, D., Zacharko, R.M., Le Melledo, J.M., Young, S.N., Bradwejn, J., 1996. Effects of acute tryptophan depletion on behavioral, cardiovascular and hormonal sensitivity to cholecystokinin-tetrapeptide challenge in healthy volunteers. Biological Psychiatry 40: 648 - 655. Loeschke, H.H., 1983. Central chemoreceptors. In: Pallot, D.J. (Ed.), Control of respiration.

Croom Helm Ltd., Beckenham, pp. 41- 77.

McQueen, D.S.,Pallot, D.J., 1983. Peripheral arterial chemoreceptors. In: Pallot, D.J. (Ed.),

Control of respiration. Croom Helm Lid., Beckenham, pp. 7- 40.

Miller, H.E., Deakin, J.F., Anderson, I.M, 1996. Acute tryptophan depletion increases panic 
anxiety in panic disorder patients. Journal of Psychopharmacology 9: 72.

Moja, E.A., Cipolla, P., Castoldi, D., Tofanetti, 0., 1989. Dose- response decrease in plasma tryptophan and in brain tryptophan and serotonin after tryptophan-free amino acid mixtures in rats. Life Science 44: 971-976.

Nashold, B.S. Jr., Wilson, W.P. , Slaughter, G., 1974. The midbrain and pain. In: Bonica, J.J. (Ed.), Advances in Neurology 4: International Symposium on Pain. Raven, New York, pp. 191- 196.

Nutt, D.J., 1998. Antidepressants in panic disorder: clinical and preclinical mechanisms. Journal of Clinical Psychiatry 59 (Suppl. 8): 24-28.

Pols, H., Verburg, K., Hauzer, R., Meijer, J., Griez, E., 1996. Alprazolam premedication and 35\% carbon dioxide vulnerability in panic patients. Biological Psychiatry 40: 913-917. Ruggiero, D.A., Gomez, R., Cravo, S.L., Mtui, E., Anwar, M., Reis, D.J. ,1991. The rostral ventrolateral medulla: anatomical substrates of cardiopulmonary integration. In: Koepchen, H.P. and Huopaniemi, T. (Eds.), Cardiorespiratory and motor coordination. Springer, New York, pp. $89-102$.

Sheehan, D.V., Lecrubier, Y., Harnett Sheehan, K., Janavs, J., Weiller, E., Keskiner, A., Schinka, J., Knapp, E., Sheehan, M.F., Dunbar, G.C., 1997. The validity of the Mini International Neuropsychiatric Interview (MINI) according to the SCID-P and its reliability. European Psychiatry 12: 232 - 241.

Smith, S.E., Pihl, R.O., Young, S.N., Ervin, F.R. , 1987. A test of possible cognitive and environmental influences on the mood lowering effect of tryptophan depletion in normal males. Psychopharmacology 91: 451- 457.

Tagliamonte, A., Biggio, G., Vargiu, L., Gessa, G.L., 1973. Free tryptophan in serum controls brain tryptophan level and serotonin synthesis. Life Science 12: 277- 287.

Targum, S.D., 1991. Panic attack frequency and vulnerability to anxiogenic challenge studies. Psychiatry Research 36: $75-83$.

Van Eijk, H.M.H., Rooyakkers, D.R. , Deutz, N.E.P., 1993. Rapid routine determination of amino acids in plasma by high performance liquid chromatography with a 2-3 $\mu \mathrm{M}$ Spherisorb ODS-Il column. Journal of Chromatography 620: $143-148$. 
Van Eijk, H.M.H., De Jong, C.H.C., Deutz, N.E.P., Soeters, P.B., 1994. Influence of storage conditions on normal plasma amino-acid concentrations. Clinical Nutrition 14: 374-380. Van Vliel, I.M., Slaap, B.R., Westenberg, H.G., Den Boer, J.A., 1996. Behavioral, neuroendocrine and biochemical effects of different doses of 5-HTP in panic. European Neuropsychopharmacology 6: $103-110$.

Verburg, K., Perna, G., Bellodi, L. , Griez, E., 1998. The $35 \% \mathrm{CO}_{2}$ panic provocation challenge as diagnostic lest for panic disorder. In: Bellodi, L., Perna, G. (Eds.), The panic respiration connection. MdM Medical Media SrL, Milan, pp. 51- 68.

Weltzin, T.E., Fernstrom, J.D., McConaha, C. , Kaye, W.H., 1994. Acute tryptophan depletion in bulimia: effects on large neutral amino acids. Biological Psychiatry 35: 388-397. Young, S.N., Smith, S.E., Pihl, R.O., Ervin, F.R., 1985. Tryptophan depletion causes a rapid lowering of mood in normal males. Psychopharmacology 87: 173 - 177.

Young, S.N., Ervin, F.R., Pihl, R.O., Finn, P., 1989. Biochemical aspects of tryplophan depletion in primates. Psychopharmacology 98: 508 - 511. 


\title{
Chapter 6
}

\section{L-5 Hydroxytryptophan induced increase in salivary cortisol in healthy volunteers and panic disorder patients}

\begin{abstract}
Background: Hypersensitivity of brain serotonin receptors has been proposed as a causal mechanism in the pathophysiology of panic disorder. This theory can be lested, using serotonergic stimulation of the HPA-axis. Up to now, mainly plasma cortisol has been used as outcome measure in such studies. Assessment of salivary cortisol is a non-invasive alternative to measure HPA-axis activity. Method: Salivary cortisol levels were measured in 24 panic disorder patients and 24 healthy volunteers, following ingestion of $200 \mathrm{mg}$ L-5 hydroxytryptophan or placebo. Results: A significant rise in cortisol was observed in both patients and normals following ingestion of L-5 hydroxytryptophan. No such effects were seen in the placebo condition. Conclusion: The results argue against a serotonin receptor hypersensitivity in panic disorder and show that $L-5$ hydroxytryptophan stimulated salivary cortisol is a probe of serotonin function in panic disorder.
\end{abstract}

\section{Introduction}

Several lines of evidence suggest the involvement of serotonin (5-HT) in panic disorder (PD). The exact mechanisms remain unclear, however. A first line of evidence comes from treatment studies. Those studies show that antidepressants with a combined noradrenergic and serotonergic profile like the tricyclics (TCA's) imipramine and clomipramine or MAO inhibitors are effective in the treatment of PD. Selective serotonin reuptake inhibitors (SSRI's) are also effective in PD (Bell and Nutt 1998). Direct comparison of the SSRI fluvoxamine with the mainly noradrenergic TCA maprotiline showed a clear superiority of the SSRI in alleviating panic (den Boer and Westenberg 1988). Further, in a study with imipramine, the antipanic 
effect correlated with the plasma concentration of the serotonergic as well as noradrenergic parent compound, but not with that of the mainly noradrenergic metabolite $N$-desmethylimipramine (Bell and Nutt 1998; Mavissakalian and Perel 1989; Mavissakalian and Perel 1996). Those studies suggest that the antipanic action of antidepressants depends on their effect on the 5-HT system. Another line of evidence comes from tryptophan depletion studies, where a decrease in brain 5-HT is induced by rapidly reducing the availability of the essential amino acid tryptophan, a precursor of 5-HT (Young et al. 1985). Tryptophan depletion alone was not anxiogenic or panicogenic in unmedicated PD-patients (Goddard et al 1994). However, it did increase the vulnerability to a laboratory panic provocation, using a $5 \%$ or $35 \% \mathrm{CO}_{2}$ challenge (Miller et al. 2000; Schruers et al 2000). Treatment and tryptophan depletion studies logether provide strong evidence for the involvement of 5-HT in panic. However, the results from the tryptophan depletion studies, in particular, are more suggestive for a modulatory than a causal role. To elaborate upon this distinction, we conducted the present study to test the theory that hypersensitivity of 5-HT receptors is causally involved in the pathophysiology of PD (Kahn et al. 1988; Nutt 1998).

A direct way to test this hypothesis is to use a neuroendocrine challenge paradigm (Kahn and Wetzler 1991). This involves stimulating central 5-HT neurons with 5-HT transmission enhancing drugs and measuring the neuroendocrine consequences. Neuroendocrine challenge lests offer clear advantages over other methods of assessing 5-HT function. Cerebrospinal fluid 5-HIAA (5-hydroxy indol aminic acid, the main metabolite of 5-HT) levels provide only a static measure of a single component of the 5-HT system, whereas challenge lests provide a dynamic, in vivo measure of the response of the 5-HT system to a particular challenge. Some aspects of 5-HT function can also be studied in platelets. However, these lack connections to other cells and are therefore not regulated in the same way as brain neurons (Yatham and Steiner 1993).

The release of adrenocorticotrope hormone (ACTH) and hence cortisol, is considered to be under serotonergic control (Tuomisto and Mannisto 1985). Measuring cortisol response to 5 HT challenges therefore allows assessment of 5-HT receptor sensitivity in the hypothalamus. Previous serotonergic challenge studies used intravenous administration of serotonergic 
agents and used plasma cortisol as outcome measure, which requires insertion of an intravenous catheter and obtaining several blood samples during the course of the experiment. This could have affected results, since even mild stress is known to cause a rise in cortisol secretion, especially in PD patients (Kirschbaum and Hellhammer 1989; Stones et al. 1999). A non-invasive way to measure 5 -HT receptor sensitivity is by using salivary cortisol. Salivary cortisol highly correlates with free plasma cortisol, which is the biologically active fraction (Kirschbaum and Hellhammer 1989).

The goals of the present study, therefore, are twofold. Firstly, to investigate the effect of orally administered L-5-hydroxytryptophan (L-5 HTP) on salivary cortisol as a probe of 5-HT function in PD patients and healthy volunteers. Secondly, to assess a possible 5 -HT receptor hypersensitivity in PD.

\section{Methods}

\section{Subjects}

Twenty-four patients with panic disorder (13 men and 11 women, mean age $39,96 \pm 10,69$ years) with or without agoraphobia (DSM IV criteria) and 24 healthy volunteers (10 men and 14 women, mean age $29,75 \pm 11,65$ years) participated in the study. Patients were recruited among the patients of the Academic Anxiety Center Maastricht and healthy volunteers through advertisement in a local newspaper. The diagnosis was made by means of a structured interview (Mini-International Neuropsychiatric interview, Sheehan et al 1997) and confirmed by two experienced psychiatrists (K.S. and E.G.). There was no concurrent axis I or axis II disorder. Also, none of the participants had a prior history of affective disorder. Healthy volunteers were also excluded if first degree relatives were affected by a major psychiatric disorder. Inclusion criteria were further, age between 18 and 65, good physical health and written informed consent. No concurrent psychotropic medication (benzodiazepines, antidepressants or beta blockers) was allowed in the three weeks before the experiment. The study was approved by the local medical ethics committee. 


\section{Design and procedures}

The study consisted of two experiments, one carried out in PD patients and the other in normals. Both experiments were conducted according to a randomized, double blind, placebo controlled, separate group design. Twelve PO patients ( 6 men and 6 women) were allocated to the 5-HTP condition and 12 (7 men and 5 women) to the placebo condition. Similarly, 12 healthy volunteers ( 5 men and 7 women) were assigned to the 5-HTP condition and 12 (5 men and 7 women) to placebo. Cortisol is secreted following a circadian rhythm and in a pulsatile fashion. Pulse amplitude and absolute values of cortisol are lowest in the afternoon (Kirschbaum and Hellhammer 1989). Therefore the experiment was always carried in that period of the day. The subjects arrived at the clinic at $13.00 \mathrm{~h}$. At $13.30 \mathrm{~h}$, after half an hour of acclimatisation, they filled in the Profile of Mood states (POMS, MCNair et al 1971) and a first saliva sample was obtained. At $14.00 \mathrm{~h}$, participants ingested a capsule with $200 \mathrm{mg}$ L5-hydroxytryptophan or placebo and the POMS was again filled in.

side effects (headache, feeling cold, feeling hot, dizziness, sleepiness, perspiration, blurred vision, drowsiness, nausea, palpitations, dry mouth, abdominal complaints and fatigue) were noted on a five point scale (Klaassen et al. 1998).

POMS and side effects scores were used 10 assess a possible indirect influence of 5-HTP on cortisol via psychological effects or physical discomfort due to the experimental procedures. Saliva samples were further obtained at $14.30 \mathrm{~h}, 15.00 \mathrm{~h}$ and $15.30 \mathrm{~h}$. To reduce a possible effect of stress on cortisol levels, subjects remained in the same room of the laboratory during the whole experiment, the same room in which the screening for the study had taken place. Since nicotine has been shown to affect plasma and salivary cortisol levels (Kirschbaum and Hellhammer 1989), subjects were instructed not to smoke the day of the study and the day before. Participants, used to taking high amounts of nicotine (more than 20 cigarettes a day) were excluded in any case. Gonadal steroids and menstrual cycle phase are also known to affect cortisol secretion (Kirschbaum et al. 1999). To minimize these effects, female subjects were studied in the first half of their menstrual/pill cycle. All had regular menstrual cycles.

Saliva was collected by holding a cotton dental roll in the mouth for approximately 1 minute. 
The saturated roll was placed in a capped plastic vial ("Salivelte", Sarstedt"), which was stored in a freezer at $-20^{\circ}$ Celsius until analysis. Salivary cortisol levels were determined by direct radio immunoassay (Ansseau el al 1984), using 125 I-cortisol (Farmos diagnostica, Finland) and antiserum made against the 3-CMO-BSA conjugate by Prof. J. Sulon, University of Liège, Belgium. The lower detection limit of the assay was $12.5 \mathrm{ng} / \mathrm{dl}$, with a mean intra assay coefficient of $4.3 \%$.

\section{Statistical analysis}

To approach normality and homogeneity in the data, salivary cortisol concentrations were log 10 transformed before analysis. To test the first hypothesis, cortisol values were analyzed, for patients and normals separately, using repeated measures analysis of variance (ANOVA). Time was the within subjects factor (four levels) and condition, 5HTP or placebo, the between subjects factor. When significant interactions were lound, post hoc 1-tests were performed to locate the time points with significant differences in the means of cortisol values. To assess the second hypothesis, a similar procedure was followed. A repeated measures ANOVA was carried out, comparing the patients who received 5-HTP with the normals who received 5-HTP, with time as within subjects factor and group (patient or normal) as between subjects factor.

To assess a possible influence of 5-HTP on cortisol via psychological effects or physical discomfort, the POMS and total side effects scores were compared between the 5-HTP and placebo condition, in patients as well as in normals. Due to the non-normal distribution of the POMS and total side effects scores, non parametric tesis were used for analysis (MannWhitney U-test). Because multiple testing may increase type I error, only the values at baseline and at $15.30 \mathrm{~h}$ (the time of the peak mean cortisol values) were included in the analysis. 


\section{Results}

\section{Cortisol values}

With respect to the first question, the repeated measures ANOVA revealed that the time"condition effect, time effect and condition effect (5-HTP vs placebo) were significant in both groups (table 1).

\section{Table 1}

\begin{tabular}{|l|l|l|l|l|l|l|}
\hline & \multicolumn{2}{|c|}{ time * condition } & \multicolumn{2}{c|}{ time } & \multicolumn{2}{c|}{ condition } \\
\hline \multirow{3}{*}{} & $F$ & $\rho$ & $F$ & $P$ & $F$ & $P$ \\
PD & 7.97 & 0.001 & 4.39 & 0.016 & 27.40 & 0.001 \\
normals & 4.06 & 0.021 & 13.45 & 0.001 & 10.77 & 0.003 \\
\hline
\end{tabular}

The significant time" condition effects in both groups were further examined with post-hoc t-tests (table 2).

\section{Toble 2}

\begin{tabular}{|l|l|l|l|l|}
\hline & PD & & normals & \\
\hline & $\mathrm{t}$ & $\mathrm{P}$ & $\mathrm{t}$ & $\mathrm{P}$ \\
\hline 13.30 & 1.65 & NS & 0.74 & NS \\
\hline 14.30 & 2.05 & NS & 0.78 & NS \\
\hline 15.00 & 4.26 & 0.001 & 3.69 & 0.001 \\
\hline 15.30 & 5.77 & 0.001 & 3.72 & 0.001 \\
\hline
\end{tabular}


In both groups, significant differences in salivary cortisol between the two conditions were present at $15.00 \mathrm{~h}$ and $15.30 \mathrm{~h}$ and were absent at $13.30 \mathrm{~h}$ and $14.30 \mathrm{~h}$. These significant differences are related to a significant increase in salivary cortisol in PD patients and in controls approximately one hour after ingestion of 5-HTP (Figure 1 and 2), an increase that was absent in the placebo condition.

With respect to the second question, the repeated measures ANOVA revealed a significant time effect $(F=12.18 ; p<0.001)$, whereas the group"time effect $(F=0.40 ; N S)$ and the group effect (PD vs controls; $F=0.575 ;$ NS) were not significant. Inspection of figures 1 and 2 indeed shows that the salivary corlisol levels run almost parallel in both groups and were not significantly different at any time point.

\section{POMS scores}

In the patient group, Mann-Whitney $U$ test revealed no significant differences between the 5-HIP and placebo condition, for any of the five POMS mood states (anger, depression, tension, fatigue and vigor) at baseline (13.30h), nor at $15.30 \mathrm{~h}$. The same was true for the POMS scores in the healthy volunteers.

\section{Side effects scores}

In patients nor in healthy volunteers were there any differences in total side effect scores at $13.30 \mathrm{~h}$ or $15.30 \mathrm{~h}$.

\section{Discussion}

The results from the present study show that $200 \mathrm{mg}$ oral L-5-HTP induced a significant rise in salivary cortisol in PD patients as well as in healthy volunteers. No such effects were seen in the placebo condition. The cortisol increase following 5-HTP was equally strong in normals and patients. There were no effects on mood states or side effect scores.

The results in healthy volunteers confirm previous studies, demonstrating that administration 
of L-5-HTP promotes cortisol secretion. In a study in 12 male volunteers, Meltzer and Maes (1994) found a significant increase in plasma cortisol, following ingestion of 200mg L-5.HTP versus placebo. Similarly, a highly significant difference in plasma cortisol was found after oral administration of $200 \mathrm{mg}$ L-5-HTP to 8 male volunteers, versus placebo (Lee et al. 1991). The outcome of the present study is in line with these results. Although no plasma cortisol levels were measured in the present study, this suggests that salivary cortisol values can be used as a less invasive alternative to plasma cortisol, yielding similar results. Different kinds of stress and mood states are known to increase cortisol secretion (Kirschbaum and Hellhammer 1989; van Eck el al. 1996). The fact that no effects were found in the POMS nor on the side effect scores points to a pure pharmacological effect of 5-HTP on cortisol secretion.

Generally it is assumed that it is the 5-HT mediated release of corticotropin releasing hormone (CRH) from the hypothalamus which stimulates adrenocorticotrophe hormone (ACTH) release from the anterior pituitary and the release of cortisol from the adrenal cortex (Abel and Cleare 1999). This effect is probably mediated by 5-HT2 / 5-HT1C receptors, since pretreatment with the 5-HT2 / 5-HT1C antagonist ritanserin significantly inhibited 5-HTP induced cortisol secretion (Lee et al. 1991). However, recent data in animals support the view that 5-HT also stimulates ACTH release by acting at the pituitary level. There is also accumulating evidence that 5-HT directly acts to stimulate cortisol release from the adrenal cortex (Dinan 1996). This possibility cannot be ruled out in the present study, since no CRH or ACTH levels were measured. However, in a recent study, the hypothesis was tested that d-fenfluramine, a 5-Hr releasing agent, elicits cortisol release by a direct effect on the adrenal gland. Eight healthy volunteers were pretreated with dexamethasone, to prevent ACTH release from the pituitary, prior to a d-fenfluramine challenge test. The administration of dexamethasone completely blunted the cortisol response to d-fenfluramine (Abel and Cleare 1999). This indicates that cortisol responses to d-fenfluramine, and likely also to 5-HTP, in humans are of central origin only.

The present results in PD patients are also in line with previous studies, investigating 5-HT function in PD. Den Boer and Westenberg (1990) administered 60mg L-5HTP intravenously to 
20 PO patients and 20 healthy volunteers. They monitored several biochemical parameters, as well as behavioral effects. Both the PD patients and the normals showed a significant rise in plasma cortisol following 5-HTP infusion. There was however no difference in the cortisol response to 5-HTP between patients and controls. None of the patients experienced a panic attack, nor did any patient report an increase in generalized anxiety. Some of the PD patients even experienced the 5-HTP infusion as a relief. Also, no anxiety symptoms were observed in the control group. The severe side effects in this study, mainly nausea and vomiting, may however have obscured differences in behavioral and neuroendocrine effects between patients and normals. This may have been due to the relatively high dose of 5-HTP, in combination with the intravenous administration. The same group subsequently studied the effects of different, lower, dosages of IV 5-HTP in 7 PD patients and 7 healthy volunteers (van Vliet et al. 1996). None of the three different dosages of 10,20 and $40 \mathrm{mg}$ did induce panic attacks or anxiety in patients nor in controls. As in the present study, none of the subscales of the POMS was significantly influenced by 5-HTP administration, in any group. Similarly, there was no difference in the response of cortisol in PD patients, compared to the normals. The results of these two studies and the ones from the present study, together argue against a supersensitivity of 5 - $\mathrm{HT}$ receptors in PD.

Studies with other serotonergic agents are less unequivocal. Meta-chiorophenylpiperazine (MCPP), a predominantly selective $5-\mathrm{HI} 2 \mathrm{C}$ agonist, in a dosage of $0,25 \mathrm{mg} / \mathrm{kg}$ PD, augmented cortisol release in PD patients, compared with normal control subjects and depressed patients (Kahn et al. 1988). On the other hand, a dosage of $0,1 \mathrm{mg} / \mathrm{kg}$, administered IV, induced a comparable cortisol increase in PO patients and normal control subjects. Blood pressure and heart rate increases were comparable in both groups, and the increase in panic and anxiely was also equivalent (Charney et al. 1987). Further, oral administration of $0,25 \mathrm{mg} / \mathrm{kg}$ MCPP did not cause significant differences in panic or anxiely between normals and PD patients either. Also, no difference was found in plasma cortisol levels following MCPP between the two groups (Wetzler et al. 1996). It is therefore possible that the observed differences between PD patients and controls in the first experiment were due to an indirect effect of MCPP on cortisol secretion, via its anxiogenic or stress-enhancing effect. 
A racemic mixture of $\mathrm{d}$, I-fenfluramine, a 5-HT releasing agent, caused significantly greater anxiogenic responses in 9 women with PD, compared to 9 healthy women and 9 women with major depression. Cortisol responses were also significanlly greater in the PD patients, compared to the depressives and the normals (Targum and Marshall 1989). Similarly, d, I fenfluramine caused a greater increase in prolactin response in 11 PD patients, as compared to 12 controls (cortisol levels were not determined in this study). The authors considered this result consistent with the hypothesis of increased 5-HT receptor function in PD (Apostolopoulos et al. 1993). However, evidence indicates that d, I-fenfluramine lacks absolute specificity for the 5-HT system: it also affects the turnover of dopamine and noradrenalin (Rowland and Carlton 1986). This effect is probably mediated by the I-isomer (Invernizzi et al. 1986). Moreover, prolactin is also under dopaminergic control (Gudelsky et al. 1984). d-Fenfluramine on the other hand, is specific for 5-HT neurons (Garattini et al.1987). Therefore the same group which conducted the latter experiment with $d$, I fenfluramine in PD, carried out a study in 16 PD patients and 14 healthy controls, this time using d-fenfluramine (Judd el al 1994). No significant differences were found in cortisol or prolactin responses between the two groups.

Overall, the data from neuroendocrine challenge studies do not support the notion of a hypersensitivity of 5 -HT receptors in PD.

In conclusion, the present study shows that 5-HTP stimulated salivary cortisol is a probe of 5-HT function in PD patients as well as healthy volunteers and provides further evidence against the 5-HT receptor supersensitivity theory of PD. 
Figure 1 Cortisol levels in healthy volunteers (+SEM)

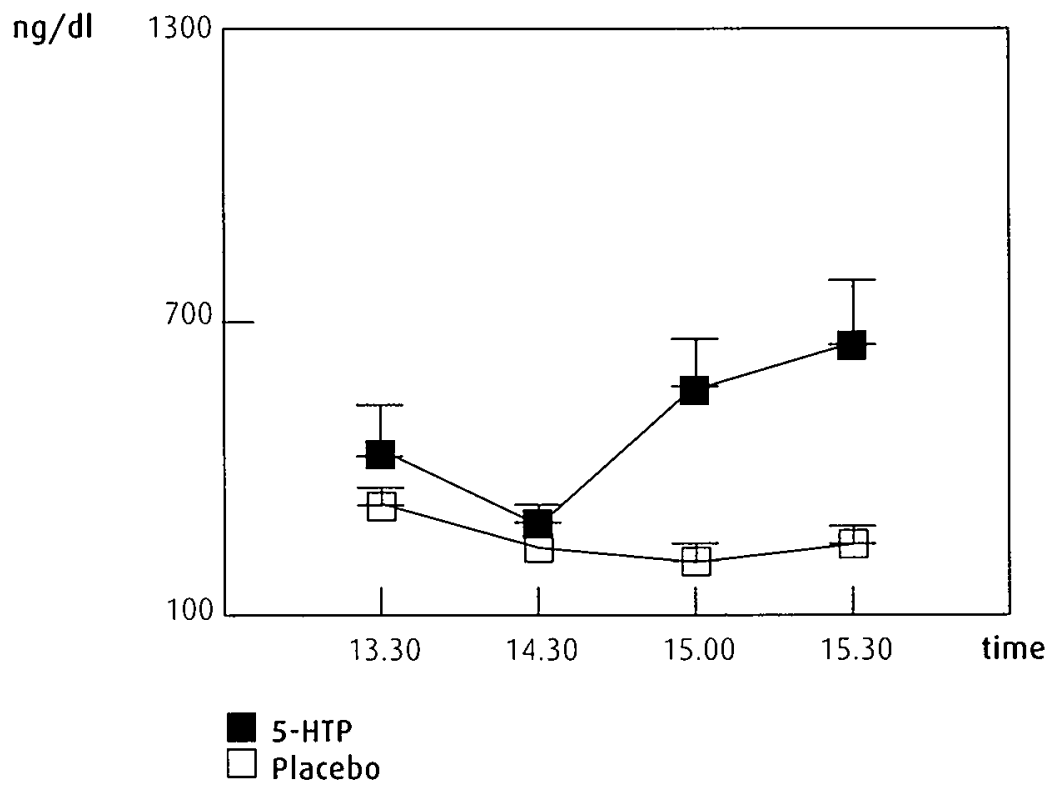

Figure 2 Cortisol levels in PD Potients (+SEM)

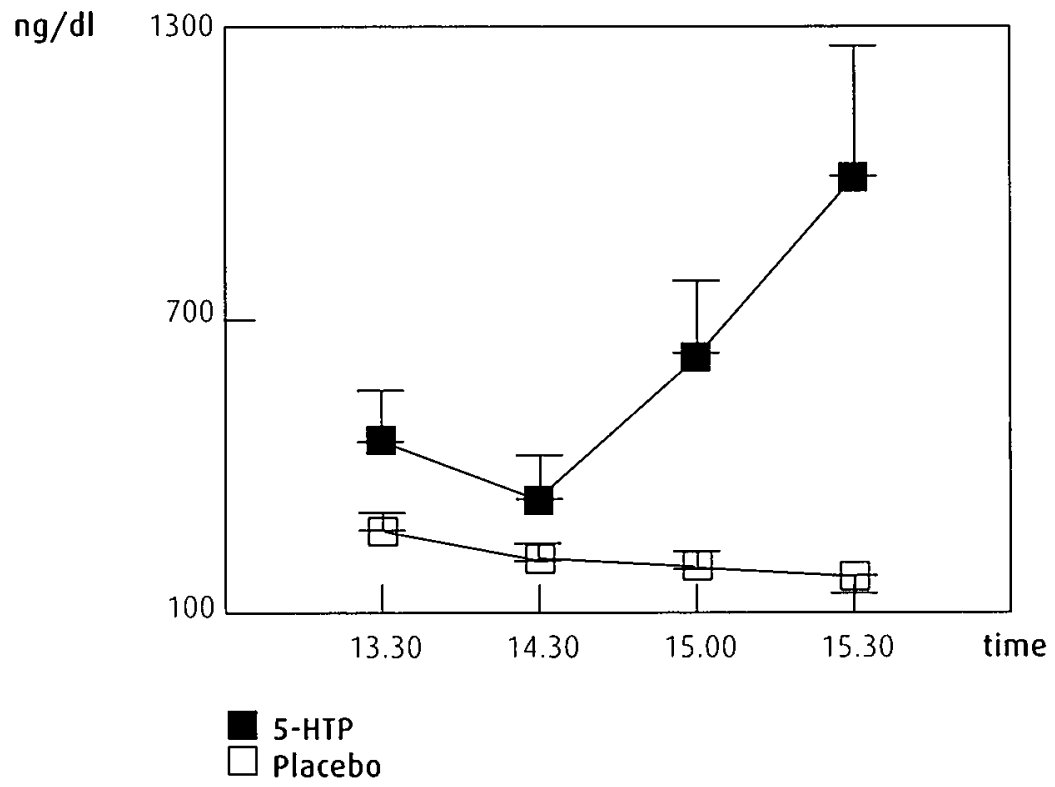




\section{REFERENCES}

Abel KM, Cleare AJ (1999): Peripheral hormonal responses to D-fenfluramine as a probe of central serotonergic function in humans. Psychopharmacology 142:68-72.

Ansseau $M$, Sulon \}, Doumont A, el al (1984): Use of saliva cortisol in the dexamethasone suppression test. Psychiatry research 13:203-11.

Apostolopoulos M, Judd FK, Burrows GD, Norman TR (1993): Prolactin response to dl-fenfluramine in panic disorder. Psychoneuroendocrinology 18:337-42.

Bell C), Nutt DJ (1998): Serotonin and panic. The British journal of psychiatry 172:465-71. Charney DS, Woods SW, Goodman WK, Heninger GR (1987): Serotonin function in anxiety.

II. Effects of the serotonin agonist MCPP in panic disorder patients and healthy subjects. Psychopharmacology 92:14-24.

den Boer JA, Westenberg HG (1988): Effect of a serotonin and noradrenaline uptake inhibitor in panic disorder; a double-blind comparative study with fluvoxamine and maprotiline. International clinical psychopharmacology 3:59-74.

den Boer JA, Westenberg HG (1990): Behavioral, neuroendocrine, and biochemical effects of 5-hydroxytryptophan administration in panic disorder. Psychiatry research 31:267-78. Dinan TG (1996): Serotonin and the regulation of hypothalamic-pituitary-adrenal axis function. Life sciences 58:1683-94.

Garattini S, Mennini I, Samanin R (1987): From fenfluramine racemate to d-fenfluramine. Specificity and potency of the effects on the serotoninergic system and food intake. Annals of the New York Academy of Sciences 499:156-66.

Goddard AW, Sholomskas DE, Walton KE, et al (1994): Effects of Iryptophan depletion in panic disorder. Biological psychiatry 36:775-7.

Gudelsky GA, Simonovic M, Meltzer HY (1984): Dopaminergic and serotonergic control of neuroendocrine function. Monogr. Neural Sci. 10:85-102.

Invernizzi R, Berettera C, Garattini S, Samanin R (1986): d-and 1-isomers of fenfluramine differ markedly in their interaction with brain serotonin and catecholamines in the rat. European journal of pharmacology 120:9-15. 
Judd FK, Apostolopoulos M, Burrows GD, Norman TR (1994): Serotonergic function in panic disorder: endocrine responses $10 \mathrm{D}$-fenfluramine. Progress in neuro psychopharmacology and biological psychiatry 18:329-37.

Kahn RS, Asnis GM, Wetzler S, van Praag HM (1988): Neuroendocrine evidence for serotonin receptor hypersensitivity in panic disorder. Psychopharmacology 96:360-4.

Kahn RS, Wetzler S (1991): m-Chlorophenylpiperazine as a probe of serotonin function. Biological psychiatry 30:1139-66.

Kirschbaum C, Hellhammer DH (1989): Salivary cortisol in psychobiological research: an overview. Neuropsychobiology 22:150-69.

Kirschbaum C, Kudielka BM, Gaab \}, Schommer NC, Hellhammer DH (1999): Impact of gender, menstrual cycle phase, and oral contraceptives on the activity of the hypothalamus-pituilary-adrenal axis. Psychosomatic medicine 61:154-62.

Klaassen T, Klumperbeek J, Deutz NE, van Praag HM, Griez E (1998): Effects of tryptophan depletion on anxiety and on panic provoked by carbon dioxide challenge. Psychiatry research 77:167-74.

Lee MA, Nash JF, Barnes M, Meltzer HY (1991): Inhibitory effect of ritanserin on the 5 hydroxytryptophan-mediated cortisol, $\mathrm{ACTH}$ and prolactin secretion in humans. Psychopharmacology 103:258-64.

Mavissakalian MR, Perel JM (1989): Imipramine dose-response relationship in panic disorder with agoraphobia. Preliminary findings. Archives of general psychiatry 46:127-31. Mavissakalian MR, Perel JM (1996): The relationship of plasma imipramine and $\mathrm{N}$-desmethylimipramine to response in panic disorder. Psychopharmacology bulletin 32:143-7. McNair DM, Lorr M, Droppeiman LF (1971): Manual for the Profile of Mood States. San Diego: Education and industrial Testing Service.

Meltzer HY, Maes M (1994): Effect of pindolol on the L-5-HTP-induced increase in plasma prolactin and cortisol concentrations in man. Psychopharmacology 114:635-43.

Miller HE, Deakin JF, Anderson IM (2000): Effect of acute tryptophan depletion on $\mathrm{CO}_{2}$-induced anxiety in patients with panic disorder and normal volunteers. The British journal of psychiatry 176:182-8. 
Nutl DJ (1998): Antidepressants in panic disorder: clinical and preclinical mechanisms. The Journal of clinical psychiatry 59 Suppl 8:24-8; discussion 29.

Rowland NE, Carlton $J$ (1986): Neurobiology of an anorectic drug: fenfluramine. Progress in neurobiology 27:13-62.

Schruers K, Klaassen T, Pols H, Overbeek T, Deutz NE, Griez E (2000): Effects of tryptophan depletion on carbon dioxide provoked panic in panic disorder patients. Psychiatry research 93:179-87.

Sheehan DV, Lecrubier Y, Harnett Sheehan K, et al (1997): The validity of the Mini International Neuropsychiatric Interview (MINI) according to the SCIO-P and its reliability. European Psychiatry 12:232-241.

Stones A, Groome D, Perry D, Hucklebridge F, Evans P (1999): The effect of stress on salivary cortisol in panic disorder patients. Journal of affective disorders 52:197-201.

Targum SD, Marshall LE (1989): Fenfluramine provocation of anxiely in patients with panic disorder. Psychiatry research 28:295-306.

Tuomisto J, Mannisto P (1985): Neurotransmitter regulation of anterior pituitary hormones. Pharmacological reviews 37:249-332.

van Eck M, Berkhof H, Nicolson N, Sulon J (1996): The effects of perceived stress, traits, mood states, and stressful daily events on salivary cortisol. Psychosomatic medicine $58: 447-58$

van Vliet IM, Slaap BR, Westenberg HG, Den Boer JA (1996): Behavioral, neuroendocrine and biochemical effects of different doses of 5-HTP in panic disorder. European neuropsychopharmacology 6:103-10.

Wetzler S, Asnis GM, Delecuona JM, Kalus O (1996): Serotonin function in panic disorder: intravenous administration of meta-chlorophenylpiperazine. Psychiatry research 64:77-82.

Yatham L.N, Steiner M (1993): Neuroendocrine probes of serotonergic function: a critical review. Life sciences 53:447-63.

Young SN, Smith SE, Pihl RO, Ervin FR (1985): Tryptophan depletion causes a rapid lowering of mood in normal males. Psychopharmacology 87:173-7. 


\title{
Chapter 7
}

\section{L-5 Hydroxytryptophan inhibits 35\% carbon dioxide induced panic}

\begin{abstract}
Background: previous research showed that lowering availability of serotonin to the brain by tryptophan depletion increases the vulnerability of panic disorder patients for an experimental $35 \% \mathrm{CO}_{2}$ panic challenge. The results also suggested that increased availability of serotonin inhibits the response to such a challenge. In the present study, this possibility is examined.

Method: The reaction of 24 panic disorder patients and 24 healthy volunteers to a $35 \% \mathrm{CO}_{2}$ panic challenge was assessed following administration of $200 \mathrm{mg} \mathrm{L}-5$ hydroxytryptophan (the immediate precursor of serotonin) or placebo. Results: L-5 hydroxytryptophan significantly reduced the reaction to the panic challenge in panic disorder patients. No such effect was observed in the placebo condition. Conclusion: L-5 hydroxytryptophan acts to inhibit panic, which supports a modulatory role of serotonin in panic disorder.
\end{abstract}

\section{Introduction}

Insight in the nature of the relationship between serotonin (5-HT) and panic disorder was considerably enhanced by studies in which the availability of $5-\mathrm{HT}$ is manipulated, especially in combination with a laboratory panic challenge. A method to reduce brain 5-HT is by Iryptophan depletion. In healthy volunteers, most studies failed to detect increased anxiety or panic following tryptophan depletion alone (Park et al. 1994, Cleare and Bond, 1995, Oldman et al. 1995). In combination with a 35\% C02 panic challenge, however, tryptophan depletion caused a greater increase in neurovegetative symptoms compared to placebo, although no true panic was induced (Klaassen et al. 1998).

Tryptophan depletion alone was not anxiogenic or panicogenic in a sample of unmedicated PD patients either (Goddard al. 1994). Again, matters were different when combined with a 
panic challenge. Tryptophan depletion caused an increased panic response to a $5 \% \mathrm{CO}_{2}$ challenge in 20 PD patients (Miller el al. 2000). A similar result was obtained in a study in 24 PD patients by our group, using a $35 \% \mathrm{CO}_{2}$ challenge (Schruers et al. 2000a). In the latter experiment, an increase in panic occurred in the depletion condition, whereas a possible panic inhibiting effect was observed in the placebo condition. This was possibly due to an observed increase in plasma tryptophan, leading to increased brain 5-HT availability. Previous studies have examined the effect of a raised availability of $5-\mathrm{HT}$ to the brain in PD by administrating L-5 hydroxytryptophan (L-5HTP), the immediate precursor of serotonin. In a study in 20 PO patients and 20 healthy volunteers, L-5HTP was administrated intravenously in a dosage of $60 \mathrm{mg}$. The authors failed to find the worsening of symptoms they expected in PD patients, based on their initial hypothesis of a 5-HT receptor hypersensitivity in PD. On the contrary and quite unexpectedly, a decrease of anxiety was observed in the PD patients. Such an effect was not found in the healthy volunteers. The results were obscured, however, by severe side effects, mainly nausea and vomiting (den Boer and Westenberg, 1990a). In a subsequent study, based on the same hypothesis, 3 different dosages of L-HTP $(10,20$ and $40 \mathrm{mg}$.) were administrated intravenously to 7 PO patients and 7 healthy controls. Side effects were limited, especially at the lower doses, but once again, contrary to the hypothesis, none of the dosages caused anxiety or panic, neither in PD patients nor in healthy volunteers (van Vliet et al. 1996). Taken together, the results from the above tryptophan depletion and L-5HTP administration studies suggest a restraining effect of 5-HT on panic, that may only be observed when acute manipulation of 5-HT availability is combined with a panic challenge. The present study was undertaken to investigate such an eflect by administrating L-5HTP or placebo to PD patients and healthy volunteers. We hypothesized that L5HTP would inhibit the panicogenic effect of a $35 \% \mathrm{CO}_{2}$ challenge in PD patients.

\section{Methods}

\section{Subjects}

Iwenty-four patients with panic disorder (13 men and 11 women, mean age 39.96 
\pm 10.69 years) with or without agoraphobia (DSM IV criteria) and 24 healthy volunteers ( 10 men and 14 women, mean age $29.75 \pm 11.65$ years) participated in the study. Patients were recruited from the Academic Anxiety Center Maastricht and healthy volunteers through advertisement in a local newspaper. The diagnosis was made by means of a structured interview (Mini international Neuropsychiatric Interview, Sheehan et al. 1997) and confirmed by Iwo experienced psychiatrists ( $K S$ en $E G$ ). There was no concurrent axis I or II disorder. Also, none of the participants had a prior history of affective disorder. Healthy volunteers were also excluded if first degree relatives were affected by a major psychiatric disorder.

Additional inclusion criteria were: age between 18 and 65, good physical health and written informed consent. No concurrent psychotropic medication (benzodiazepines, antidepressants or beta blockers) was allowed in the three weeks before the experiment. The study was approved by the local medical ethics committee.

\section{Design and procedures}

The study consisted of two parts, one carried out in PD patients and the other in normals. Both parts were conducted according to a randomized, double blind, placebo controlled design. Twelve PD patients ( 6 men and 6 women) were allocated to the 5-HTP condition and 12 ( 7 men and 5 women) were assigned to the placebo condition. Similarly 12 healthy volunteers ( 5 man and 7 women) were assigned tot the 5-HTP condition and 12 ( 5 men and 7 women) to placebo. The subjects ingested a capsule with $200 \mathrm{mg} \mathrm{L-5} \mathrm{HTP} \mathrm{or} \mathrm{placebo} \mathrm{at} 14.00$ h. At $15.30 \mathrm{~h}$. they underwent a $35 \% \mathrm{CO}_{2}$ challenge.

The entire procedure of the $35 \% \mathrm{CO}_{2}$ challenge has been described in detail elsewhere (Klaassen et al. 1998). In brief, subjects were informed that they would be inhaling a harmless gas mixture, containing $65 \% \mathrm{O}_{2}$ and $35 \% \mathrm{CO}_{2}$ and that they might experience some discomfort, ranging from a few neurovegetative symptoms to a definite sensation of anxiety. The possibility of a panic attack was not mentioned, to avoid any negative expectational bias related to expectation. Vital capacity was measured before inhaling the gas mixture. The test was considered valid only if the subject had inhaled at least $80 \%$ of the previously measured vital capacity. 
Immediately before and after the inhalation, anxiety was measured on a visual analogue scale of anxiely (VAAS), describing the degree of subjective anxiety from $0 \mathrm{~mm}$ (no anxiety) $10100 \mathrm{~mm}$ (the worst anxiety imaginable) and by a panic symptom list (PSL), containing the 13 panic symptoms described by DSM NV on a scale from 0 to 4 (Klaassen et al. 1998, Schruers el al. 2000a). Salivary cortisol levels were monitored as a noninvasive probe of central 5-HT function. These results were presented in a previous paper (Schruers et al. 2000b).

\section{Doto analysis}

Due to the non-normal distribution of the data, non-parametric tests were used for all analyses. Significance levels were set at $P<0.05$ (two-tailed). Outcome measures were pre- and post- $\mathrm{CO}_{2}$ as well as delta (post minus pre) VAAS and PSL scores. In the patient group, the 5HTP and placebo condition were compared, using a Mann-Whitney $U$ test. The pre and post $\mathrm{CO}_{2}$ scores on the VAAS and PSL within each condition were compared using a Wilcoxon signed rank test. The same procedure was followed for the healthy volunteers group. Both 5HTP conditions and both placebo conditions were compared, using a Mann-Whitney $U$ lest. The number of panic attacks following the $\mathrm{CO}_{2}$ challenge was calculated for each group and condition, and compared with a chi-square test. Criteria for a panic attack were a rise of at least $25 \mathrm{~mm}$ on the VAAS plus an increase in at least four panic symptoms on the PSL (Klaassen et al. 1998, schruers et al. 2000a).

\section{Results}

\section{Potients}

In the placebo condition, there was a significant rise in VAAS $(P=0.002)$ and PSL $(P=0.002)$ scores. This was not the case in the 5-HTP condition, although a trend was observable (VAAS: $P=0.06$, PSL: $P=0.084$ ). When the 5 -HTP and placebo condition were compared, significant differences were found in the post $\mathrm{CO}_{2}$ VAAS $(P=0.012)$ and $P S L(P=0.002)$ scores, as well as delta VAAS $(P=0.038)$ and delta PSL $(P=0.002)$ scores. Baseline values (before the $\mathrm{CO}_{2}$ chal- 
lenge) were not significantly different for VAAS nor PSL (fig. 1). The number of PA's was 9 in the placebo condition and 3 in the 5-HTP condition $(P<0.05$, with continuity correction).

\section{Normals}

In the placebo condition, a significant rise in VAAS $(P=0.05)$ and $P S L(P=0.002)$ was observed. In the 5-HTP condition, there was a significant rise in PSL $(P=0.003)$ but not in VAAS $(P=0.091)$. Comparing the two conditions, no significant differences were found in pre and post $\mathrm{CO}_{2}$ VAAS or PSL, nor in delta VAAS or PSL (fig. 1). The number of PA's was 2 in each condition.

\section{Patients compared to normals}

When the placebo conditions of each group were compared, patients had significantly higher scores on pre $\mathrm{CO}_{2}$ VAAS $(P=0.016)$, post $\mathrm{CO}_{2}$ VAAS $(P=0.001)$, delta VAAS $(P=0.001)$, pre $\mathrm{CO}_{2}$ PSL $(P=0.02)$, post $\mathrm{CO} 2$ PSL $(P=0.003)$ and delta PSL $(P=0.028)$. Comparing the 5 -HTP conditions, no significant differences were found on the same scales.

\section{Discussion}

Panic anxiety and symptoms, as well as number of PA's following $\mathrm{CO}_{2}$ inhalation were significantly reduced by L-5HTP in PD patients. No such effect was observed in healthy volunteers. Patients reacted with more panic anxiety and symptoms to the challenge than controls in the placebo condition. This difference was not present in the 5-HTP condition.

\section{The role of 5-HT in panic}

Previous studies have suggested that 5-HT acts to inhibit panic (den Boer et al. 1990a, Ben Zion et al. 1999, Miller et al. 2000, Schruers et al. 2000a). The results from the present study confirm these findings. The anti-panic effect of L-5HTP in the present study already occurs 2 
hours after a single administration, however. This is at odds with findings from clinical studies with 5-HT transmission enhancing drugs like SSRI's, showing an anti-panic effect only after several weeks of treatment. In the initial phase of treatment even a transient worsening of the clinical condition has been reported (Bell and Nutt, 1998). Furthermore, acute administration of the 5-HT agonists m-chlorophenylpiperazine (mcpp) or fenfluramine has also been claimed to cause panic or anxiety (Kahn et al. 1988, Targum and Marshall, 1989). In a study, comparing the clinical efficacy of fluvoxamine, ritanserin and placebo, the SSRI fluvoxamine caused an increase in anxiety in the first week of treatment. Frequency of PA's was not different from placebo, however (den Boer and Westenberg, 1990b). Another study, comparing the MAO-inhibitor brofaromine with placebo in $\mathrm{PD}$, also lound an increase of anxiety during the first treatment week. The number of PA's however, decreased in both conditions (van Vliet et al. 1996). The initial deterioration noted with these drugs therefore seems due to an increase in general level of anxiely, part of the condition PD, but not to the phenomenon of panic per se.

As for mcpp, the behavioral response caused by administration of this compound is characterized by a gradual increase of anxiety that lasts for several hours (Kahn et al. 1990). Such a response does not resemble a natural PA, which is characterized by sudden crescendo anxiely and neurovegetative symptoms, as described in DSM IV. In the only study in which "a combination of anxiety and somatic symptoms meeting DSM-III criteria for a panic attack" was found, according to well defined experimental criteria, a high dose of intravenous mcpp was used (Charney et al. 1987). However, while mcpp may be a selective serotonin receptor agonist at low doses, the effect on alfa 2-adrenoreceptors may become more important at higher doses and be responsible for the panic-like effect.

The 5-HT releasing agent d, I-fenfluramine also precipitated an anxiogenic response, that was less acute and crescendo-like than the reaction following lactate infusion. The response lasted for several hours and was noted to "differ markedly from the typical short-lived panic attack described by DSM-III-R" (Targum 1989). This response could partly have been due to the catecholaminergic properties of the l-isomer (Judd et al. 1994). The d-isomer, however, does act as a specific 5 - $\mathrm{HT}$ releasing agent and has recently been shown to reduce, rather 
than increase, $5 \% \mathrm{CO}_{2}$ induced panic (Anderson and Mortimore, 1999).

These findings, logether with the ones from the present study may suggest that 5-HT has a dual role, inhibiting panic on the one hand but possibly increasing anxiety on the other. These findings are accounted for in a hypothesis, formulated by Deakin and Graeff (1991). The theory proposes that 5 -HT restrains panic responses by an inhibiting effect at the level of the periaqueductal gray (PAG). The PAG has been shown to command flight reactions, in response to unconditioned aversive stimuli (Graeff et al. 1996). $\mathrm{CO}_{2}$ has been suggested to have its effect through this mechanism, acting as an internal unconditioned aversive stimulus. According to the Deakin-Graeff theory, 5-HT, on the other hand, facilitates active escape or avoidance behavior, as well as generalized anxiety, at the level of the amygdala.

\section{Theropeutic possibilities}

The present study concerns the acute effects of 5-HT on experimentally induced panic. The results suggest that it might also be worthwhile to investigate its therapeutic possibilities in PD. In an open, uncontrolled study in 10 outpatients suffering from different anxiety states, the therapeutic effects of L-5-HTP have been studied, during 12 weeks. In general, 5-HTP had beneficial effects, and it was noted in particular that panic attacks, if present, disappeared completely (Kahn and Westenberg, 1985). A similar result was obtained in an 8 week double blind placebo controlied study in 45 patients, again suffering from different anxiely disorders, comparing 5-HTP, clomipramine and placebo. General levels of anxiety decreased slightly in the 5-HTP group and, again, panic attacks disappeared almost completely if present. Unfortunately, a specific instrument to assess the severity of PO was not used, however (Kahn et al. 1987). The results from those studies, together with the ones from the present study, suggest that 5-HTP can have a clinical therapeutic effect in PD and certainly warrant further study.

A second conclusion that can be drawn from these studies is that the inhibition of the panicogenic effect of a $35 \% \mathrm{CO}_{2}$ challenge, few hours after administration, might be predictive for the anti-panic properties of a compound. Up to now, it has already been shown that the reduction of reaction to a $35 \% \mathrm{CO}_{2}$ challenge after one week does predict a therapeutic effect, later 
on in treatment (Perna et al. 1997). It would therefore be interesting to investigate whether one single dose of an anti-panic agent, bares any relationship to later therapeutic efficacy.

\section{Limitations}

Some caution is necessary when interpreting the present results. Firstly, there was a significant difference in age between the patients and the healthy volunteers. Although this may have influenced results, vulnerability to a $35 \% \mathrm{CO}_{2}$ challenge is not related to age (Perna et al. 1994). It may also be noted that the behavioral effect of a serotonergic challenge may decrease with age (Kahn et al. 1991). Yet, if such an effect was present in the present study, it would not have affected outcome, since the patient group was the older one anyway and still showed a stronger effect of 5-HTP than the healthy volunteers.

secondly, it might be argued that the effect observed in the 5-HTP-condition may, in part, have been due to actions of other neurotransmitters than 5-HT. Indeed, it has been suggested that 5-HTP affects noradrenalin turnover as well (van Praag and Westenberg, 1983). However, administration of 5-HTP to patients has been shown not to affect plasma levels of MHPG, the main metabolite of noradrenalin (den Boer and Westenberg, 1988).

\section{Conclusion}

The results from the present study show that L-5-HTP administration inhibits $35 \% \mathrm{CO}_{2}$ induced panic. This strongly supports a role for $5-\mathrm{HT}$ in the modulation of panic. Further research on the therapeutic properties of L-5-HTP in PD and on the predictive value of an acute inhibition of vulnerability to $35 \% \mathrm{CO}_{2}$ for the therapeutic properties of future anti-panic agents would be welcome. 
Figure 1
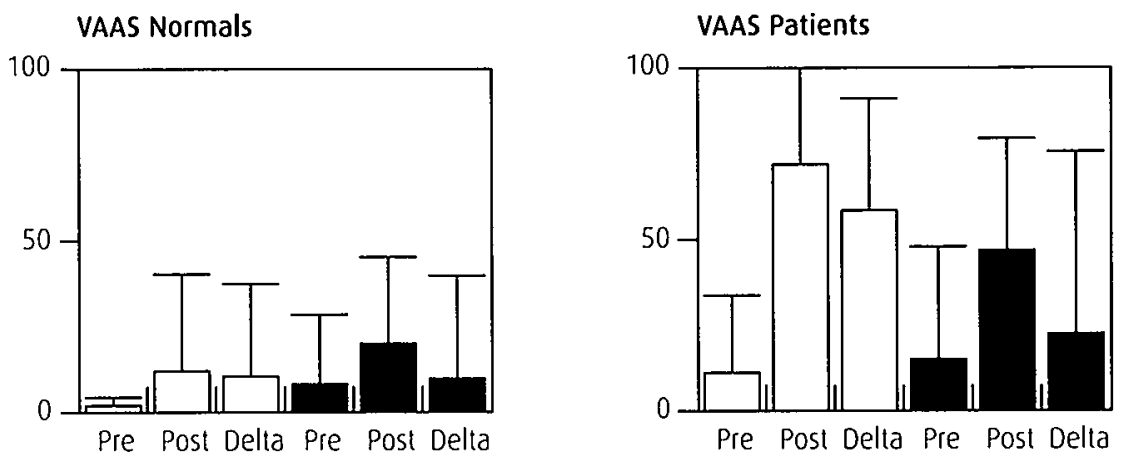

PSL Normals

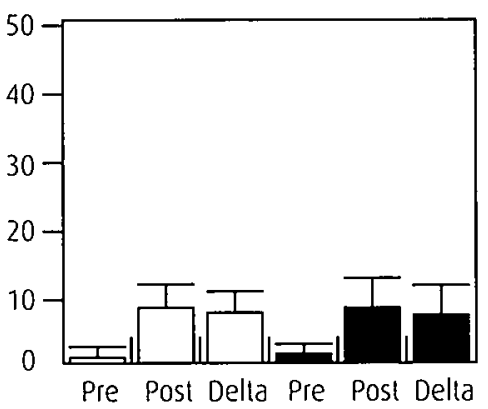

PSL Patients

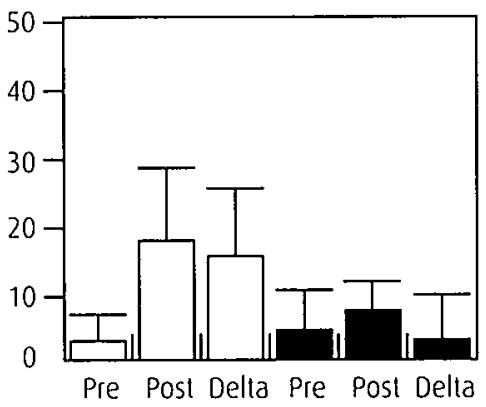

5HTP
$\square$ Placebo

Pre = belore $\mathrm{CO}_{2}$

Post $=$ after $\mathrm{CO}_{2}$

Delta = Post - Pre 


\section{REFERENCES}

Anderson IM, Mortimore C (1999): 5-HT and human anxiety. Evidence from studies using acute tryptophan depletion. Advances in experimental medicine and biology 467:43-55.

Bell CJ, Nutt DJ (1998): Serotonin and panic. The British journal of psychiatry 172:465-71. Ben Zion IZ, Meiri G, Greenberg BD, Murphy DL, Benjamin J (1999): Enhancement of $\mathrm{CO}_{2}$ induced anxiety in healthy volunteers with the serotonin antagonist metergoline. The American journal of psychiatry 156:1635-7.

Charney DS, Woods SW, Goodman WK, Heninger GR (1987): Serotonin function in anxiety. II. Effects of the serotonin agonist MCPP in panic disorder patients and healthy subjects. Psychopharmacology 92:14-24.

Cleare AJ, Bond AJ (1995): The effect of tryptophan depletion and enhancement on subjective and behavioural aggression in normal male subjects. Psychopharmacology 118:7281.

Deakin JFW, Graeff F (1991): 5-HT and mechanisms of defence. Journal of psychopharmacology 5:305-315.

den Boer JA, Westenberg HG (1988): Effect of a serotonin and noradrenaline uptake inhibitor in panic disorder; a double-blind comparative study with fluvoxamine and maprotiline. International clinical psychopharmacology 3:59-74.

den Boer JA, Westenberg HG (1990a): Behavioral, neuroendocrine, and biochemical effects of 5-hydroxytryptophan administration in panic disorder. Psychiatry research 31:267-78. den Boer JA, Westenberg HG (1990b): Serotonin function in panic disorder: a double blind placebo controlled study with fluvoxamine and ritanserin. Psychopharmacology 102:85-94. Goddard AW, Sholomskas DE, Walton KE, et al (1994): Effects of tryptophan depletion in panic disorder. Biological psychiatry 36:775-7.

Graeff FG, Guimaraes FS, De Andrade T8C, Deakin JFW (1996): Role of 5-HT in stress, anxiety and depression. Pharmacology, biochemistry and behavior 54:129-141.

Judd FK, Apostolopoulos M, Burrows GD, Norman TR (1994): Serotonergic function in panic disorder: endocrine responses to 0 -fenfluramine. Progress in neuro psychopharmacology 
and biological psychiatry 18:329-37.

Kahn RS, Westenberg HG (1985): L-5-hydroxytryptophan in the treatment of anxiety disorders. Journal of affective disorders 8:197-200.

Kahn RS, Westenberg HG, verhoeven WM, Gispen de Wied CC, Kamerbeek WD (1987): Effect of a serotonin precursor and uplake inhibitor in anxiety disorders; a doubleblind comparison of 5-hydroxytryptophan, clomipramine and placebo. International clinical psychopharmacology 2:33-45.

Kahn RS, Wetzler S, van Praag HM, Asnis GM, Strauman T (1988): Behavioral indications for serotonin receptor hypersensitivity in panic disorder. Psychiatry research 25:101-4.

Kahn RS, Wetzler S, Asnis GM, Kling MA, Suckow RF, van Praag HM (1990): Effects of mchlorophenylpiperazine in normal subjects: a dose-response study. Psychopharmacology 100:339-44.

Kahn RS, Wetzler S (1991): m-Chlorophenylpiperazine as a probe of serotonin function. Biological psychiatry 30:1139-66.

Klaassen T, Klumperbeek J, Deutz NE, van Praag HM, Griez E (1998): Effects of tryptophan depletion on anxiety and on panic provoked by carbon dioxide challenge. Psychiatry research 77:167-74.

Miller HE, Deakin JF, Anderson IM (2000): Effect of acute tryptophan depletion on $\mathrm{CO}_{2}$-induced anxiety in patients with panic disorder and normal volunteers. The British journal of psychiatry 176:182-8.

Oldman A, Walsh A, Salkovskis P, Fairburn CG, Cowen PJ (1995): Biochemical and behavioural effects of acute tryptophan depletion in abstinent bulimic subjects: a pilot study. Psychological medicine 25:995-1001.

Park SB, Coull JT, MCShane RH, et al (1994): Tryptophan depletion in normal volunteers produces selective impairments in learning and memory. Neuropharmacology 33:575-88.

Perna G, Battaglia M, Garberi A, Arancio C, Bertani A, Bellodi L (1994): Carbon dioxide/oxygen challenge test in panic disorder. Psychiatry research 52:159-71.

Perna G, Bertani A, Gabriele A, Politi E, Bellodi L (1997): Modification of 35\% carbon dioxide hypersensitivity across one week of treatment with clomipramine and fluvoxamine: 
a double-blind, randomized, placebo-controlled study. Journal of clinical psychopharmacology 17:173-8.

Schruers K, Klaassen T, Pols H, Overbeek T, Deutz NE, Griez E (2000a): Effects of tryptophan depletion on carbon dioxide provoked panic in panic disorder patients. Psychiatry research $93: 179-87$.

Schruers K, van Diest R, Overbeek T, Griez E (2000b): L-5HTP induced increase in salivary cortisol in healthy volunteers and panic disorder patients. Submitted for publication.

Sheehan DV, Lecrubier Y, Harnetl Sheehan K, et al (1997): The validity of the Mini International Neuropsychiatric Interview (MINI) according to the SCID-P and its reliability. European Psychiatry 12:232-241.

Targum SD, Marshall LE (1989): Fenfluramine provocation of anxiety in patients with panic disorder. Psychiatry research 28:295-306.

Targum SD (1992): Cortisol response during different anxiogenic challenges in panic disorder patients. Psychoneuroendocrinology 17:453-8.

van Praag HM, Westenberg HGM (1983): The treatment of depressions with L-5-hydroxytryptophan. Adv Biol Psychiat 10.

van Vliet IM, Slaap BR, Westenberg HG, Den Boer JA (1996): Behavioral, neuroendocrine and biochemical effects of different doses of 5-HTP in panic disorder. European neuropsychopharmacology 6:103-10. 


\title{
Chapter 8
}

\section{Effects of Tianeptine on $35 \% \mathrm{CO}_{2}$ provoked panic in panic disorder patients}

\begin{abstract}
Background: Antidepressants that inhibil the reuptake of serotonin (5-HT) are particularly effective in the treatment of panic disorder. Tianeptine is an antidepressant with 5-HT reuptake enhancing properties, the opposite pharmacological profile. It has however been shown to effectively reduce anxiety in patients with major depression. Aim of the present study was to compare the anti-panic effect of tianeptine with that of paroxetine, a selective 5-HT reuptake inhibitor, on the vulnerability to a laboratory panic challenge in panic disorder patients. Melhod: Twenty panic disorder patients were treated with either tianeptine or paroxetine for a period of six weeks, in a randomized, double blind, separate group design. The reaction to a $35 \% \mathrm{CO}_{2}$ panic challenge was assessed at baseline and after treatment. Improvement on severat clinical scales was also monitored. Results: Tianeptine and paroxetine both induced a significant reduction in vulnerability to the panic challenge, along with clinical improvement. Conclusion: Both tianeptine and paroxetine appeared to have beneficial effects in panic disorder, rather than the opposite action that could be expected from their opposite influence on 5-HT uptake.
\end{abstract}

\section{Introduction}

A number of effective anti-panic treatments are now available to the clinician. These include pharmacotherapy with tricyclic antidepressants (ICA's), monoamine oxidase inhibitors (MAOI's), and selective serotonin reuptake inhibitors (SSRI's), and psychological approaches with cognitive behavior therapy (Bell and Nutt 1998). As far as monoamine reuptake is concerned, there has been some debale about the relative contribution of the serotonergic 
(5-HT) and noradrenergic (NE) systems in the treatment of panic disorder (PD).

A study, comparing the noradrenergic TCA maprotiline with the SSRI fluvoxamine showed that the SSRI was superior in improving panic and anxiety symptoms (den Boer and Westenberg 1988). In another study, the response 10 imipramine was found to correlate with the plasma concentration of the parent compound which is as well serotonergic as noradrenergic but not with that of the more noradrenergic metabolite $\mathrm{N}$-desmethylimipramine (Mavissakalian and Perel 1989). These studies confirm the clinical evidence that, in general, serotonergic agents are more effective in Po than purely noradrenergic ones.

The efficacy of other serotonergic agents than SSRI's in PD has also been examined. Controlled studies found buspirone and flesinoxan, both 5-HT1a agonists, and ritanserin, a 5HT2 antagonist, to be ineffective (den Boer and Westenberg 1990, Sheehan et al. 1993, van Vliet et al. 1996). In general, it is assumed that the mechanism of 5-HT reuptake inhibition is important for the therapeutic efficacy of pharmacological compounds in PO (Bell and Nult 1998).

Tianeptine is a modified tricyclic compound with proven efficacy in major depression (Costa e Silva et al. 1997, Invernizzi et al. 1994, Loo et al. 1999). In contrast to SSRI's, the drug has been shown 10 increase rather than to inhibit 5-HT uptake (Fattaccini et al. 1990, Datla and Curzon 1993). If it is correct to assume that 5-HT reuptake inhibition is a key factor in the pharmacology of panic, tianeptine may, in theory, be devoid of a specific clinical effect against panic attacks (PA's), compared to SSRI's. Evidence however suggests that tianeptine has anxiolytic effects in patients with coexisting anxiety and depression (Guelfi et al. 1989, Wilde and Benfield 1995).

To sort out whether tianeptine may have a specific effect in patients with a primary diagnosis of PD, the present study compared tianeptine to the SSRI paroxetine, which effectiveness in PD has been well established (Dunner and Dunbar, 1992). A considerable amount of work has shown that hypersensitivity to inhalation of $35 \% \mathrm{CO}_{2}$ is a laboratory challenge that yields a high specificity for PD (Verburg el al. 1994, 1995, Perna el al. 1994, 1995a, 1995b). The test - retest reliability is good as treatment with placebo does not significantly modify the response (Perna et al. 1994, verburg et al. 1998). These studies, together with several 
others, linking a decreased $\mathrm{CO}_{2}$ reactivity with favorable treatment outcome, show that $35 \%$ $\mathrm{CO}_{2}$ inhalation is not only a valid experimental model for panic, but that it can serve as a probe for the evaluation of future pharmacological treatments of PD. Recent studies even suggest that a reduction of $\mathrm{CO}_{2}$ reactivity as early as after one week of treatment is a predictor of final clinical outcome (Bertani et al. 1997). Accordingly, under the assumption that the response $\mathrm{CO}_{2}$ is a state dependent probe for the susceptibility to panic, we assessed the effect of tianeptine treatment compared to paroxetine on a $35 \% \mathrm{CO}_{2}$ challenge.

\section{Methods}

\section{Subjects}

Twenty-two patients with panic disorder with or without agoraphobia (DSM IV criteria) participated in the study. Fwenty completed the study and were included in the analysis. Participants were recruited from the Academic Anxiety Center in Maastricht, the Netherlands. The diagnosis was made by means of a structured interview (Mini International Neuropsychiatric Interview, lecrubier el al. 1997) and confirmed by two experienced psychiatrists (KS and EG). Patients with major depression or dysthymia as main diagnosis, presenting criteria for melancholic type, with psychotic features or considered to be at risk for suicide were excluded.

No concurrent psychotropic medication was allowed during the study period, except for benzodiazepines at an equivalent dose of $5 \mathrm{mg}$ diazepam. Additional inclusion criteria were: age between 18 and 65 , good physical health and written informed consent.

The study was approved by the local medical ethics committee.

\section{Design and Procedures}

The study was conducted according to a randomized, double blind, separate group design. The duration was six weeks. After a two week diagnostic period, in which an evaluation of the psychiatric condition was made, patients were allocated to the tianeptine or paroxetine 
condition.

Tianeptine was administered in tablets of $12.5 \mathrm{mg}$, three times a day. The patients in the paroxetine group received one lablet of $20 \mathrm{mg}$ paroxetine in the morning, plus a placebo tablet at noon and in the evening, during the first week. Ouring the next five weeks, they received $20 \mathrm{mg}$ of paroxetine in the morning and in the evening, plus a placebo tablet at noon. Patients were asked to return the treatment box and blister, whether or not empty, at days 7, 14, 28 and 42 of the sludy. The number of the returned capsules was counted and compliance was calculated at each visit.

At day 0 and 42, the clinical status of the patients was evaluated by means of several questionnaires: general level of anxiely was evaluated by the CAS (Clinical Anxiety Scale, Snaith et al. 1982), SAS (Self Rating Anxiety Scale, Zung 1971), STAI (State-Trait Anxiety Inventory, slate version, Spielberger el al. 1970). Phobic avoidance was assessed with the FQ (Fear Questionnaire, Marks and Mathews, 1979). Depressive symptoms were evaluated with the MADRS (Montgomery Asberg Depression Rating Scale, Montgomery and Ásberg, 1979). A general assessment of the patients status was given by means of the CGI (Clinical Global Impression scale).

In addition to the above clinical parameters the patients underwent a $35 \% \mathrm{CO}_{2}$ challenge at day 0 and 42 . The entire procedure of the $35 \% \mathrm{CO}_{2}$ challenge has been described in detail elsewhere (Klaassen et al. 1998). In brief, subjects were informed that they would be inhaling a harmless gas mixture, containing $65 \% \mathrm{O}_{2}$ and $35 \% \mathrm{CO}_{2}$, and that they might experience some discomfort, ranging from a few neurovegetative symptoms to a definite sensation of anxiety. The possibility of a panic attack was not mentioned, to avoid any negative expectational bias.

Vital capacity was measured before inhaling the gas mixture. The test was considered valid only if the subject had inhaled at least $80 \%$ of the previously measured vital capacity. Immediately before and after the inhalation, anxiety was measured on a visual analogue anxiety scale (VAAS), describing the degree of subjective anxiety from $0 \mathrm{~mm}$ (no anxiety) to $100 \mathrm{~mm}$ (the worst anxiety imaginable). An increase of $25 \mathrm{~mm}$ was required for inclusion. Panic symptoms were assessed by a panic symptom list (PSL), containing the 13 panic symp- 
toms described by DSM IV on a scale from 0 lo 4 (Klaassen el al. 1998). Criteria for an experimental panic attack were a rise of at least $25 \mathrm{~mm}$ on the VAAS plus an increase in at least four panic symploms on the PSL (Klaassen et al. 1998).

\section{Data analysis}

Due to the non-normal distribution of the data, non parametric lests were used for all analyses. Significance levels were set at $P<0.05$ (two-tailed). A Mann-Whitney U-test was used to calculate differences in the clinical scales at day 0 and day 42 , between the two conditions. A Wilcoxon signed rank test was used to compare the values on the scales between day 0 and day 42 , for each condition. The same methods were used for analysis of the $\mathrm{CO}_{2}$ challenge results, using the pre- and post $\mathrm{CO}_{2}$ VAAS and PSL scores, as well as the delta scores of the VAAS and PSL (post $\mathrm{CO}_{2}$ score minus pre $\mathrm{CO}_{2}$ score). Spearman's rank correlation analysis was used to examine a possible correlation between the difference in scores on the clinical scales between day 0 and 42 on the one hand, and the difference in $\mathrm{CO}_{2}$ reactivity between day 0 and 42 on the other (expressed by the delta VAAS and PSL scores in both conditions). The number of PA's following the $\mathrm{CO}_{2}$ challenge was calculated for each group at day 0 and 42 , and compared with a chi square test, within each group and between groups.

\section{Results}

\section{Demographics and comorbidity}

There were 4 men and 6 women in the paroxetine group, and 3 men and 7 women in the tianeptine group. Mean age was $44 \pm 11$ and $39 \pm 11$ years for the respective groups. Ten patients were allocated to each condition. In the paroxetine group, 3 patients had comorbid major depression, one had social phobia, and one generalized anxiety disorder. In the tianeptine group, there were also 3 patients with major depression, and further 1 with social phobia and 1 with specific phobia (for heights). 


\section{Compliance}

Overall, compliance (\%) was good: $96.5 \pm 8.3,98.1 \pm 6.1,99.8 \pm 1.7$ and $100.0 \pm 2.5$ for days $7,14,22$ and 42 respectively. Mean global compliance for the whole study was $98.1 \pm 4.4 \%$.

\section{The $\mathrm{CO}_{2}$ challenge}

Post $\mathrm{CO}_{2}$ VAAS $(P=0.017)$ and delta VAAS $(P=0.012)$ scores, as well as post $(P=0.022)$ and delta PSL. $(P=0.033)$ scores decreased significantly from day 0 to day 42 in the paroxetine group. Pre $\mathrm{CO}_{2}$ VAAS and PSL scores did not differ significantly between the two lest days. In the tianeptine condition, the delta VAAS and delta PSL scores decreased significantly from day 0 to 42 ( $P=0.009$ and 0.046 respectively). There was also a trend for the pre $\mathrm{CO}_{2}$ VAAS scores to be higher on day 42 as compared to day $0(P=0.074)$ (fig. 1 and 2 ). This rise was observable in 8 out of 10 patients in the tianeptine condition. Also, pre $\mathrm{CO}_{2}$ VAAS $(P=0.028)$ and PSL scores $(P=0.036)$ were significantly higher in the tianeptine condition at day 42, compared to the paroxeline condition.

The PA rate decreased from 8 at day 0 to 2 at day 42 in the paroxetine condition $(P<0.01)$. In the tianeptine group, the number of PA's decreased from 10 at day 0103 at day 42 $(P<0.005)$. The differences in $P A$ rates at day 0 or 42 between the two groups were not significant.

\section{Secondary criteria: clinical scales}

The paroxetine group showed a significant improvement between day 0 and day 42 on the CAS $(P=0.012)$, SAS $(P=0.012)$ and STAI $(P=0.037)$. No differences were found in the tiane tine group on these scales between day 0 and 42 . Improvement on the FQ was not significant in either condition. Both groups showed significant improvement between day 0 and 42 on the MADRS ( $P=0.007$ ).

Improvement on the CGI was only significant in the paroxetine condition $(P=0.039)$.

When both conditions were compared, no significant differences were found on any of the scales, at day 0 nor at day 42 . There was only a trend for the CAS to be lower in the paroxetine group on day $42(P=0.052)$ (table 1$)$. 


\section{Correlations}

A significant correlation was found between the difference in FQ agoraphobia subscale score (the subscale that is specific for PD) between day 0 and day 42 on the one hand and the difference in delta VAAS score on the other, in the tianeptine group $(P=0.006)$ as well as the paroxetine group $(P=0.013)$. Apart from the total $F Q$ total score, none of the other correlations between the clinical scales and the delta VAAS or PSL scores reached statistical significance.

\section{Discussion}

As far as the susceptibility to panic is concerned, as assessed by a $35 \% \mathrm{CO}_{2}$ challenge, a significant reduction in $\mathrm{CO}_{2}$ vulnerability occurred both in the tianeptine and paroxetine condition. Both conditions also showed an improvement in global clinical status and in generalized anxiety, the latter reaching statistical significance in the paroxetine group only.

\section{Effects on panic and anxiety}

PD is a complex condition characterized both by PA's, most often associated to agoraphobic avoidance, and intercurrent anticipatory anxiety. As opposed to acute panic, this latter type of chronic anxiety features continuous tension and worry about the occurrence of a next attack. As such, it is qualitatively different of the panic itself and close to the anxiety of the generalized type seen in generalized anxiety disorder (GAD) (Faravelli and Paionni, 2000). In the present study, tianeptine definitely inhibited experimental PA's induced by a $35 \% \mathrm{CO}_{2}$ laboratory challenge. This is strongly suggestive of specific anti-panic properties of tianeptine. Earlier studies with a large number of drugs have repeatedly shown that antipanic activity is linked with a blunted response to $\mathrm{CO}_{2}$ challenges. Reaction to a single inhalation of $35 \% \mathrm{CO}_{2}$ or prolonged inhalation of $5 \% \mathrm{CO}_{2}$ was attenuated by a short treatment with the high potency benzodiazepines clonazepam or alprazolam (Beckelt et al. 1986, Woods et al. 1986, Pols et al. 1996a, Fishman et al. 1994, Nardi et al. 2000). There is also ample evidence 
that antidepressants that are clinically effective in treating PD atso decrease the response to a 35\% $\mathrm{CO}_{2}$ challenge (Woods et al. 1990, Bertani et al. 1997, Pols et al. 1996b). The finding of the present study can be interpreted in the light of the above results. Moreover, a significant correlation was found between changes in $\mathrm{CO}_{2}$ reactivity and scores on the agoraphobia subscale of the fear questionnaire, assessing a behavioral dimension specifically bound to PD. Thus as far as PA's and agoraphobia are concerned, it appears from our data that tianeptine may yield specific therapeutic properties in PD. Assessing the dimension of generalized anxiety, results reveal that tianeptine did not cause a similar improvement on the CAS, SAS and STAI as did paroxetine. It is also worth noting that baseline anxiely as assessed on the VAAS was increased at the time of the second $\mathrm{CO}_{2}$ challenge in 8 out of 10 patients in the tianeptine group. As a consequence, tianeptine may compare somewhat less lavorably with paroxetine having a definite anxiolytic profile, both on the $\mathrm{CO}_{2}$ challenge and on generalized anxiely. Two comments apply, however, when interpreting the above results. Firstly, it is possible that tianeptine has a differential action on different types of anxiety. However, tianeptine has been shown to reduce anxiety in patients with coexisting anxiely and depression. Both tianeptine and amitryptiline significantly reduced Hamilton Anxiety Rating Scale (HAM-A) scores, compared with baseline, in 2 studies in patients with depression or dysthymic disorder (Bersani et al. 1989, Guelfi et al. 1989). The efficacy of tianeptine in reducing HAM-A scores was similar to that of imipramine and greater than that of placebo in a European multicenter study involving 186 patients with major depression or depressed bipolar disorder (Staner et al. 1994). Both tianeptine and fluoxetine reduced coexisting anxiety from baseline in patients with major depression or dysthymic disorder (Alby et al. 1993). Improvement in HAM-A scores with tianeptine was significantly greater than with maprotiline in a study in premenopausal or menopausal women with coexisting anxiety and depression (Chaby et al. 1993). Also, in a recent study comparing tianeptine with paroxetine, both products were found to have a similar effect on the anxious component of depression (Lepine et al. 2000). It is therefore less likely that tianeptine would not work on generalized anxiety. Secondly, in this first study in an anxiety disorder, a matter of dosage may have masked the full pharmacological properties of tianeptine: In accordance with pre- 
vious trials in $\mathrm{PD}$, paroxetine was given at a daily dose of $40 \mathrm{mg}$. At this dose, paroxetine has been shown to reduce generalized anxiety in PD, as measured with the HAM-A. At lower doses, no difference with placebo could be detected (Ballenger et al. 1998). This dosage is however twice the optimal dose of paroxetine for depression, which is $20 \mathrm{mg} /$ day for most patients (Dunner and Dunbar, 1992). For tianeptine, there being no literature reference about its use in $\mathrm{PD}$, the dosage of $37.5 \mathrm{mg}$ daily was chosen, which is the usual scheme in the treatment of depression. It is therefore conceivable that the regimen of tianeptine used in the present study was suboptimal. At a higher dose, a more pronounced anxiolytic effect might have occurred.

\section{Possible mechanisms}

Given their opposite effect on 5-HT uptake, the similar clinical effects of tianeptine and paroxetine on panic and anxiety are surprising. The results of the present study are apparently at odds with preclinical research, were tianeptine has been shown to have an opposite effect to that of paroxetine, on several types of 5-HT dependent behavior (Koshikawa et al. 1991). Several factors may account for this discrepancy. There is much evidence for the 5-HT uptake enhancing properties of tianeptine (Mennini et al. 1987, Fattacini et al. 1990, Datla and Curzon 1993). However, this increase seems to depend on the region of the brain, the doses of tianeptine and the duration of administration. Piñeyro et al. (1995a) found tianeptine to induce adaptive changes on the 5-HT transporter in cortical but not in hippocampal neurons. Tianeptine did activate hippocampal CA3 neurons, but not due to 5-HT uptake. Watanabe et al. (1993) observed a significant decrease in [3H] paroxetine binding in hippocampus and cortex, when tianeptine was administered for 14 days at a total dose of 30 $\mathrm{mg} / \mathrm{kg} /$ day, but the same group could not reproduce such an effect when tianeptine was administered at a dose of $10 \mathrm{mg} / \mathrm{kg} /$ day and for a period of 4 days (Frankfurt et al. 1995). Piñeyro et al. (1995a) found that, administered at a dose known to stimulate 5-HT reupta$\mathrm{ke}(20 \mathrm{mg} / \mathrm{kg} /$ day) and for a period of time (14 days) for which other antidepressants have been shown to enhance 5-HT function, tianeptine did not modify the efficacy of 5-HT synaptic transmission in the rat hippocampus. Interestingly, plasma tianeptine concentrations 
obtained in that study were similar to those in a study in depressed patients $12 \mathrm{~h}$ after the last administration of a long term tianeptine treatment $(37,5 \mathrm{mg} /$ day $\times 22$ days) (Chamba et al. 1991, Piñeyro et al. 1995a). This suggests that, at the doses used in clinical trials and also in the present study, tianeptine would not produce its effect by enhancing 5-HT neurotransmitter function.

Non-serotonergic mechanisms may be at work as well. Frankfurt et al. (1995) showed that treatment with tianeptine leads to several anatomically specific changes in steady state and turnover rates of norepinephrine (NE). Norepinephrine plays an important role in the pathophysiology of panic, and some noradrenergic antidepressants have anti-panic properties, albeit weaker than the SSRI's (Bell and Nutt 1998, Sullivan et al. 1999). The effects of tianeptine on NE transmission have been shown to be similar in some brain regions compared to the ones induced by the SSRI fluoxetine, although both compounds have an opposite effect on 5-HT uptake (Frankfurt et al. 1995, Mc Kittrick et al. 1995). It has been suggested that, following the initial opposite actions to 5-HT uptake, subsequent neurochemical events may occur that lead to similar changes in NE transmission, providing a point of convergence for tianeptine and fluoxetine that may play an important role in mediating the common therapeutic effect of the two drugs (Frankfurt et al. 1995). This might provide an explanation for the effects of tianeptine and paroxetine in the present study.

Finally, the 5-HT uptake enhancing properties of tianeptine could still have played a role in its anxiolytic and/or antipanic effect. Data suggest that tianeptine reduces stimulation of the HPA-axis in response to stress and antagonizes stress-induced behavior. Furthermore, evidence also suggests that the effecl of tianeptine on the response of the HPA-axis to stress could be accounted for by its effect on serotonin uptake (Wilde and Benfield 1995). Links have been reported between fear circuitry and the stress response (Sullivan et al. 1999). There is some controversy about the role of the HPA-axis in panic, however. For Klein (1993), the absence of HPA axis activation is the hallmark of panic, distinguishing it from extreme anxiety. A recent study, however, showed some HPA axis activation following natural PA's (Bandelow et al. 2000). To what degree the effects of tianeptine on the HPA axis are related to its possible therapeutic properties remains to be determined. 


\section{Conclusion}

In sum, in the present study tianeptine and paroxetine appeared both to have beneficial effects in panic disorder patients, rather than the opposite action that could be expected from their opposite influence on 5 -HT uptake. These results could be related to non 5 -HT actions of tianeptine or to an indirect effect of 5-HT uptake enhancement, via modulation of the HPA axis. These results need to be confirmed, however, and the exact dose range for tianeptine to yield optimal anxiolytic effects requires further exploration. 
Figure 1

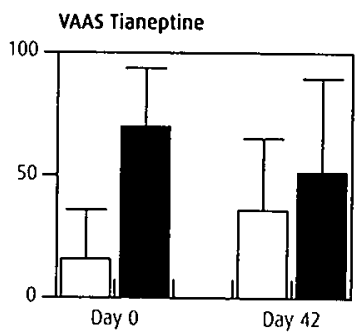

PSL Tianeptine

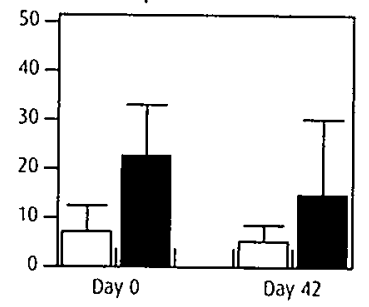

$\square$ Pre $\mathrm{CO}_{2} \quad \square$ Post $\mathrm{CO}_{2}$
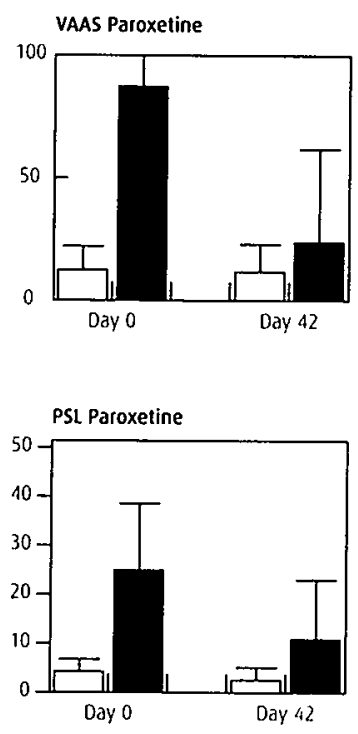

Figure 2
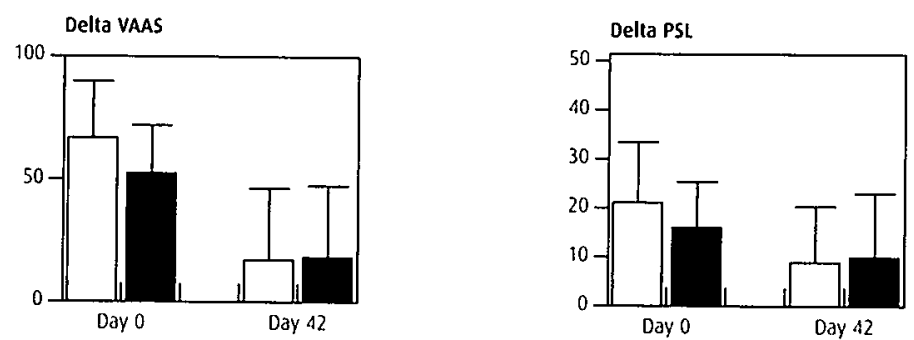

$\square$ Paroxetine $\quad$ arianeptine 


\section{REFERENCES}

Alby JM, Ferreri $M$, Cabanne J (1993): Efficacy of tianeptine for the treatment of major depression and dysthynia with somatic complaints. A comparative study versus fluoxetine. Ann. de Psychiatrie 8:136-144.

Ballenger JC, Wheadon DE, Steiner M, Bushnell W, Gergel IP (1998): Double-blind, fixeddose, placebo-controlled study of paroxetine in the treatment of panic disorder. The American journal of psychiatry 155:36-42.

Bandelow B, Wedekind D, Pauls J, Broocks A, Hajak G, Ruther $E$ (2000): Salivary cortisol in panic attacks. The American journal of psychiatry 157:454-6.

Beckett A, Fishman SM, Rosenbaum JF (1986): Clonazepam blockade of spontaneous and $\mathrm{CO}_{2}$ inhalation-provoked panic in a patient with panic disorder. The journal of clinical psychiatry 47:475-6.

Bell CJ, Nutt D) (1998): Serotonin and panic. The British journal of psychiatry 172:465-71.

Bersani G, Pasini A, Brancato T, Valducci M, Ciani N (1989): Serotonin and depression: controlled multicenter trial tianeptine versus amitryptiline. XXXVII Congresso Nazionale SIP, Roma 6-11 febbraio 1989.

Bertani A, Perna G, Arancio C, Caldirola D, Bellodi L (1997): Pharmacologic effect of imipramine, paroxetine, and sertraline on 35\% carbon dioxide hypersensitivity in panic patients: a double-blind, random, placebo-controlled study. Journal of dinical psychopharmacology 17:97-101.

Chaby L, Grinsztein A, Weitzman J, de Bodinat C, Dagens V (1993): Etats anxio-depressifs de la femme en periode premenopausique et menopausique. Etude de l'efficacite el de l'acceptabilite de la tianeptine versus maprotiline. La Presse Medicale 22:1133-1138.

Chamba G, Lemoine P, Flachaire E, et al (1991): Increased serotonin platelet uptake after tianeptine administration in depressed patients. Biological psychiatry 30:609-17.

Costa e Silva JA, Ruschel SI, Caetano D, et al (1997): Placebo-controlled study of tianeptine in major depressive episodes. Neuropsychobiology 35:24-9.

Datla KP, Curzon G (1993): Behavioural and neurochemical evidence for the decrease of 
brain extracellular 5-HT by the antidepressant drug tianeptine. Neuropharmacology 32:839-45.

den Boer JA, Westenberg HG (1988): Effect of a serotonin and noradrenaline uptake inhibitor in panic disorder; a double-blind comparative study with fluvoxamine and maprotiline. International clinical psychopharmacology 3:59-74.

den Boer JA, Westenberg HG (1990): Serotonin function in panic disorder: a double blind placebo controlled study with fluvoxamine and ritanserin. Psychopharmacology 102:85-94. Dunner DL, Dunbar GC (1992): Optimal dose regimen for paroxetine. The Journal of clinical psychiatry 53 Suppl:21-6.

Faravelli C, Paionni N (2000): Panic disorder: clinical course, morbidity and comorbidity. In Griez E, Faravelli C, Nutt D, Zohar J (eds), The European Certificate Textbook of Anxiety Disorders: In press, John Wiley \& Sons.

Fattaccini CM, Bolanos Jimenez F, Gozlan H, Hamon M (1990): Tianeptine stimulates uptake of 5-hydroxytryptamine in vivo in the rat brain. Neuropharmacology 29:1-8.

Fishman SM, Carr DB, Beckett A, Rosenbaum JF (1994): Hypercapneic ventilatory response in patients with panic disorder before and after alprazolam treatment and in pre- and postmenstrual women. Journal of psychiatric research 28:165-70.

Frankfurt M, Mckittrick CR, MCEwen BS, Luine VN (1995): Tianeptine treatment induces regionally specific changes in monoamines. Brain research 696:1-6.

Guelfi JD, Pichot P, Dreyfus JF (1989): Efficacy of tianeptine in anxious-depressed patients: results of a controlled multicenter trial versus amitriptyline. Neuropsychobiology 22:41-8. Invernizzi G, Aguglia E, Bertolino A, et al (1994): The efficacy and safety of tianeptine in the treatment of depressive disorder: results of a controlled double-blind multicentre study vs. amitriptyline. Neuropsychobiology 30:85-93.

Klaassen T, Klumperbeek J, Deutz NE, van Praag HM, Griez E (1998): Effects of tryptophan depletion on anxiety and on panic provoked by carbon dioxide challenge. Psychiatry research 77:167-74.

Klein DF (1993): False suffocation alarms, spontaneous panics, and related conditions. An integrative hypothesis. Archives of general psychiatry 50:306-17. 
Koshikawa N, Mocaer E, Stephenson JD (1991): The effects of tianeptine on wet-dog shakes, fore-paw treading and a flexor reflex in rats are consistent with enhancement of 5-hydroxytryptamine uptake. European journal of pharmacology 198:51-7.

Lecrubier $Y$, Sheehan DV, Weiller E, et al (1997): The Mini International Neuropsychiatric Interview (MINI). A short diagnostic structured interview: reliability and validity according to the CIDI. Eur Psychiarty 12:224-232.

Lepine JP, Altamura C, Ansseau M, et al (2000): Tianeptine and Paroxetine in Major Depressive Disorder, with a special focus on the anxious component in depression: an international, 6-week double-blind study. Submitted for publication.

Loo H, Saiz Ruiz J, Costa e Silva J, et al (1999): Efficacy and safety of tianeptine in the treatment of depressive disorders in comparison with fluoxetine. Journal of affective disorders 56:109-18.

Marks IM, Mathews AM (1979): Brief standard self-rating for phobic patients. Behaviour research and therapy 17:263-7.

Mavissakalian MR, Perel JM (1989): Imipramine dose-response relationship in panic disorder with agoraphobia. Preliminary findings. Archives of general psychiatry 46:127-31. Mckittrick CR, Frankfurt M, Schindler C), McEwen BS, Luine VN (1995): Effects of chronic fluoxetine and tianeptine administration on monoamine levels and turnover in discrete brain nuclei. Soc.Neurosc.Abstr. 21:975.

Mennini T, Mocaer E, Garattini S (1987): Tianeptine, a selective enhancer of serotonin upta$k e$ in rat brain. Naunyn Schmiedeberg's archives of pharmacology 336:478-82.

Montgomery SA, Asberg M (1979): A new depression scale designed to be sensitive to change. The British journal of psychiatry; the journal of mental science 134:382-9.

Nardi AE, Valenca AM, Nascimento I, Mezzasalma MA, Zin WA (2000): Double-blind acute clonazepam vs. placebo in carbon dioxide-induced panic attacks. Psychiatry research 94:179-84.

Perna G, Barbini B, Cocchi S, Bertani A, Gasperini M (1995a): $35 \% \mathrm{CO}_{2}$ challenge in panic and mood disorders. Journal of affective disorders 33:189-94.

Perna G, Battaglia M, Garberi A, Arancio C, Bertani A, Bellodi L (1994): Carbon 
dioxide/oxygen challenge test in panic disorder. Psychiatry research 52:159-71.

Perna G, Bertani A, Arancio C, Ronchi P, Bellodi L (1995b): Laboratory response of patients with panic and obsessive-compulsive disorders to 35\% CO2 challenges. The American journal of psychiatry 152:85-9.

Pineyro G, Deveault L, Blier P, Dennis T, de Montigny C (1995a): Effect of acute and prolonged tianeptine administration on the 5-HT transporter: electrophysiological, biochemical and radioligand binding studies in the rat brain. Naunyn Schmiedeberg's archives of pharmacology 351:111-8.

Pineyro G, Deveault L, de Montigny C, Blier P (1995b): Effect of prolonged administration of tianeptine on 5-HT neurotransmission: an electrophysiological study in the rat hippocampus and dorsal raphe. Naunyn Schmiedeberg's archives of pharmacology 351:119-25.

Pols H, Verburg K, Hauzer R, Meijer J, Griez. E (1996a): Alprazolam premedication and 35\% carbon dioxide vulnerability in panic patients. Biological psychiatry 40:913-7.

Pols HJ, Hauzer RC, Meijer JA, Verburg K, Griez EJ (1996b): Fluvoxamine attenuates panic induced by $35 \% \mathrm{CO}_{2}$ challenge. The journal of clinical psychiatry 57:539-42.

Sheehan DV, Raj AB, Harnell Sheehan K, Soto S, Knapp E (1993): The relative efficacy of high-dose buspirone and alprazolam in the treatment of panic disorder: a double-blind placebo-controlled study. Acta psychiatrica Scandinavica 88:1-11.

Snaith RP, Baugh S), Clayden AD, Husain A, Sipple MA (1982): The Clinical Anxiety Scale: an instrument derived from the Hamilton Anxiety Scale. The British journal of psychiatry; the journal of mental science 141:518-23.

Spielberger CD, Gorsuch RL, Lushene RD (1970): STAI Manual. Palo Alto, California: Consulting psychologisis press.

Staner L, Bertolino A, Cassano GB, et al (1994): European multicentre study of tianeptine versus imipramine and placebo in the treatment of major depression and depressed bipolar disorder. European Psychiatry 9:140s.

Sullivan GM, Coplan JD, Kent JM, Gorman JM (1999): The noradrenergic system in pathological anxiety: a focus on panic with relevance to generalized anxiety and phobias. Biological psychiatry 46:1205-18. 
van Vliet IM, Westenberg HG, den Boer JA (1996): Effects of the 5-HT1A receptor agonist flesinoxan in panic disorder. Psychopharmacology 127:174-80.

Verburg C, Griez E, Meijer J (1994): A 35\% carbon dioxide challenge in simple phobias. Acta psychiatrica Scandinavica 90:420-3.

Verburg K, Griez E, Meijer J, Pols H (1995): Discrimination between panic disorder and generalized anxiety disorder by $35 \%$ carbon dioxide challenge. The American journal of psychiatry 152:1081-3.

Verburg K, Pols H, de Leeuw M, Griez E (1998): Reliability of the 35\% carbon dioxide panic provocation challenge. Psychiatry research 78:207-14.

Watanabe Y, Sakai RR, McEwen BS, Mendelson S (1993): Stress and antidepressant effects on hippocampal and cortical 5-HT1A and 5-HT2 receptors and transport sites for serotonin. Brain research 615:87-94.

Wilde MI, Benfield P (1995): Tianeptine. A review of its pharmacodynamic and pharmacokinetic properties, and therapeutic efficacy in depression and coexisting anxiety and depression. Drugs 49:411-39.

Woods SW, Charney DS, Delgado PL, Heninger GR (1990): The effect of long-term imipramine treatment on carbon dioxide-induced anxiety in panic disorder patients. The Journal of clinical psychiatry 51:505-7.

Woods SW, Charney DS, Loke J, Goodman WK, Redmond DE, Jr., Heninger GR (1986): Carbon dioxide sensitivity in panic anxiety. Ventilatory and anxiogenic response to carbon dioxide in healthy subjects and patients with panic anxiely before and after alprazolam treatment. Archives of general psychiatry 43:900-9.

Zung WW (1971): A rating instrument for anxiety disorders. Psychosomatics 12:371-399 


\section{Summary and concluding remarks}

The initial part of this thesis concerns the $35 \% \mathrm{CO}_{2}$ challenge as an experimental model for panic. A considerable amount of previous work has shown that the challenge is specific, clinically valid and reliable, necessary properties for a good experimental model. Symptom convergence between consecutive challenges was also proven to be good. However, the matter of symptom convergence between experimentally provoked and naturally occurring panic attacks was still open. The study in chapter 2 shows that the 35\% $\mathrm{CO}_{2}$ panic challenge reproduces well the majority of symptoms of real-life panic attacks. This study therefore further establishes the value of the challenge as an experimental model and as a diagnostic test for panic. The test can be used as an aid to differentiate between different anxiety disorders. However, an experienced clinician might not often need such a test to make a diagnostic decision. Matters may be different when a differential diagnosis must be made with somatic complaints with an unclear clinical picture or resembling conditions like, for example, myocardial infarction or irritable bowel disorder. In this field might lie the greatest opportunities for the $35 \% \mathrm{CO}_{2}$ challenge as a diagnostic instrument in daily clinical practice. First steps in this direction have already been made, by the group of Adriaan Honig from our department, in collaboration with our group.

The major part of this thesis, however, is devoled to the study of the neurobiological mechanisms of panic disorder and, more specifically, of the unexpected panic attack which is the core of the disorder. In these studies, the $35 \% \mathrm{CO}_{2}$ challenge is not as much used as a diagnostic test, but as an experimental model for the key element of panic disorder. Other, biochemical manipulations were then used to study different aspects. The combination of challenge methods like in chapter 3 , where $\mathrm{CO}_{2}$ and cholecystokinin (CCK) challenges were combined, proved to be a fruitful way of gaining more insight in the pathophysiology of panic. The results suggest that both challenges act upon different neural mechanisms and raised some important questions that must be answered in future research. These include the effects of simultaneous rather than consecutive administration of two different panicogens, or the administration in reverse order.

In chapter 4 , the respiratory effects of CCK were examined. Outcome measures of the experiment were not only subjective reports of anxiety or neurovegetative symptoms, but also 
objective measurements of respiratory parameters. It was shown that $\mathrm{CCK}$ has direct effects on respiration, possibly important for its panicogenic effect, independent of its effect on anxiety or panic symptoms. Future research in patients should take both these aspects into account.

Chapters 5108 are about the role of serotonin $(5 \mathrm{HT})$ in panic. In chapter 5 it is shown that lowering $5 \mathrm{HT}$ availability to the brain increases vulnerability to a $35 \% \mathrm{CO}_{2}$ panic challenge. The results from chapter 6 show that there is probably no $5 \mathrm{HT}$ receplor hypersensitivity in panic disorder. Chapter 7 is the converse experiment of chapter 5 , showing that increasing availability of $5 \mathrm{HT}$ reduces the reaction to the challenge.

These three chapters together confirm that $5 \mathrm{HI}$ indeed has a very important role in panic. However, contrary to what is proposed by some, this role is probably not a causal but rather a modulatory one. This is possibly the most important conclusion from this thesis.

Notwithstanding the important role of $5 \mathrm{HI}$, the results from chapter 8 show that the mechanism of $5 \mathrm{HT}$ reuptake, by which most of the effective medications for PD are thought to act, is not crucial for the effect of pharmacological treatment of PD. The results also point out that locussing on one particular neurotransmitter system, for research purposes, bears the danger of forgetting other neurotransmitter systems that are of importance. An example is the noradrenergic system, which seems to have become "out of fashion". very much in fashion, on the other hand, is the hypothalamus-pituitary-adrenal axis, and especially corticotropin releasing hormone which not only has a neuroendocrine role but also acts as a neurotransmitter. Finally, recent research also implicates immunological factors in the pathophysiology of panic disorder. Cytokines have been shown to influence $5 \mathrm{HT}$ metabolism and have a reciprocal influence on different elements of the HPA-axis. Ongoing and future research at the Academic Anxiety Center will include neuroendocrine aspects of panic disorder as well as other anxiety disorders. Joint ventures including immunological expertise may prove fruitful as well.

Other synergies may be interesting as well. The effect of biochemical substances and the production of neurotransmitters is often confined to discrete regions in the brain.

For example, the panicogenic effect of $\mathrm{CO}_{2}$ probably involves activation of brain centers such 
as the chemoreceptor trigger zone, nucleus tractus solitarius and periaqueductal gray. CCK is also supposed to act upon the nucleus solitarius. Additionally, most of the serotonergic neurons in the brain originate from the raphe nuclei. However, the experimental models we have used up to now only provide indirect evidence as to the neurocircuitry involved in panic. Therefore, a topographical approach such as that provided by modern neuroimaging techniques may ideally complement the approach used in experimental psychiatry. Of the different techniques available, positron emission tomography (PET) and functional magnetic resonance imaging (FMRI) seem the most promising. These techniques also offer the advantage that they provide information which is independent of the subjective reports of study participants.

Several problems remain to be solved, however. Spatial resolution of PET is insufficient to visualize some of the small brain stem centers that are involved in panic. The technique can deliver more precise information by using radioactive ligands for specific receptors.

However, their availability is still limited. IMRI has a much higher spatial resolution but shows other drawbacks. For example, making an MRI scan involves lying in the narrow tunnel of the scanner for quite some time. This is an extremely difficult task for patients with panic disorder, who are typically afraid of places where escape is difficult in the event of a panic attack. These difficulties probably explain why, up to now, only very few functional imaging studies have been performed in panic disorder. Nevertheless, neuroimaging techniques, as well as neuroendocrine and immunological studies offer exciting possibilities to learn more about the pathophysiology of panic disorder. 


\section{Dankwoord}

Aan het eind van een proelschrift worden een aantal mensen bedankt. Dat hoort niet alleen zo, ik doe het ook met plezier.

Een groot aantal patiënten vond in een moeilijke periode van hun leven de moed om deel te nemen aan onderzoek. Wanneer ik hen vroeg naar hun motivatie was het antwoord steeds hetzelfde: ze wilden bijdragen aan het vergroten van de kennis van de aandoening die hun leven zodanig verstoorde. I $k$ hoop dat ik hun vertrouwen niet heb beschaamd. Aan hen mijn dank en respect.

Van mijn promotor Eric Griez heb ik het vak van onderzoeker geleerd. Het is inderdaad een aparl vak en ik kon geen betere leermeester treffen. Eric, je toonde me hoe onderzoek op te zetten: eenvoudig, kort en duidelijk. Je leerde me naar ruwe data kijken alvorens er statistiek op los te laten. Door je geduldige (en soms ongeduldige) en volhardende commentaar leerde je me ook hoe een wetenschappelijk artikel te schrijven, een kunst die je zo goed beheerst. Hiervoor allemaal mijn dank. Daarnaast mocht ik je ook persoonlijk leren kennen en bijzonder waarderen. Ook hiervoor mijn dank.

Mijn co-promotor Rob van Diest moet vaak gedacht hebben "Daar heb je hem weer" (or erger) als ik hem voor de zoveelste keer die dag kwam lastigvallen voor methodologisch of statistisch advies. Rob, je vermogen om problemen op een abstracte manier en volgens een ijzeren logica aan te pakken werkte vaak verhelderend. Ook hielp je me mijn boekenkennis van statistiek om te zelten in de praktijk. Daarnaast was (en is) hel erg prettig en verfrissend om jou, als Amsterdammer op de planeet Limburg, als buurman te hebben. Ik dank ook mijn mede-onderzoekers van het Academisch Angsicentrum, Thea Overbeek en Henk Pols. Thea, je had je aandeel bij het screenen van de paliënten, je hielp me vaak met mijn databestanden en voorzag mijn schrijfsels in alle stadia trouw van steeds constructieve commentaar. Henk, jouw kritische, bijna cynische kijk op wetenschap gaf me vaak juist een gerust gevoel: als iets de toets van Henk doorstond moest er wel wat in zitten. Je hebt nu, na zoveel jaren, het team verlaten. I $k$ wens je veel succes.

Als je een baan hebt waarin onderzoek, naast patiëntenzorg en onderwijs, slechts één van de taken is, is goede research-assistentie geen luxe maar pure noodzaak. Ik dank dan ook inge Leclair en Nicolette Bongaerts voor hun hulp. Inge, jij hebt de gave om met mensen 
om te gaan. Je maakt ze enthousiast of stelt ze op hun gemak. Daarnaast ben je door je kleurrijke, immer opgewekte persoonlijkheid zoveel als de mascotte van de afdeling. Nicolette, jij doet je werk op een wat ingetogener manier, maar je zorgvuldigheid, geduld en bereidwilligheid zijn goud waard.

Ik dank ook Leni Noteborn, Lea Esten, Yolanda Koch en len Kusters die de leksten hielpen vorm geven. Jullie vormen samen een secretariaat dat velen ons benijden, ook wat betreft de prettige sleer die er altijd heerst. Marijke van Kempen, later opgevolgd door Mark Ahsmann, nam de functie van documentalist war. Marijke en Mark, jullie leverden een deel van de grondstof aan warmee dit werk gebouwd is, en dat steeds met een verbluffende snelheid en een glimlach erbij: bedankt.

De overige leden van het Academisch Angstcentrum zijn Julien Peeters, Mariette ubaghs, Louis Kersten, Rudy Nijssen, Marjan Böhm, François Wilms, Nicole van Beek, Marlies van Duinen, Erika Jaegers, Englyke Nitrauw en Linda Zwambag. Jullie zorgen ervoor dat ik met plezier kom werken.

Hel Academisch Angstcentrum maakt deel uit van het Psychomedisch streekcentrum Vijverdal in Mastricht en bewijst al jaren dat samenwerking tussen de universiteit en het psychiatrisch ziekenhuis in de vorm van een geacademiseerde afdeling vruchten afwerpt, zowel op wetenschappelijk gebied als wat betreft de kwaliteit van de gezondheidszorg. Het stimuleren van zo'n afdeling, die toch een beetje een vreemde eend in de bijt is, vergt moed en visie. Hiervoor dank ik Chris Breemer ter Steege, directeur, en Olga Sollet, clusterleidster. Onderzoek doen dat leidt tot een proefschrift binnen vijf jaar in een baan die daar slechts gedeeltelijk tijd voor voorziet is zonder meer onmogelijk binnen de werkuren. Het betekent vaak's avonds of in het weekend werken. Net de persoon die me het dierbararst is van allemaal was daar het slachtoffer van. Het krijgen van twee lieve kinderen in dezelfde periode maakte het leven weliswar mooier, maar niet direct eenvoudiger. Ik dank je, Ann, voor al je geduld en steun en voor je liefde.

Ik dank ook mijn ouders, zus en grootouders, die mij altijd gesteund hebben tijdens mijn opleiding en bij de keuzes die ik maakte.

Tot slot wil ik Hugo De Cuyper herdenken, die mijn mentor was in Leuven en die mij hielp de eerste stappen le zetten in het onderzoek. Hugo moest ons veel te vroeg verlaten. 


\section{Curriculum vitae}

Koen Schruers werd geboren op 9 augustus 1966 in Hasselt, België. Hij doorliep de lagere en middelbare school aan het Sint Jozefscollege in dezelfde stad. De kandidaturen geneeskunde volgde hij aan het Limburgs Universitair Centrum (LUC) te Diepenbeek. Vervolgens zette hij zijn studie voort aan de Katholieke Universiteit Leuven (KUL), war hij in 1991 het diploma van arts behaalde. Aansluitend startte hij met de opleiding tot psychiater, eveneens aan de KUL (opleider Prof. Or. P. Igodt). In 1996 behaalde hij het getuigschrift van geneesheer-specialist in de psychiatrie. Sindsdien is hij als voltijds docent verbonden aan de Universiteit Maastricht. In het kader van deze aanstelling is hij ook aldelingspsychiater van het Academisch Angstcentrum, een geacademiseerde afdeling van het Psychomedisch streekcentrum Vijverdal te Maastricht. In 1999 behaalde hij het Universitair Postgraduaat gedragstherapie aan de faculteit psychologie van de KUL (Opleider Prof. Or. P. Eelen). 